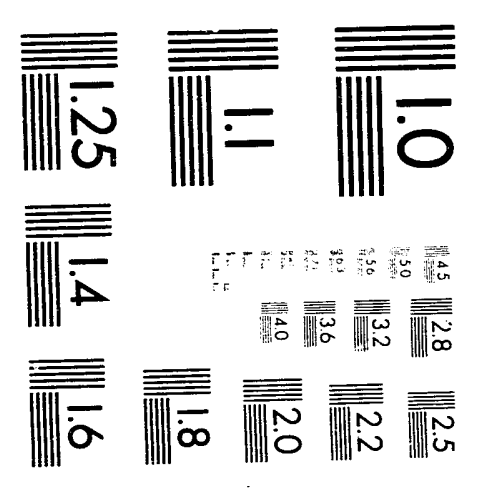

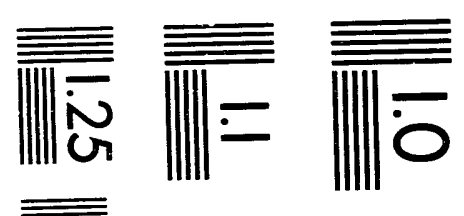

$$
\begin{aligned}
& \text { 椋, }
\end{aligned}
$$

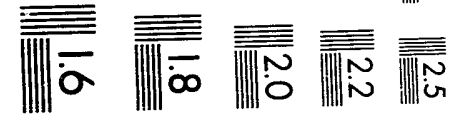



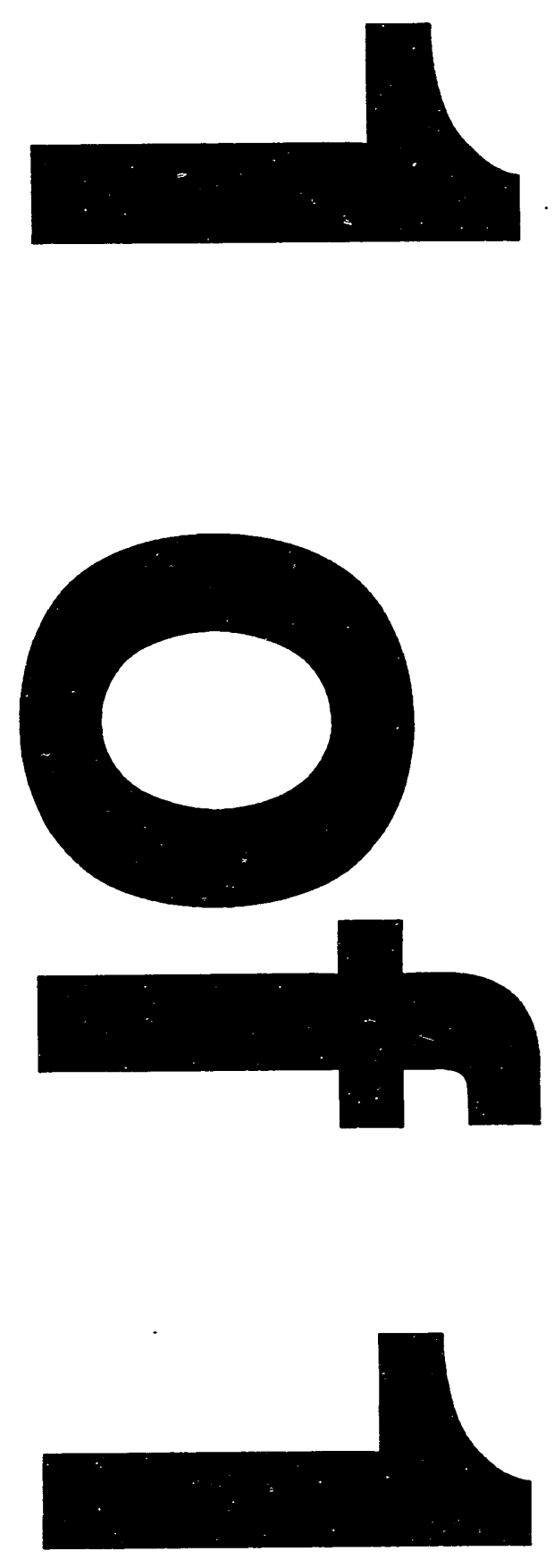
Dist: UC-905, Mathematics

K/CSD/TM-93

and Computer Sciences

Revision 2

\title{
PROJECT RECORDS INFORMATION SYSTEM (PRIS)
}

\section{USER'S MANUAL}

\author{
B. E. Cline \\ P. S. Smith \\ Engineering Design Information Systems Section \\ Engineering and Production Management Systems
}

Edited by: R. K. Schwarz

October 1993

\footnotetext{
COMPUTING AND TELECOMMUNICATIONS SERVICES

at

Oak Ridge K-25 Site

Past Office Bor. 2003

Oak Ridge, Tennessee 37831

MARTIN MARIETTA ENERGY SYSTEMS, INC.

managing the

Oat Ridge K-25 Site

Oak Ridge Y-12 Plant

Oak Ridge National Laboratory

for the US. DEPARTMENT OF ENERGY

under Contract DE-AC05-84OR21400
} 


\section{TABLE OF CONTENTS}

Page

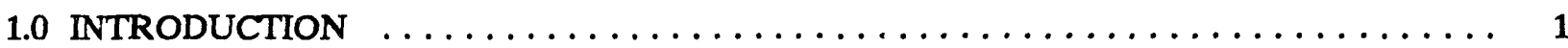

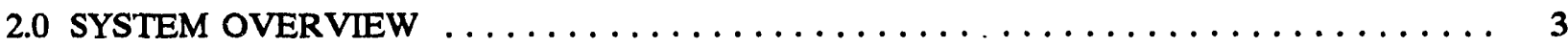

2.1 System Purpose $\ldots \ldots \ldots \ldots \ldots \ldots \ldots \ldots \ldots \ldots \ldots \ldots \ldots \ldots \ldots \ldots \ldots \ldots$

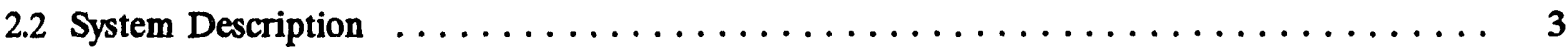

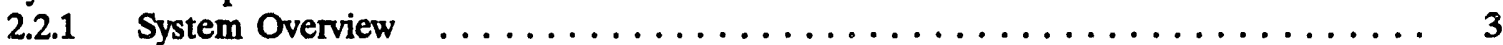

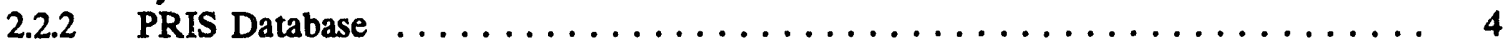

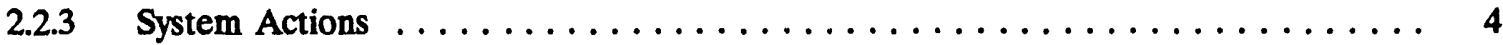

2.2.3.1 Select Project $\ldots \ldots \ldots \ldots \ldots \ldots \ldots \ldots \ldots \ldots \ldots \ldots \ldots \ldots \ldots$

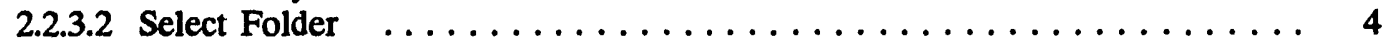

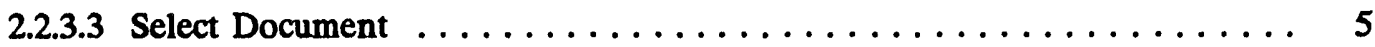

2.2.3.4 Select Reports $\ldots \ldots \ldots \ldots \ldots \ldots \ldots \ldots \ldots \ldots \ldots \ldots \ldots \ldots$

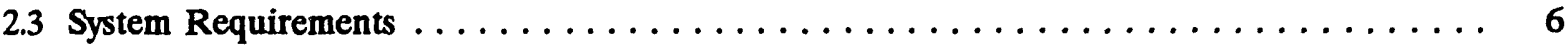

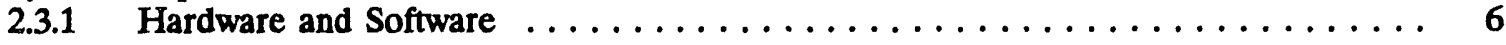

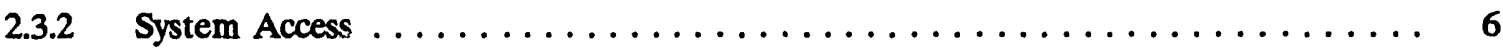

3.0 SYSTEM OPERATION $\ldots \ldots \ldots \ldots \ldots \ldots \ldots \ldots \ldots \ldots \ldots \ldots \ldots \ldots \ldots$

3.1 Conventions in System Commands and Keys $\ldots \ldots \ldots \ldots \ldots \ldots \ldots \ldots \ldots \ldots$

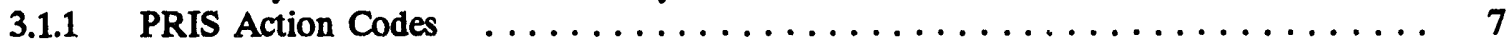

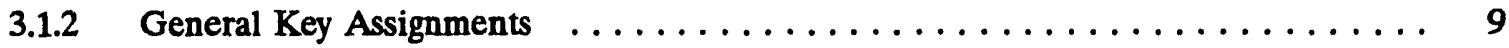

3.1.3 Help Screens and System Messages $\ldots \ldots \ldots \ldots \ldots \ldots \ldots \ldots \ldots \ldots \ldots$

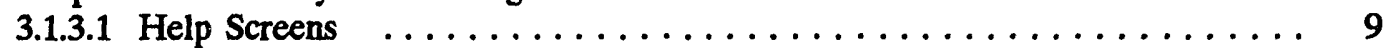

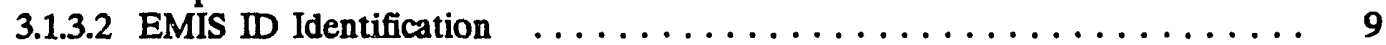

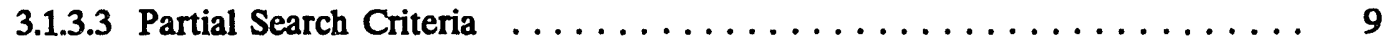

3.1.3.4 System Messages $\ldots \ldots \ldots \ldots \ldots \ldots \ldots \ldots \ldots \ldots \ldots \ldots . \ldots \ldots$

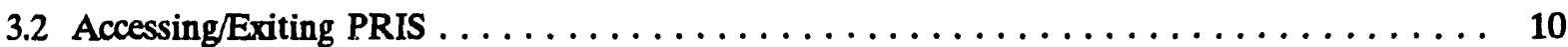

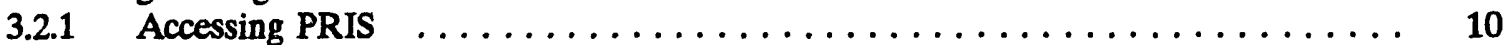

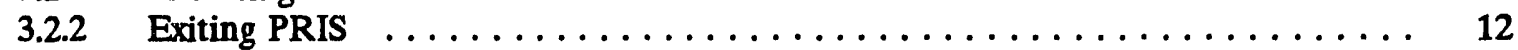

3.3 The PRIS Primary Option Menu $\ldots \ldots \ldots \ldots \ldots \ldots \ldots \ldots \ldots \ldots \ldots \ldots \ldots$

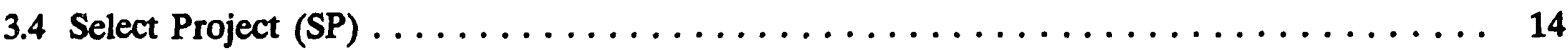

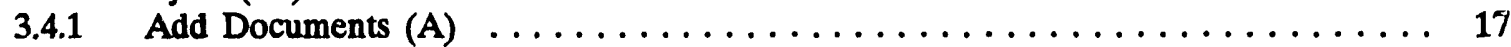

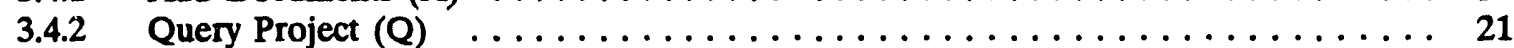

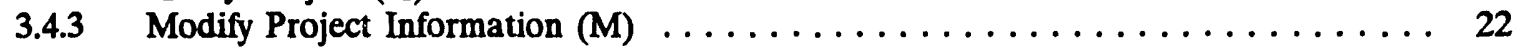

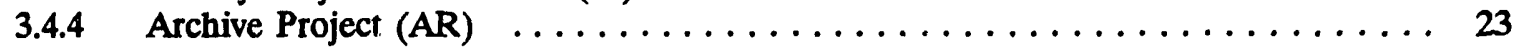

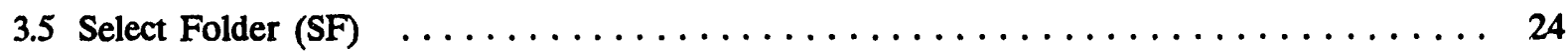

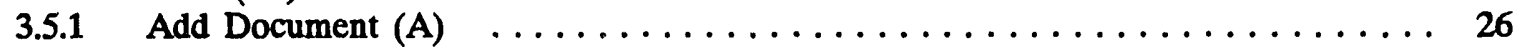

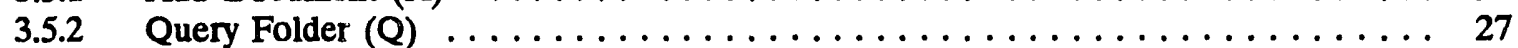

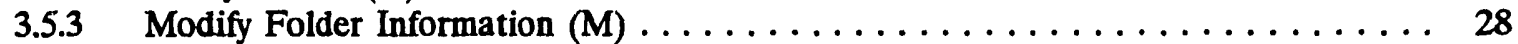

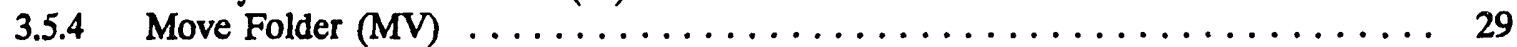




\section{TABLE OF CONTENTS (Continued)}

$\underline{\text { Page }}$

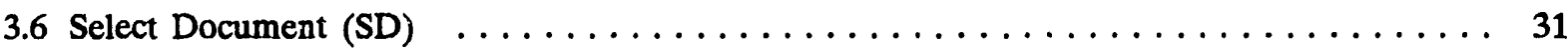

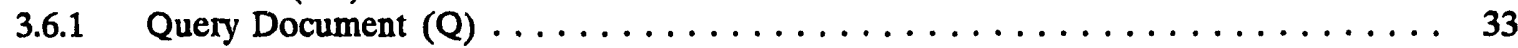

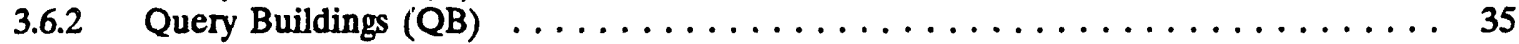

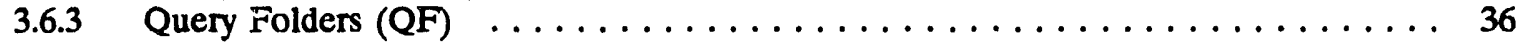

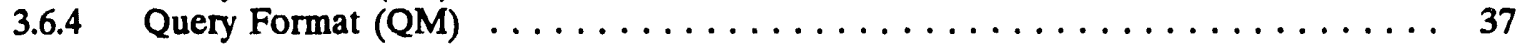

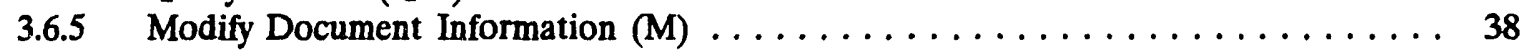

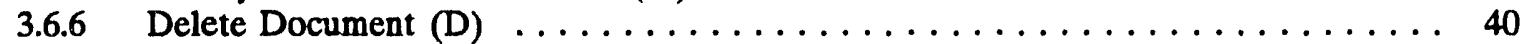

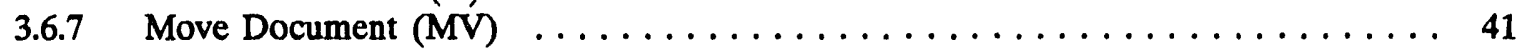

3.7 Select Reports (SR) $\ldots \ldots \ldots \ldots \ldots \ldots \ldots \ldots \ldots \ldots \ldots \ldots \ldots \ldots \ldots \ldots \ldots$

APPENDIX A: HELP AND ERROR SCREENS

APPENDIX B: PRIS REPORT FORMATS

APPENDIX C: PRIS DATA DICTIONARY 


\subsection{INTRODUCTION}

The Project Records Informatioi. System (PRIS) is an interactive system developed for the Information Services Division (ISD) of Martin Marietta Energy Systems, Inc., to perform indexing, maintenance, and retrieval of information about Engineering project record documents for which they are responsible. This PRIS User's Manual provides instruction on the use of this system.

Section 2.0 of this manual presents an overview of PRIS, describing the system's purpose; the data that it handles; functions it performs; hardware, software, and access; and help and error functions.

Section 3.0 describes the interactive menu-driven operation of PRIS.

Appendixes A, B, and C contain help screens, report descriptions, and the data dictionary, respectively. 


\subsection{SYSTEM OVERVIEW}

\subsection{SYSTEM PURPOSE}

ANSI/ASME NQA-1, Quality Assurance Program Requirements for Nuclear Power Plants provides quality assurance standards for the Department of Energy (DOE) Oak Ridge facilities managed by Martin Marietta Energy Systems, Inc. One implementation of this standard, Engineering Piocedure EP-B-36, requires maintenance of project files that contain the record copy of certain engineering project documents. The Project Records Information System (PRIS) supports the Information Services Division (ISD) in maintaining these project files.

\subsection{SYSTEM DESCRIPTION}

\section{2 .1 System Overview}

PRIS allows ISD personnel to index, maintain, and retrieve information about the engineering project records for which they are responsible. Using interactive screens, ISD personnel enter information into PRIS about engineering projects and the documents associated with these projects. They obtain this information from the Engineering Transmittal Forms attached to the documents. Using the entered information, PRIS generates records for a series of indexed project folders. ISD personnel index the documents received with a given transmittal and physically store these documents in a unique folder associated with the appropriate project. Project folders provide hard-copy storage of all documents except design drawings. For design drawings, the ISD Drawing Centers provide physical storage; project folders contain only information about them.

Users of the system retrieve information from PRIS through interactive queries. The user can search project record information by project-, folder-, and document-related fields. PRIS displays the resulting information on the terminal screen. In addition, users may interactively select from predefined hard-copy reports. The plant mail system delivers the printed reports to the user.

Version 2.0 of PRIS incorporates the following major changes and enhancements:

1. The existing PRIS software has been converted to execute under control of the Customer Information Control System (CICS). The CICS environment provides improved response time and reduces database contention and deadlocks.

2. PRIS is no longer used to establish Project Record Numbers (PRNs) and to add Engineering Service Orders (ESOs) and Project Engineers to the PRNs; instead, the Engineering Resource Management (ERM) Office enters this information into the Engineering Management Information System (EMIS). EMIS downloads PRNs, ESOs, and associated Project Engineer IDs to PRIS nightly. PRIS can enter project documents only after the PRN has been downloaded from EMIS.

3. The abbreviated document listing can be sorted either by document number (as in the previous version) or by Project Record Number, folder number, and then document number.

4. Multiple buildings can easily be entered for a document.

5. PRIS personnel can remove incorrectly entered documents from the PRIS database. 


\subsection{PRIS Database}

Information about Engineering design documents that is entered through PRIS is a subset of the index information entered into EDIS by all systems, including the CADAM system and the ISD Index Function. Information in the EDIS Index and in PRIS is stored in the same set of tables regardless of its source. When design documents are entered into the Index by other systems and are also entered in PRIS as project documents, the physical documents are maintained by the ISD Design Center or by the repository associated with the originating system.

In the database and on the system's data entry and iisting screens, data element names identify the information about projects, documents, folders, and project personnel. A dictionary defining the PRIS data elements is presented in Appendix C.

\section{System Actions}

The Primary Option Menu provides access to PRIS processing actions. This menu allows you to select a specific (1) project, (2) folder, (3) document, or (4) report to work with. Processing actions can be performed on the selected record material, such as Add, Query, Modify, Delete, Archive, Move, and produce reports. The primary menu options and the processing actions they provide are outlined below and are described in more detail in Sect. 3.0.

\subsection{Select Project}

This option allows you to select a project for further processing. The system displays a list of the projects that match selection criteria you provide. The desired project can be selected from this list. The following actions can be performed once the project is selected:

1. Add new folders and their documents to a project. When documents are added, you may input additional buildings for multi-building documents.

2. Query any project for a list of its folders.

3. Modify project information.

4. Archive project folders.

Section 3.4 describes the project processing options.

\subsubsection{Select Folder}

This option allows you to select a folder for further processing. The system displays a list of the folders that match selection criteria you provide. The desired folder can be selected from this list. The following actions can be performed once the folder is selected:

1. Add new documents to any existing folder. When documents are added, you may input additional buildings for multi-building documents.

2. Query any folder for a list of its documents.

3. Modify transmittal (folder) information.

4. Move a folder to a different project.

Section 3.5 describes the folder processing options. 


\subsubsection{Select Document}

This option allows you to select a document for further processing. The system displays a list of the documents that match selection criteria you provide. Depending on your input, PRIS will sort the document list by document number alone or by Project Record Number, folder number, and document number. The following actions can be performed from the document list:

1. Query a document for more detailed document information. From the Detail Document Information screens, you also may perform actions 2 through 7 below.

2. Query the list of buildings associated with the document. From the Document Building Listing Screen, you may modify the building list.

3. Query the list of folders associated with the document. From the Document Folder List, you may delete copies of the document from specified folders.

4. Query the list of formats associated with the document.

5. Modify document information.

6. Delete the document from PRIS.

7. Move the document to a different folder.

Section 3.6 describes the document options.

\subsection{Select Reports}

This option allows you to select hard-copy reports of project and document information. From the Select Report screen, you may generate any of the following reports:

1. Project List for a Given Plant

2. Project/Folder List for a Given Plant

3. Project/Folder Document List for a Given Plant

4. Project Document List for a Given Plant, ordered by Document Number

5. Folder/Document List for a Given Project

6. Document List for a Given Project, ordered by Document Number

7. Project List for a Given Project Engineer

8. Project/Document List for a Given Project Engineer, ordered by Document Number

Appendix B, PRIS Report Formats, provides report layouts. Section 3.7 describes the report option. 


\section{¿3 SYSTEM REQUIREMENTS}

\section{:3.1 Hardware and Software}

PRIS is located on the IBM 3090 unclassified processor located at the Oak Ridge K-25 Site.

PRIS is accessed via asynchronous communication over the unclassified DCA network using VT-1001ype terminals or microcomputers equipped with VT-100 emulation software as follows:

1. An ASCII terminal connection to the IBM 7171 (System Select 9 and 47) through the unclassified DCA network for the 3090 unclassified system or a microcomputer with communications software (e.g., SmarTerm).

2. An IBM 3270-type terminal or a microcomputer equipped with 3270 emulation, such as IRMA, connected through coaxial cable or an IBM token ring network.

In connection with the current enhancements, PRIS software has been converted to use Cross System Product (CSP), a fourth generation language product. The resulting CSP applications execute under the Customer Information Control System (CICS) environment.

\subsubsection{System Access}

Users must have a user ID, a computer password, and an authorized CICS account on the IBM 3090 computer at K-25 to access the system. Access control is enforced through user identification at the time of logon and through authorization tables that define the functions permitted to each user of the system.

EMIS maintains user access control information for PRIS. A PRIS user must first be a valid EMIS user. Validation information, including EMIS user IDs, is downloaded nightly to PRIS by EMIS. In addition, the EDIS Configuration Control Manager specifically authorizes PRIS users to access the PRIS database and to execute PRIS software. 


\subsection{SYSTFM OPERATION}

\subsection{CONVENTIONS IN SYSTEM COMMANDS AND KEYS}

System operations are performed using a series of data display, selection, and/or entry screens. PRIS performs the tasks you request by guiding you from one screen to the next based upon your responses to menu selections and screen prompts. Your responses are entered by typing requested data and/or one of the PRIS action codes (shown below) in the indicated command or select field and then pressing the <ENTER > key to initiate the action. Some screens and actions can be accessed by more than one screen path. The primary menu structure is shown in Figure 1. Section 3.1.1 lists the PRIS action codes and their associated system responses. Section 3.1.2 lists the standard cursor movement and screen processing keys to be used within a screen.

The system screens are operated from a command line, which is the second line of each screen. The commands that may be entered on this line are listed below. Command keys are enclosed in angle brackets (e.g., <ENTER >) that indicate you should press a single key to perform the action.

\subsubsection{PRIS Action Codes}

The following table lists PRIS action codes along with the associated system response. Not all codes are available from each screen. If a code can apply to more than one kind of object, the system processes the object that is currently selected.

\begin{tabular}{ll} 
Code & Action \\
\hline X & EXIT \\
E & END \\
UP & UP \\
DN & DOWN \\
SP & SELECT PROJECT \\
SF & SELECT FOLDER \\
SD & SELECT DOCUMENT \\
SR & SELECT REPORT \\
AR & ARCHIVE \\
Q & QUERY \\
QB & QUERY BUILDING \\
QF & QUERY FOLDER \\
QM & QUERY FORMAT \\
M & MODIFY \\
A & ADD \\
D & DELETE \\
MV & MOVE
\end{tabular}

\section{System Response}

Exit from current screen to Primary Option Menu Exit from current screen to previous screen Scroll up one page ("UP $M^{n}$ goes to top of list; " $M^{\text {" }}=\max$ ) Scroll down one page ("DN M" goes to end of list) Display input screen for project selection criteria Display input screen for folder selection criteria Display input screen for document selection criteria Display input screen for selecting a batch report Display archive screen for input of archive location Display additional information about project, folder, or document

Display building list for a document

Display folder list for a document

Display format list for a document

Modify project, folder, or document information

Add new folders and/or new documents to PRIS

Delete document from PRIS; delete building from building list

Move document or folder 


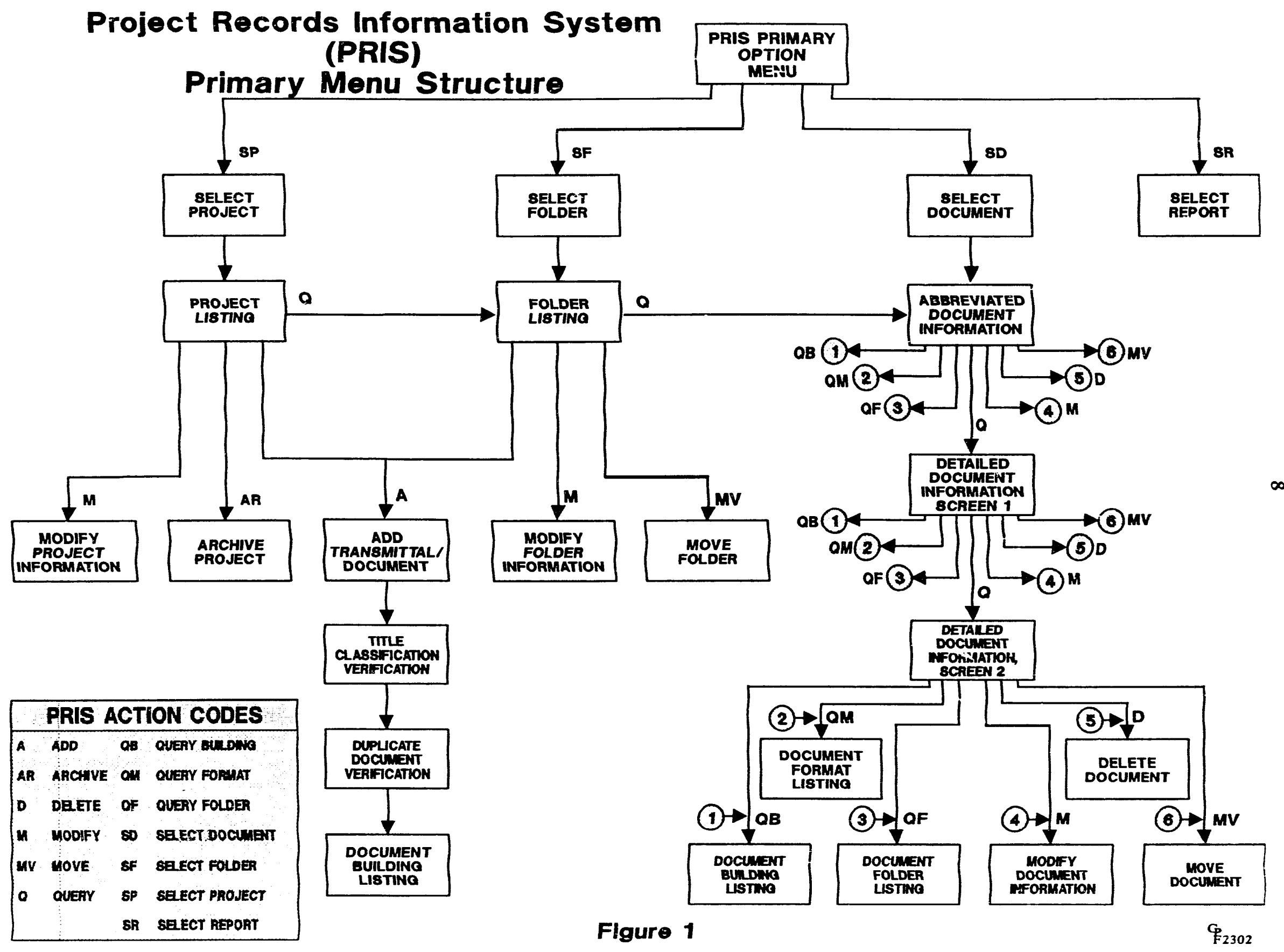




\subsubsection{General Key Assignments}

Keyboard keys and their actions to process data and move the cursor on the screen are listed below:

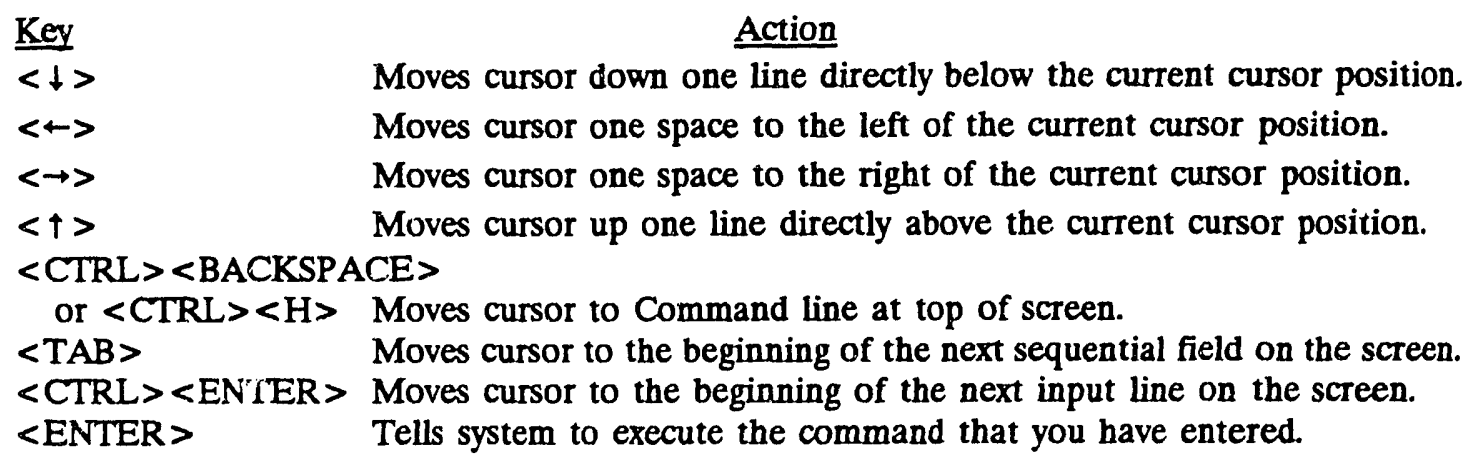

\subsubsection{Help Screens and System Messages}

\subsubsection{Help Screens}

Help screens for classification, building, company, document type, plant, and EMIS IDs are available throughout the system. While entering data or search criteria, you can type a question mark (?) in one or more of these screen fields. After you press <ENTER > to process the screen, the system displays a help screen for each field containing a ? to allow you to select the missing values. See Appendix A for examples of these help screens.

To select a value from a help screen, place an $\mathrm{X}$ beside the desired value and press <ENTER>. PRIS places the selected option in the original input field in place of the ?. When all ?'s have been replaced with valid values, PRIS finishes processing the screen. The screen will not be redisplayed unless errors are found with other values. To exit a help screen without making a selection, type END in the command field and press <ENTER>; PRIS will redisplay the original data or search screen, place the cursor at the ? in that field, and flag the ? as incorrect and needing a value.

An error screen for certain special cases is also displayed in Appendix A.

\subsubsection{EMIS ID Identification}

For input fields that require EMIS IDs, you may enter ? and press <ENTER> to display the Engineering Personnel Help Screen. This screen allows you to enter a name or other search criteria to find an employee. When you press <ENTER>, the system displays a list of EMIS IDs and associated names that meet the search criteria you entered. You may then select the needed EMIS ID from this list.

\subsubsection{Partial Search Criteria}

On search screens, you may use a percent sign (\%) or an underscore $U$ as wild-cards to represent unknown characters located before, after, or in the middle of a known string of characters. The system will search for records with the exact string characters in the indicated position and with variable characters where a \% or _ is indicated.

\subsubsection{System Messages}

System messages are displayed just below the Command line of some screens or on the bottom line of other screens. These messages may be error messages if an invalid command or information is entered, or they may be confirmation messages that confirm the system's execution of actions you have requested. 


\subsection{ACCESSING/EXITING PRIS}

\subsection{Acoessing PRIS}

To access PRIS, you must have a user ID, a computer password, and an authorized CICS production account on the IBM 3090 machine.

Several types of terminal connections may be used to access the 3090, as described in Sect. 2.3.1. To $\log$ on the K-25 IBM 3090 unclassified system using one of these terminal connections, follow one of the procedures described below.

NOTE: Whenever the system displays *** at the bottom of text, you must press $<$ ENTER > to continue.

1. For the 7171 connection to the K-25 system, answer the following prompts with the indicated responses:

Prompt

Which System (1 thru 55)?

Enter Desired Application $=>$

* Enter either 9 or 47 as the system select number.

\section{$\underline{\text { Response }}$}

$47<$ ENTER >

$<$ ENTER >

CICS <ENTER>

2. For the 3270-type terminal with coaxial or token ring connection, respond to the prompt as shown below:

Prompt

Enter Desired Application $=>$
Response

CICS <ENTER> 
After the CICS command is entered for either of these log-on sequences, the CICS log on screen is displayed:

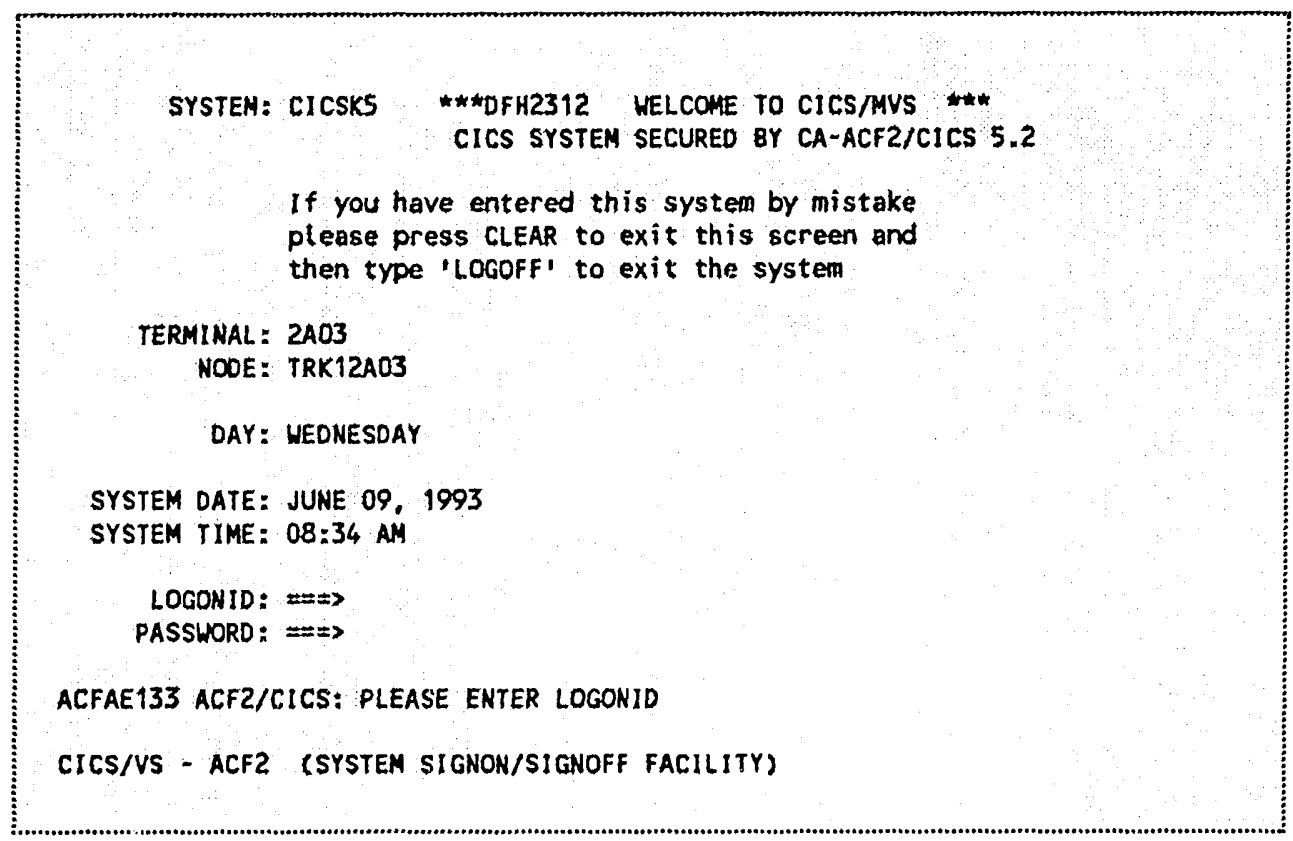

Type your user Id and password in the indicated fields, then press <ENTER>. If the log on is successful, CICS displays log-on confirmation messages:

ACF01137 XXX LAST SYSTEM ACCESS 07.43-06/09/93 FROM 5339

ACFAE139 ACF2/CICS: $2 A 03$ SIGNON COMPLETED: LOGONID=xxx

This computer and its associated subsystens, including electronic mail, are for official use onty by authorized employees of Martin Marietta Energy Systems, Inc. (Energy Systems), or by other persons authorized by Energy Systems. Users of this system are advised that there is no expectation of privacy of an individual's activities on the system. Energy Systems retains the right to monitor all activities on the system and to access any computer files or il messages without prior knowledge of user, sender, or addressee.

CICS positions your cursor in the upper left-hand corner of this screen. 
To run PRIS, type

EDPR <ENTER>

PRIS will display the Primary Option Menu shown on the next page.

\subsection{Exiting PRIS}

You leave PRIS by entering X on the Primary Option Menu. CICS then displays a blank screen and positions your cursor in the upper left-hand corner of the screen. On this CICS main screen, type

$$
\text { LOGOFF <ENTER> }
$$

CICS displays the following log-off messages:

ACFAE131 ACF2/CICS: 2A03 SIGNOFF HAS BEEN COMPLETED

ACFA3136 ACF2/CICS: THIS TERMINAL WILL BE DISCONNECTED FROM CICS 


\subsection{THE PRIS PRIMARY OPTION MENU}

When you access PRIS, the following menu of system actions is displayed:

Project Records Information Systed
COMEAN:

PRIS

PRIMARY

OPTION

MENU

Indicate the action to be performed by typing the option character(s) on the COMMAND line and pressing <ENTER>. The following sections of this manual describe the operation of the four actions on the Primary Option Menu.

Refer to the table below to find the manual section that covers each option.

Option Action

$\begin{array}{ll}\text { SP } & \text { SELECT PROJECT (see Sect. 3.4). } \\ \text { SF } & \text { SELECT FOLDER (see Sect. 3.5). } \\ \text { SD } & \text { SELECT DOCUMENT (see Sect. 3.6). } \\ \text { SR } & \text { SELECT REPORTS (see Sect. 3.7). } \\ \text { X } & \text { EXIT }\end{array}$

Entering option $\mathrm{X}$ or the command END and pressing <ENTER > will exit PRIS and return you to the CICS main screen. 


\subsection{SELECT PROJECT (SP)}

PRNs, ESOs, and Project Engineers are established in EMIS by the ERM Office. EMIS downloads PRNs, ESOs, and associated Project Engineer IDs to PRIS nightly. A PRN must be established in EMIS and downloaded to PRIS before PRIS can accept its project documents.

The Select Project option allows you to select and display project information by entering selection criteria that identify the project. PRIS searches the database for projects that match your entered criteria and displays a list of projects. You may select a project from this list for further processing. When the SP option is chosen from the Primary Option Menu, the system displays the Select Project Screen.

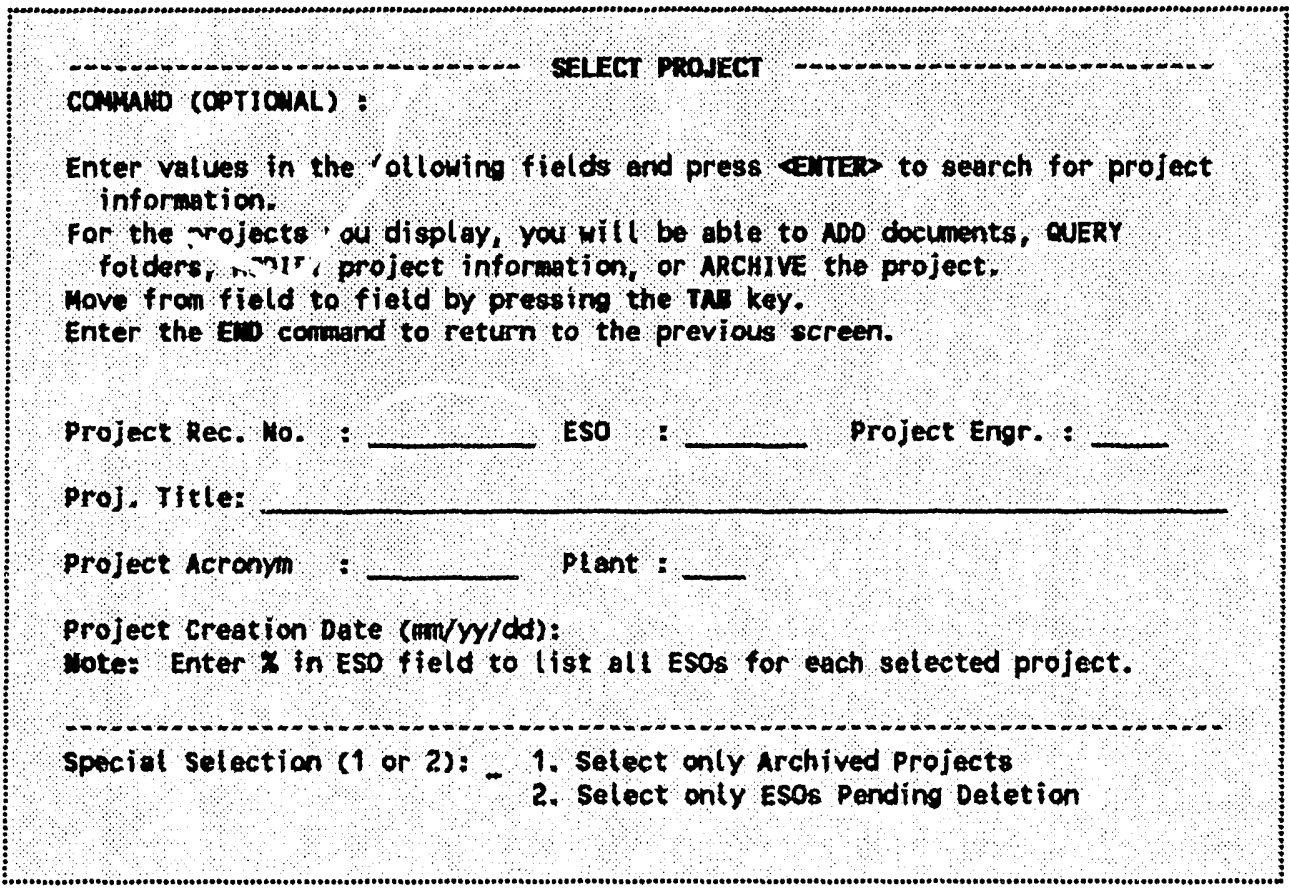

Use the $\angle \mathrm{TAB}>$ key to move the cursor through the data entry fields and enter values for one or more data elements to serve as selection criteria. To get help in data entry for the Project Engr. field and Plant field, type a question mark (?) in the field (see Sect. 3.1.3 and Appendix A). In the Project Record Number, Project Acronym, and Proj. Title fields, a percent sign (\%) or an underscore $($ "wild card" may be used as part of the values entered (see Sect. 3.1.3). To cancel the search and return to the PRIS Primary Option Menu, type END in the COMMAND field and press <ENTER>.

Enter a "\%" in the ESO field if you wish to see all ESOs for the project; otherwise, only one entry for each project will be displayed, even if multiple ESOs exist.

In the Special Selection field enter a 1 to find only archived projects or 2 to find only projects with ESOs pending deletion. If this field is left blank, all projects (active, archived, or with ESOs pending deletion) will be displayed.

Press <ENTER> to process the selection criteria, obtain help screens for fields containing ?, and begin the search. If no projects are found that match the entered criteria, the system redisplays the Select Project Screen with a message stating that no projects have been selected, and you are allowed to re-enter the criteria. 
If matching projects are found, the system displays a list of those projects on the Project Listing Screen. A message is displayed at the bottom of the screen to tell you how many projects were found. If your search criteria were too general (they returned more than 240 matches), only the first 240 are listed and a message will ask you to redefine your search.

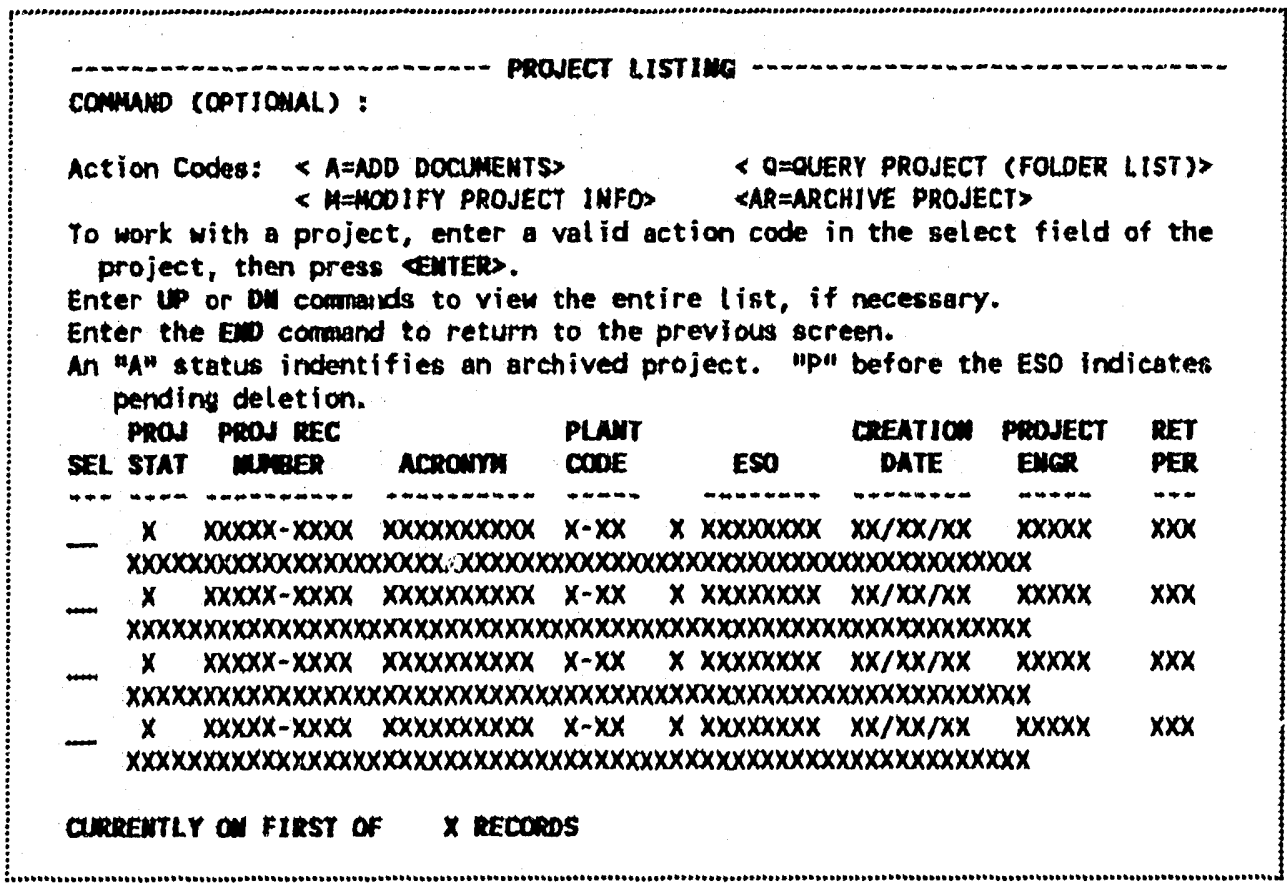

PROJECT

LISTING

SCREEN

Unless your select criteria included a "\%" to display all ESOs, this screen lists only one entry for each project, and the ESO column for the projects is blank. ESOs are displayed in this column only if the detailed ESO listing is requested.

Use the $\langle\mathrm{TAB}\rangle$ or $\langle\uparrow\rangle$ and $\langle\downarrow\rangle$ keys to move the cursor to the project you wish to select for processing. If there is more than one screen of selected projects, type DN or UP in the COMMAND line and press $<$ ENTER > to display the next or previous screens, respectively.

Processing options are requested by placing the letter of the action you wish to perform in the SEL column beside the selected project and pressing <ENTER>. The system then displays screens that allow you to perform the chosen action (these are described in the following sections of this manual). When an action is completed (or you enter an END command on a subsequent screen), the system returns to this Project Listing Screen for further selections. The actions that are available are listed below:

Option

Action

A

Q

M

AR
Add documents (create a new transmittal folder and add documents to the selected project) (see Sect. 3.4.1).

Query project (display a list of the folders belonging to the selected project) (see Sect. 3.4.2)

Modify project information for the selected project (see Sect. 3.4.3).

Archive the selected project (see Sect. 3.4.4). 
Option A may not be used to add transmittals and documents to a project ESO that is flagged as pending deletion on this listing screen. If the ESO column is preceded by a "P", that ESO or all ESOs for that project (if ESO is blank) are pending deletion. (A complete listing of ESOs will display which individual ESOs are pending deletion.)

Option M may not be used to modify project information if all the project ESOs are flagged as pending deletion.

Option Q displays a list of folders for the ESO that is displayed on this listing screen. If the ESO column for the selected project line is blank, the list of folders includes all folders for all of the project's ESOs.

When you exit the Project Listing Screen by entering END in the COMMAND line, the system returns to the Select Projest Screen. 


\subsubsection{Add Documents (A)}

Project documents are received by ISD accompanied by an Engineering Transmittal. The Transmittal provides a PRN and/or ESO number identifying the project of the associated documents. When you select a project for adding a new transmittal, the system displays the screen below.

There are three areas of information on the screen: Project Information, Transmittal Information, and Document Information. The Project Information area displays information about the project you selected, which cannot be modified from this screen. If the Project ESO is flagged as a default ESO ("Indicates default ESO) and this ESO is not the ESO you wish to use, exit this screen and select a specific ESO from a detailed ESO listing. The EMIS Project Number field is set to the EMIS project number associated with the Project ESO. Data entry for the other two areas of this screen is described below.

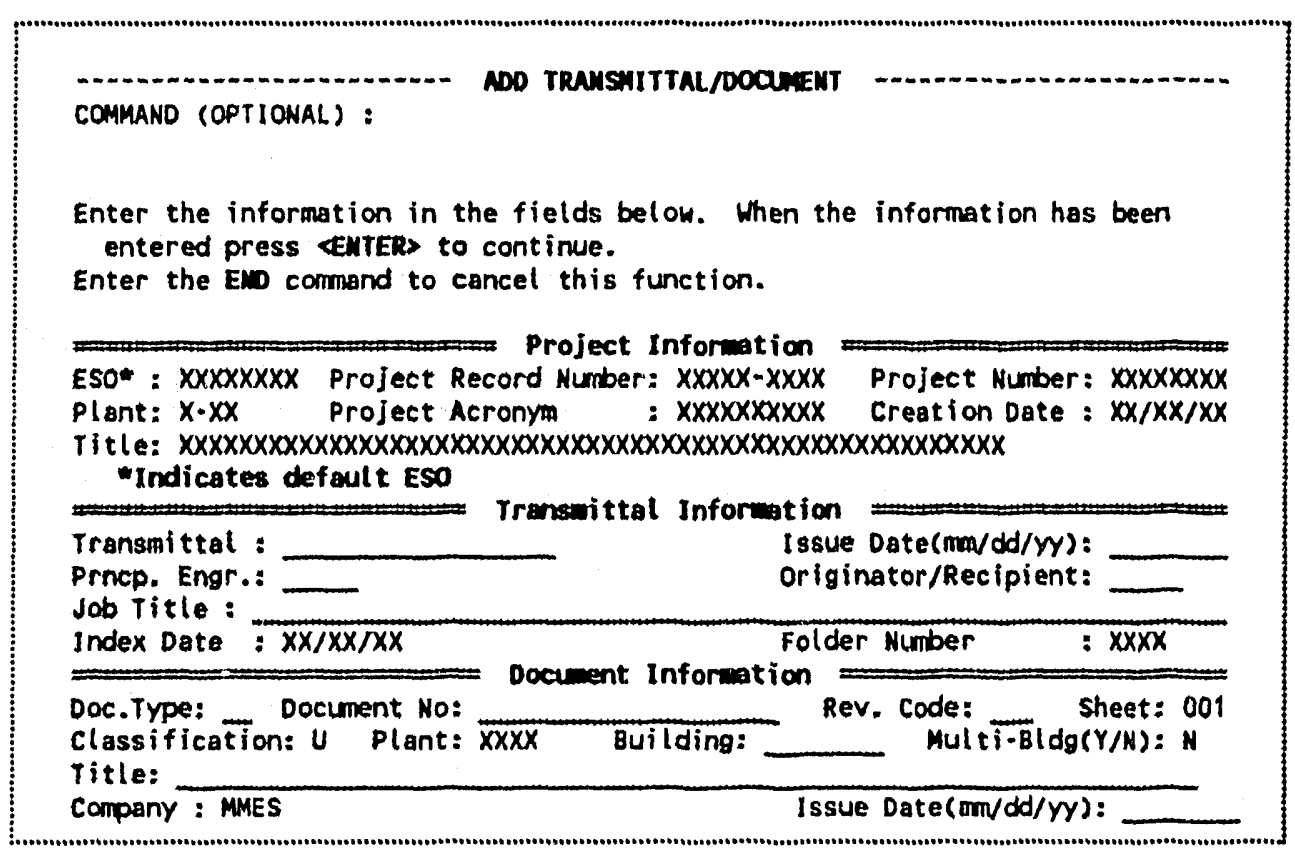

ADD

TRANSMITTAU

DOCUMENT

SCREEN

Use the $<\mathrm{TAB}>$ key to move from field to field in the Transmittal and Document Information areas. Enter information for the transmittal and the first document of the transmittal. When all information has been entered, press the <ENTER > key.

The system will validate the transmittal and document information. Then it creates a unique, sequential folder number that associates the folder with the appropriate project. It also creates a document record that corresponds to the entered information. Then PRIS redisplays the Add Transmittal/Document Screen with the transmittal fields protected and the document fields reinitialized for another document (see page 20 for more information on these processing functions).

The system continues to redisplay the Add Transmittal/Document Screen for you to add additional documents until you exit by entering END on the COMMAND line of the screen. In this way, you can enter all documents associated with a transmittal in a single session. Once you enter END, any remaining documents of a transmittal must be added to the folder using the Add Document option found on the Folder List Screen. (See Sect. 3.5.1 for a description of this option.)

When you enter END on the COMMAND line of the Add Transmittal/Document Screen, the system will display the Project Lisîing Screen with a message showing the number of documents added to the current folder. 
Data entry requirements for certain Transmittal and Document entry fields are described below.

Field

Prncp. Engr.

Originator/Recipient

Index Date

Folder Number

Doc. Type

Document No.

Rev. Code

Sheet

Classification

TTILE

CLASSIFICATION

VERIFICA-

TION
Description

To receive help with the EMIS ID for the principal engineer, enter ? in this field to display the Personnel Help Screen. (See Appendix A.)

o receive help with the EMIS ID for the originator/recipient, enter ? in this field to view the Personnel Help Screen. (See Appendix A.)

This field does not accept entry. After the system has stored the first document, it sets the value to the current date.

This field does not accept entry. After the system has created a folder, it sets this value to the number of the current folder.

To receive a list of document types, enter ? in the field. (See Appendix A)

You must enter a document number for all documents. For document types DD, JS, BM, DS, and DC, you inust enter the actual document number. For all other document types, you may enter UNKNOWN if no document number is available--PRIS will generate a unique sequential document number for the document based on the project and folder numbers.

This field is defaulted to blank, but can be changed.

This field is defaulted to 001 , but can be changed.

This field is defaulted to $U$. When you enter a title for a document with a classification level other than U, PRIS displays the Title Classification Verification Screen shown below:

COMHAND (OPTIONAL):

IITLE CLASSIFICATIOU VERIfICATIOM

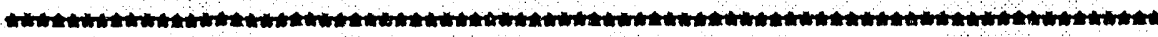

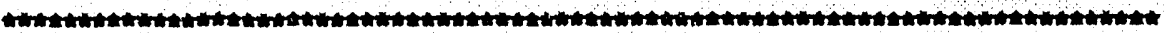

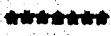
timtint whint Title should have been declared incuassifreb by an Authorized wemmen miminth Derivative Classifier (ADC).

mintinitita wherentw

Do not enter Progran Nuber, Process Nuber, Part Drawing trimbiter numbinting nowativion

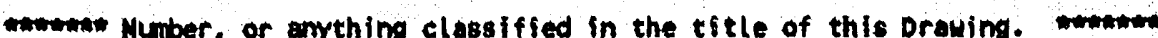
mentriate

wown correct the Title if necessary and press Eurene to continure. Himertate

Enter ED to cancel the document entry.

revinitit

mintint

Title:

$\times \times \times \times \times \times \times \times \times \times \times \times \times \times \times \times \times \times \times \times \times \times \times \times \times \times \times \times \times \times \times \times \times \times \times \times \times \times \times$

mintiont

riming

monowions

intormente

ontrover

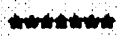
rimintw

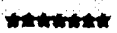

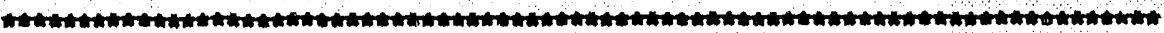

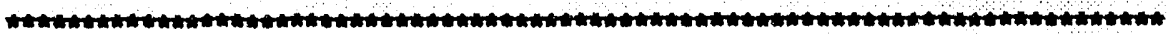


Field

Plant

Building

Multi-Bldg

DOCUMENT

BUILDING

LISTING
Description

This screen is used to verify that the entered title is unclassified. You must either (1) modify the title if necessary and confirm that the title is unclassified by pressing <ENTER> or (2) cancel addition of the document by entering END in the COMMAND line. After you confirm that the title is unclassified, PRIS will add the document to the Index.

This field is defaulted to your plant as identified in EMIS, but can be changed.

You must enter a building number for all documents except design drawings (document type DD); for DDs, leave the field blank. PRIS will retrieve the building numbers from the EDIS Index if the DD already exists. If PRIS is the first system to add the DD to the Index, the system will enter the value UNKNOWN in this field. When CADAM or ISD subsequently enters the document, the actual building number(s) will replace UNKNOWN.

To display a list of buildings for the plant in the Plant field, enter ? in the Building field (see Appendix A). Lists are available for K-25, X-10, and Y12 plants only.

This field is defaulted to $N$. If you change the value to $Y$ and the document is not a design drawing, PRIS will display the Document Building Listing and allow you to enter additional buildings for the document.

$$
\text { COMWANo (OPTIONAL) : }
$$

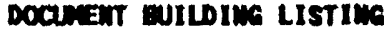

\section{Hew Building :}

The following is a list of the bulldings essociated with the current document. To add a new building, enter valld bullding number in the New Bullding field.

Press \&aTERs whon input is complate. Enter the and comand to return to the previous screan.

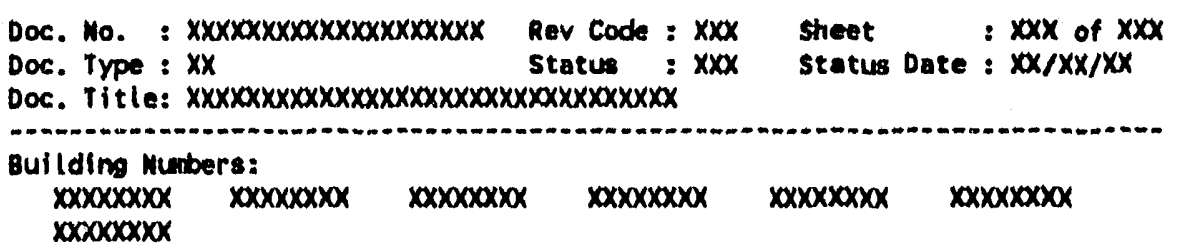

This screen displays key information and current Building Number values for the document. You may enter an additional building number for this document in the New Building field and press <ENTER>. If you enter ? in the New Building field, the system will display a list of valid building values from which to choose (see Appendix A). The screen is redisplayed after each addition until you enter END on the COMMAND line of the screen to exit the screen.

Company

The screen will be displayed with the Company field defaulted to MMES, but this may be changed. To display a list of company codes, enter ? in the field (see Appendix A). 
As each document is added, PRIS checks the entered data for valid values. If an invalid value has been entered in one or more fields, the system redisplays the screen, highlights all invalid fields, and displays a message that the highlighted fields are incorrect. You may place ? in the Principal Engineer, Originator/Recipient, Doc. Type, Classification, Building, Plant, or Company fields to display a list of valic values from which to choose (see Appendix A).

PRIS will display the following sequence of additional screens, if appropriate, before saving the document and returning to the Add Transmittal/Document screen for entry of another doct ment:

1. If a title is entered and the value of Classification is other than $U$, the system will display the Title Classification Verification Screen (as discussed on page 18).

2. When you enter a document, PRIS checks whether or not the document number already exists. If PRIS has previously stored a document with this document number in another folder of the current project or in another project, the system displays the Duplicate Document Verification Screen.

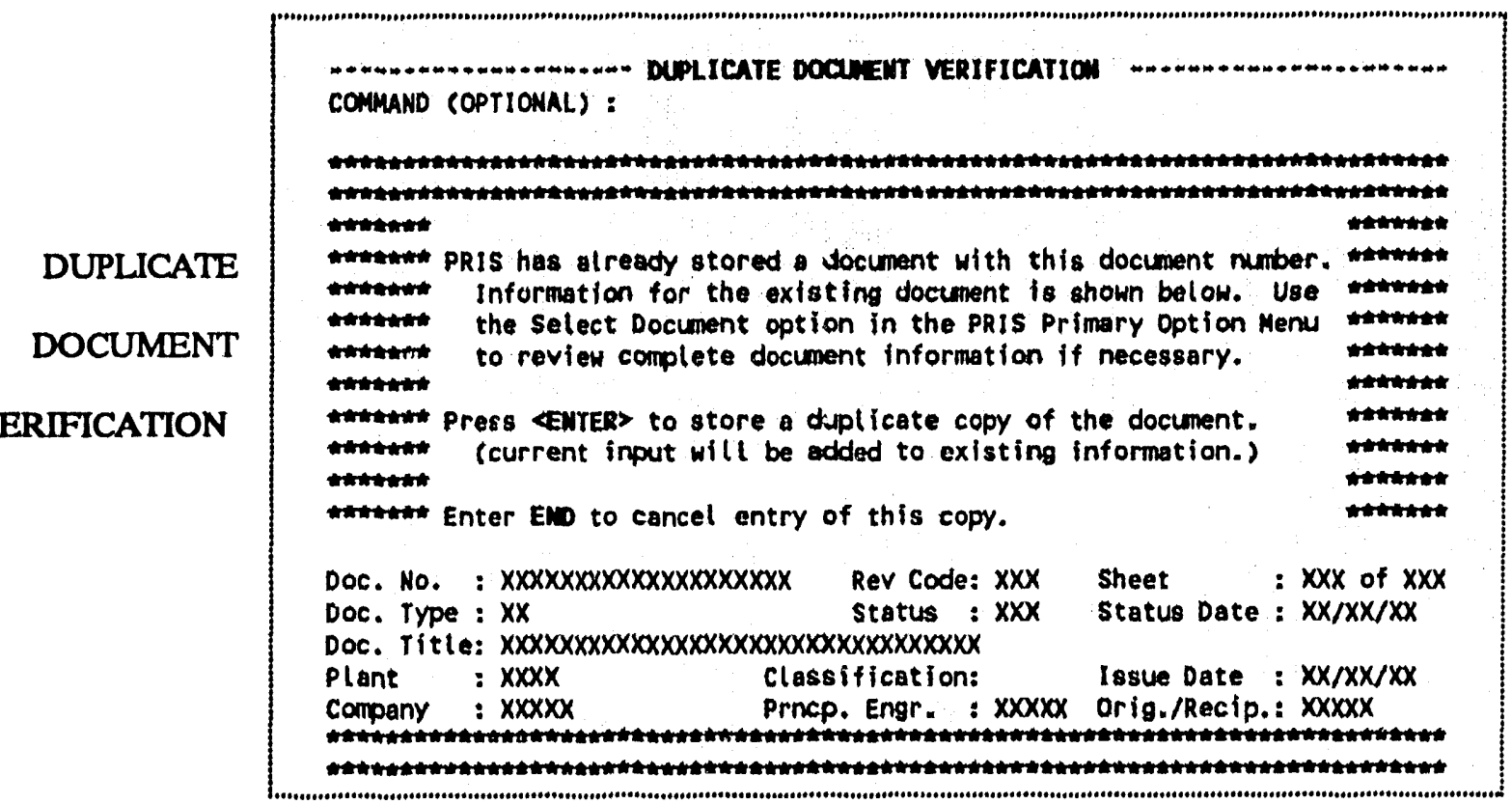

This screen shows the document information for the existing document. From this screen, you can cancel entry of the document (by entering END) if your document number was typed wrong or if there are two documents with the same document number. If you confirm that the document should be re-entered (by pressing <ENTER >), PRIS adds the document and merges your input with the existing information.

3. If the value of the Multi-Bldg field has been set to Y, PRIS will display the Document Building Listing Screen (see previous page).

4. Finally, PRIS redisplays the Add Transmittal/Document Screen with a message that the document has been added to the folder, and default values are displayed in the Document Information area to receive another document for the transmittal. After the first document is entered into a folder, the Transmittal Information can no longer be modified from this screen. 


\subsubsection{Query Project (Q)}

When you Query a project, PRIS displays a list of folders for the selected project. When Q is placed beside a project on the Project Listing Screen, the following Folder Listing Screen is displayed:

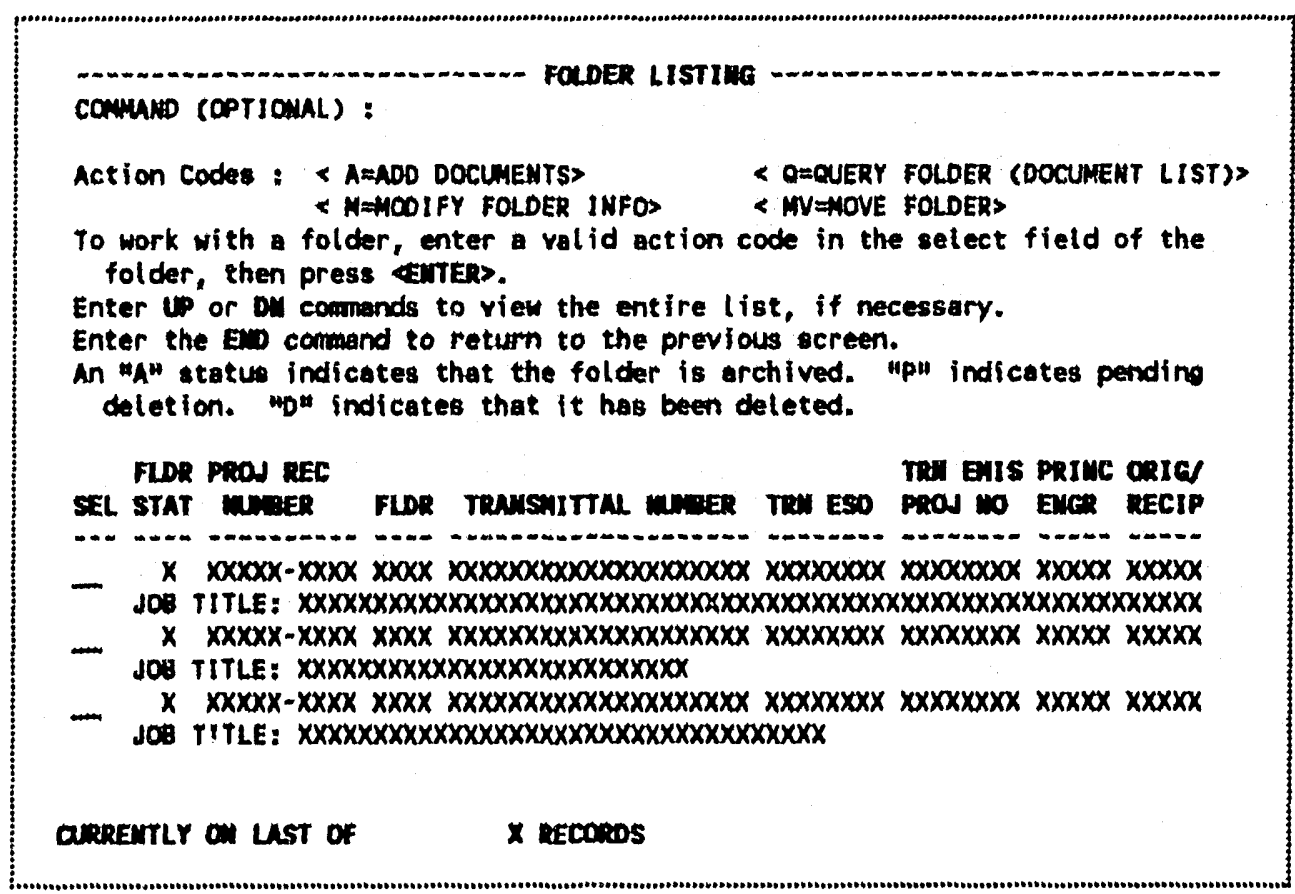

FOLDER

LISTING

SCREEN

Use the $\langle\mathrm{TAB}\rangle$ or $\langle\uparrow\rangle$ and $\langle\uparrow\rangle$ keys to move the cursor to the folder you wish to select for processing. If there is more than one screen of folders in the list, type DN or UP in the COMMAND line and press <ENTER> to display the next or previous screen of folders, respectively. To exit this screen without selecting a folder, enter END in the COMMAND line and press <ENTER>.

Processing actions are requested by placing the letter of the action you wish to perform in the SEL column beside the selected folder and pressing <ENTER>. PRIS then displays screens that allow you to perform the chosen action. When the action is completed, PRIS redisplays the Folder Listing Screen for further selections. The options that are available are listed below and described in detail in Sect. 3.5 of this manual:

\section{Option}

A

Q

M

MV

\section{Actions}

Add documents to the selected folder (see Sect. 3.5.1).

Query folder (display a list of the documents contained in the selected folder) (see Sect. 3.5.2).

Modify folder information for the selected folder (see Sect. 3.5.3).

Move folder to a different project (see Sect. 3.5.4). 


\subsubsection{Modify Project Information (M)}

The Modify Project Information option on the Project Listing Screen allows you to enter or change project information for the selected project. However, project information may not be changed if the project is pending deletion. Screen.

When $M$ is entered in the Select field of a project, the system displays the Modify Project Information

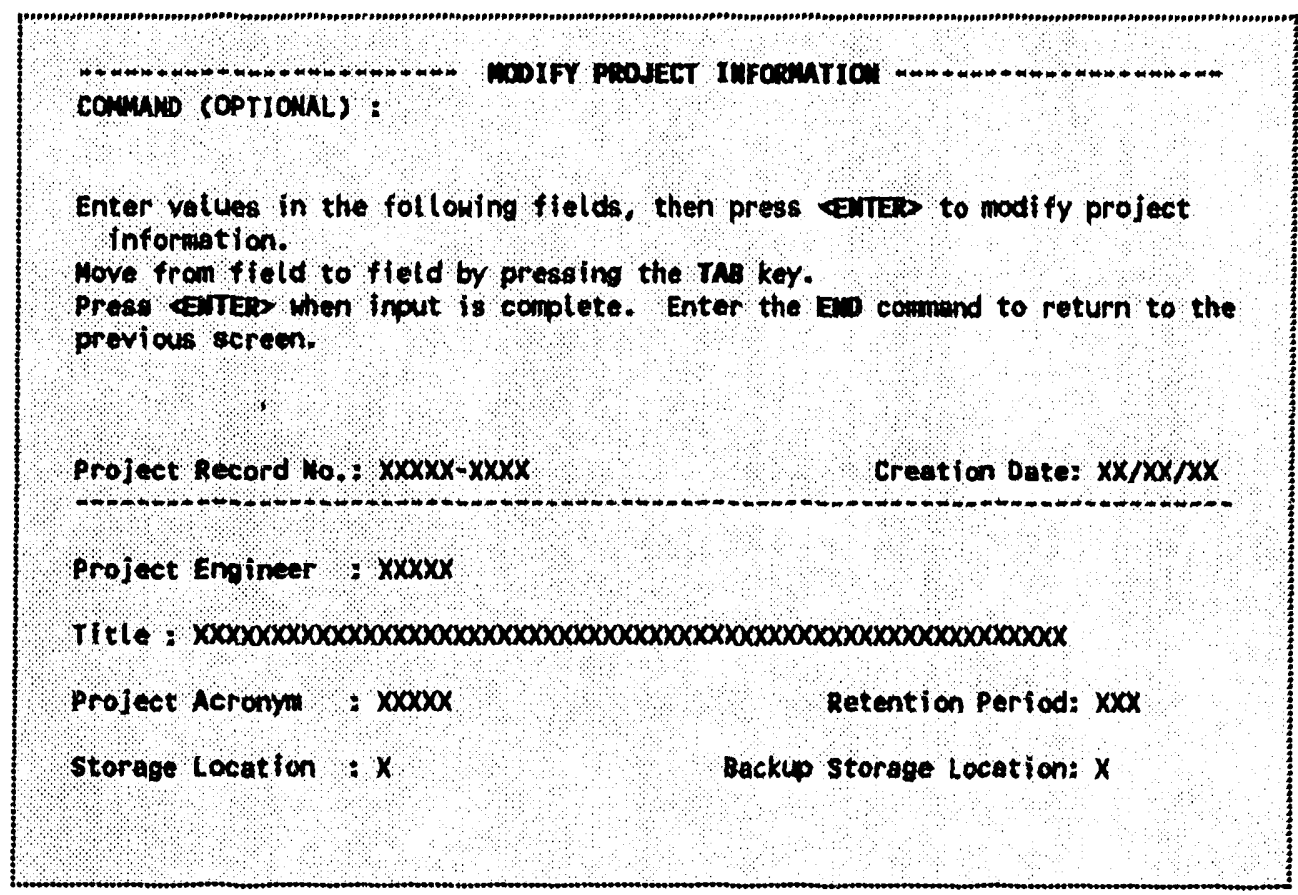

MODIFY

PROJECT

INFORMATION

This screen displays the current values for the selected project. You can change values for Project Engineer, Title, Acronym, Retention Period, Storage Location, and Backup Storage Location. Project Record Number and Creation Date may not be changed. To exit the screen without changing this information, type END in the COMMAND line and press <ENTER>.

Use the $\angle T A B>$ key to move through the data entry fields to modify the data values. You may enter a ? in the Project Engineer field to display the Personnel Help Screen. Placing a ? in the Storage Location field or in the Backup Storage Location field displays a message listing valid plant codes for these fields. After entering new values, press $<$ ENTER $>$.

PRIS validates the entered values before updating the record. If any are invalid, this screen will be redisplayed with the invalid fields highlighted for correction. When all data are valid, the system updates the project information and redisplays the Project Listing Screen with a message that project information has been changed. 


\subsubsection{Archive Project (AR)}

The Archive Project option on the Project Listing Screen allows you to enter storage information for projects whose records have been boxed and transferred to Plant Records for long-term storage. Projects or folders that have been flagged for pending deletion cannot be archived.

When AR is placed in the SEL field of a project, the system displays the Archive Project Screen.

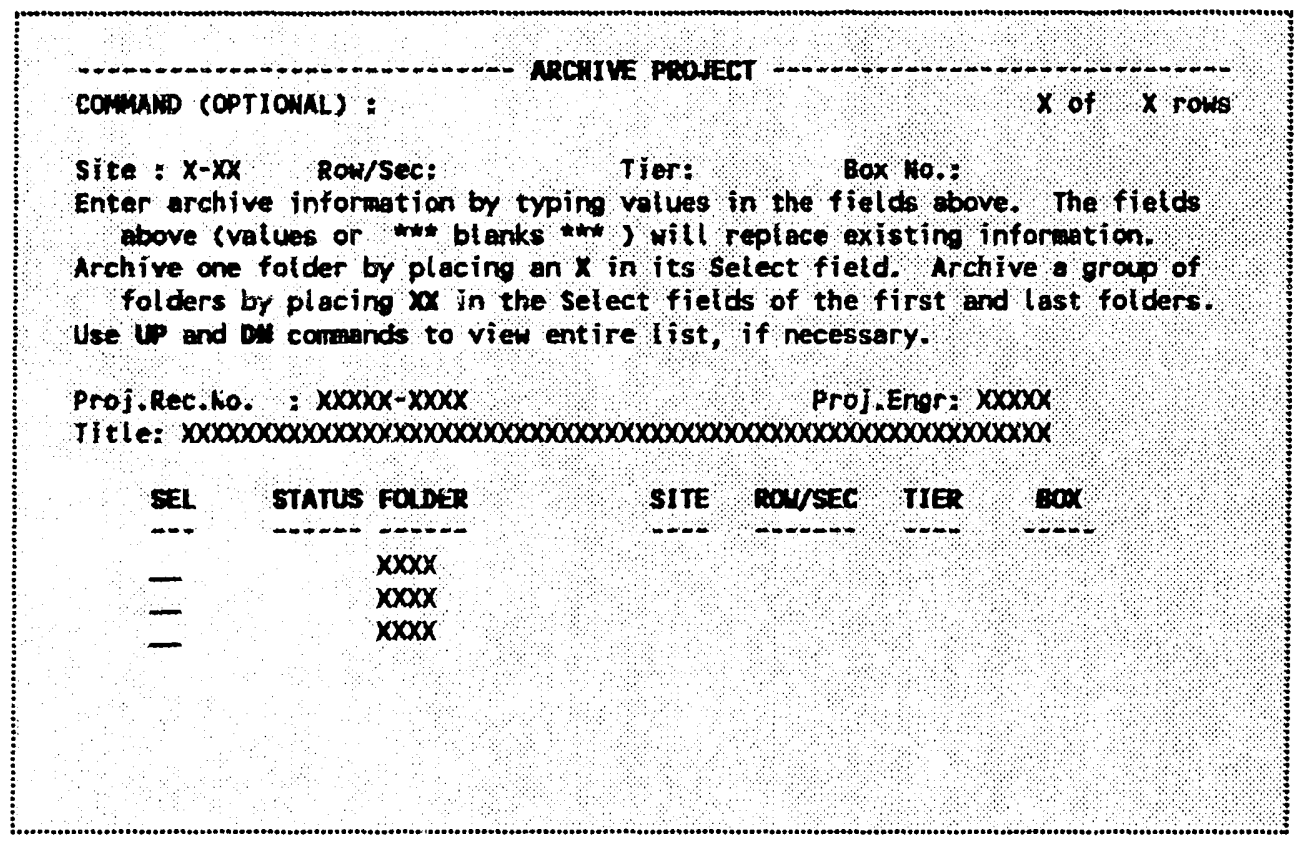

ARCHIVE

PROJECT

This screen displays the Project Record Number, Project Engineer, and Title for the selected project. The bottom of the screen displays the current list of folders for the project. If there is more than one screen of folders, you can use the DN or UP command to display the additional screens. If any folders are archived, a status of $A$ is displayed beside the folder, along with the site, row/sec, tier, and box numbers of the storage location. The top line of screen text provides fields in which to enter new or changed values for a folder. The Site field defaults to the site in the project record but may be changed.

Enter the storage information for the project folder and then $<\mathrm{TAB}>$ to the SEL fields and enter an $\mathrm{X}$ beside the folder to be archived. If a sequential group of folders are to be archived together, place $\mathrm{XX}$ in the SEL fields of the first and last folder. Press <ENTER> to process the entered information. If a blank value is entered for any part of the storage location, it will erase any information currently existing for the selected folder. Entry of all blank values will remove the selected folder's archive status-you will be prompted to confirm that the archive is to be removed.

PRIS sets the archive flag for the selected folder and then redisplays the Archive Project Screen for input of additional folders. The new screen will display the information just entered and a status of $A$ for the folder(s) that was selected. When the last folder of a project is archived, a nightly batch job will flag the entire project as archived.

The Archive Project Screen is redisplayed until you exit by entering END on the COMMAND line. The Project Listing Screen will be displayed with the message that folders have been archived. 


\subsection{SELECT FOLDER (SF)}

The Select Folder option of the Primary Option Menu allows you to find and display folder information based on selection criteria you enter. Any displayed folder may be selected for further processing.

When this option is selected by typing SF on the COMMAND line and pressing <ENTER>, the system displays the Select Folder Screen.

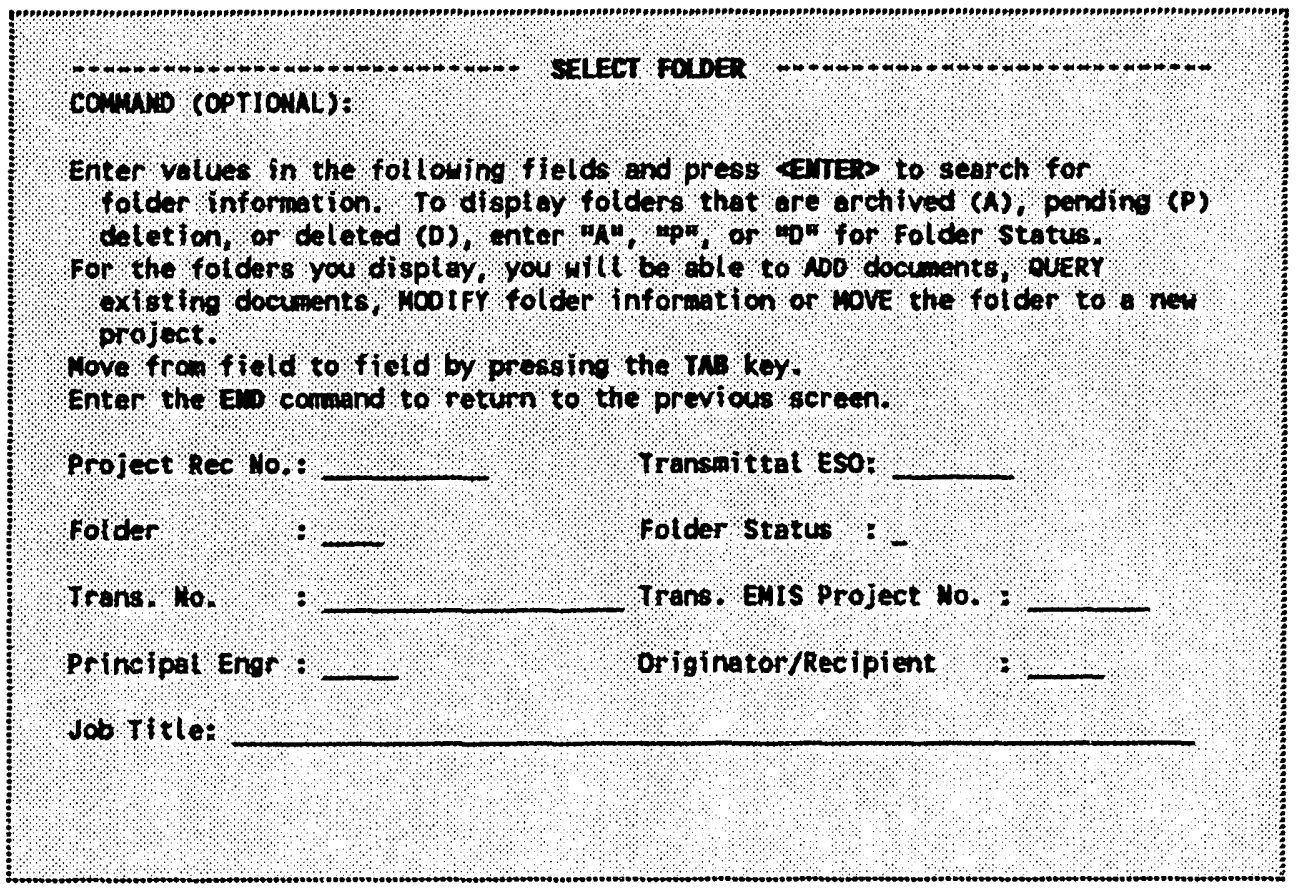

SEILCT

FOLDER

Use the $<\mathrm{TAB}>$ key to move from field to field. Enter values for one or more data elements to serve as selection criteria for searching the database. The percent sign (\%) and the underscore $U$ may be used as wild-card characters in the Job Title field. To exit this screen without performing a search, type END on the COMMAND line and press <ENTER>.

If there are no folders that match the entered criteria, the system will redisplay the Select Folder Screen with a message stating that no folders have been selected. If there are matching folders, PRIS displays information for those folders using the Folder Listing Screen shown on the next page. (This screen is also displayed when you query a single project from the Project Listing Screen.)

By default, in search listings PRIS displays all folders--active folders, archived folders, deleted folders, and folders that are marked "pending deletion." To display archived, pending, or deleted folders only, you must set the Folder Status field to A (for only archived folders), D (for only deleted folders), or P (for only folders pending deletion). 


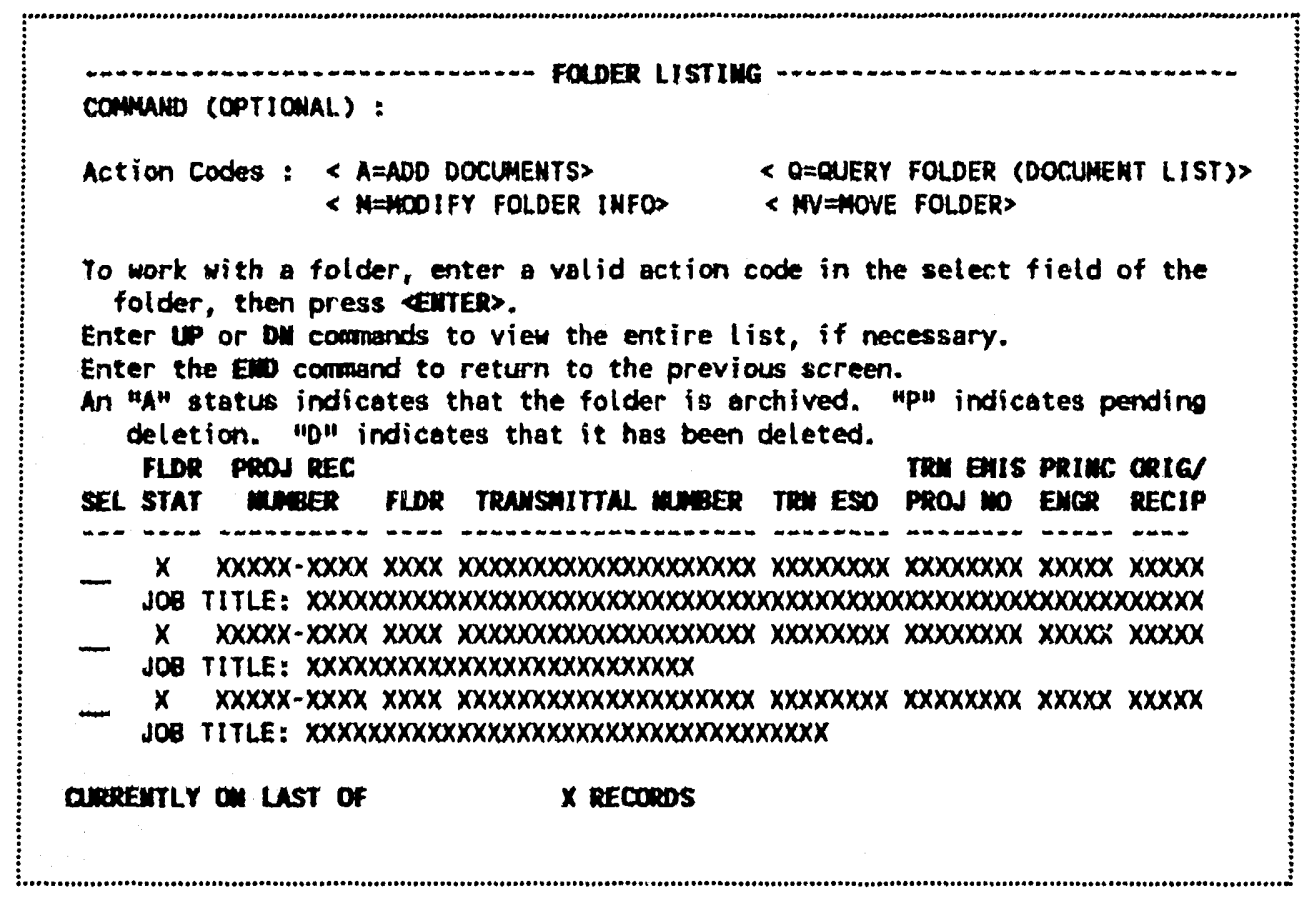

FOLDER

LISTING

Use the $\langle\mathrm{TAB}\rangle$ or $\langle 1\rangle$ and $\langle 1\rangle$ keys to move the cursor to the folder you wish to select for processing. If there is more than one screen of folders in the list, type DN or UP in the COMMAND line and press <ENTER > to display the next or previous screen of folders, respectively. To exit this screen without selecting a folder, type END in the COMMAND line and press <ENTER>.

Processing actions are requested by placing the letter of the action you wish to perform in the SEL column beside the selected folder and pressing <ENTER>. PRIS then displays screens that allow you to perform the chosen action (these are described in the following sections of this manual). When an action is completed, PRIS returns to the Folder Listing Screen for further selections. The processing options that are available are listed below:

Option

Action

A

Q

M

MV
Add documents to the selected folder (see Sect. 3.5.1).

Query folder (display a list of the documents contained in the selected folder) (see Sect. 3.5.2).

Modify folder information for the selected folder (see Sect. 3.5.3).

Move selected folder to a different project or ESO (see Sect. 3.5.4). 


\subsubsection{Add Document (A)}

The Add Document function from the Folder Listing Screen allows you add additional documents to a transmittal folder that was previously created. When an $A$ is placed beside an existing folder on the Folder Listing screen, the following Add Transmittals/Documents Screen is displayed.

There are three areas of information on the screen: Project Information, Transmittal Information, and Document Information. The Project Information area and Transmittal Information area display information about the folder you selected; this information cannot be changed from this screen. Data entry for the Document area of this screen is described below.

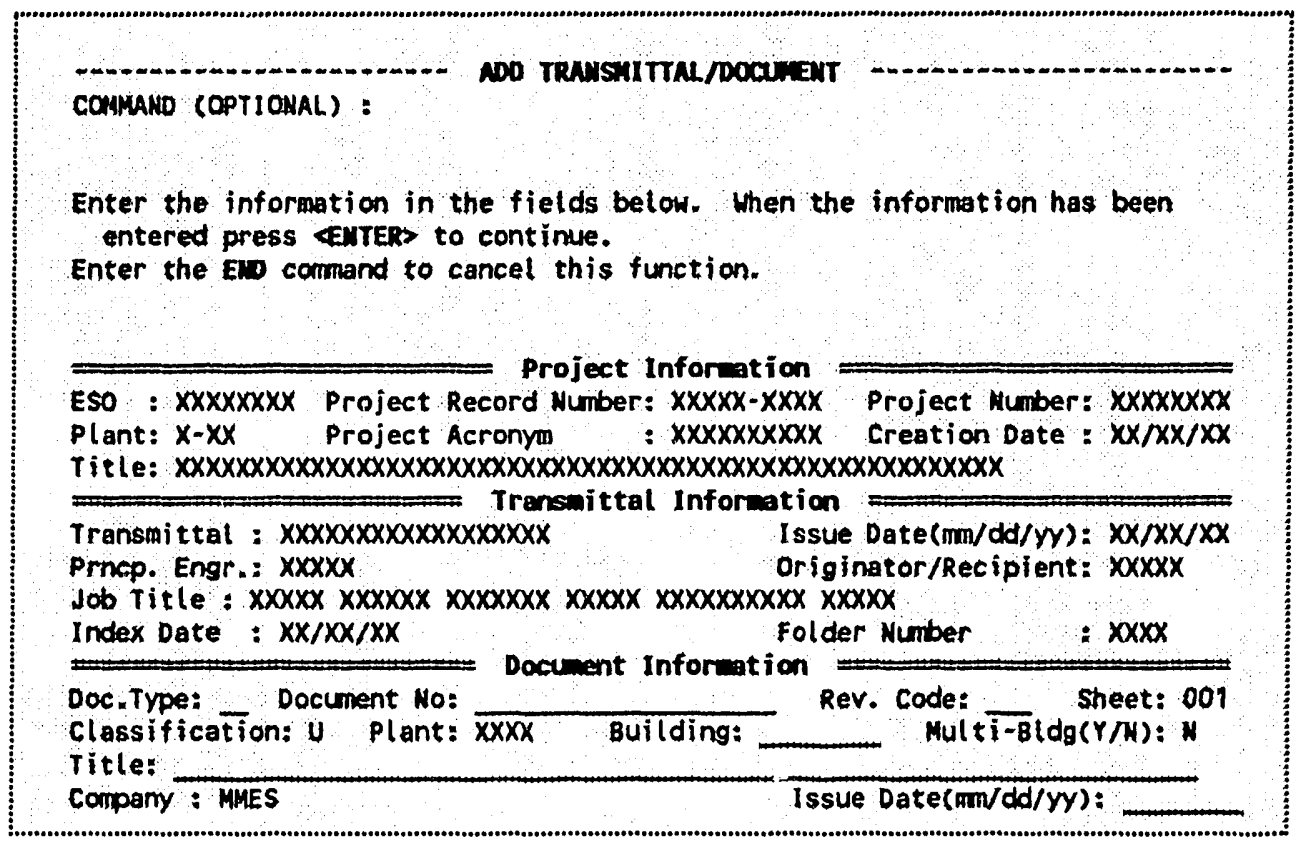

ADD

TRANSMITTAL

DOCUMENT

SCREEN

Use the $\angle \mathrm{TAB}>$ key to move from field to field in the Document Information area. Enter information for the first document to be added to this transmittal folder. When all information has been entered, press the <ENTER> key.

The system will validate the document information (see page 18 for data requirements); create a document iecord that correspond to the entered information; and then redisplay the Add Transmittal/Document Screen with the document fields reinitialized to accept entry of another document (see page 20 for details on these functions).

PRIS continues to redisplay the Add Transmittal/Document Screen for you to add additional documents until you exit by entering END on the COMMAND line of the screen. Once you enter END, you must again request the Add Document function from the Folder Listing Screen to add any additional documents to this transmittal folder.

When you enter END on the COMMAND line of the Add Transmittal/Document Screen, PRIS displays the Folder Listing Screen with a message showing the number of documents added to the current folder. 


\subsubsection{Query Folder (Q)}

When you Query a folder, PRIS displays a list of the documents in the selected folder. When a $Q$ is placed beside a folder on the Folder Listing screen, the following Abbreviated Document Information Screen is displayed.

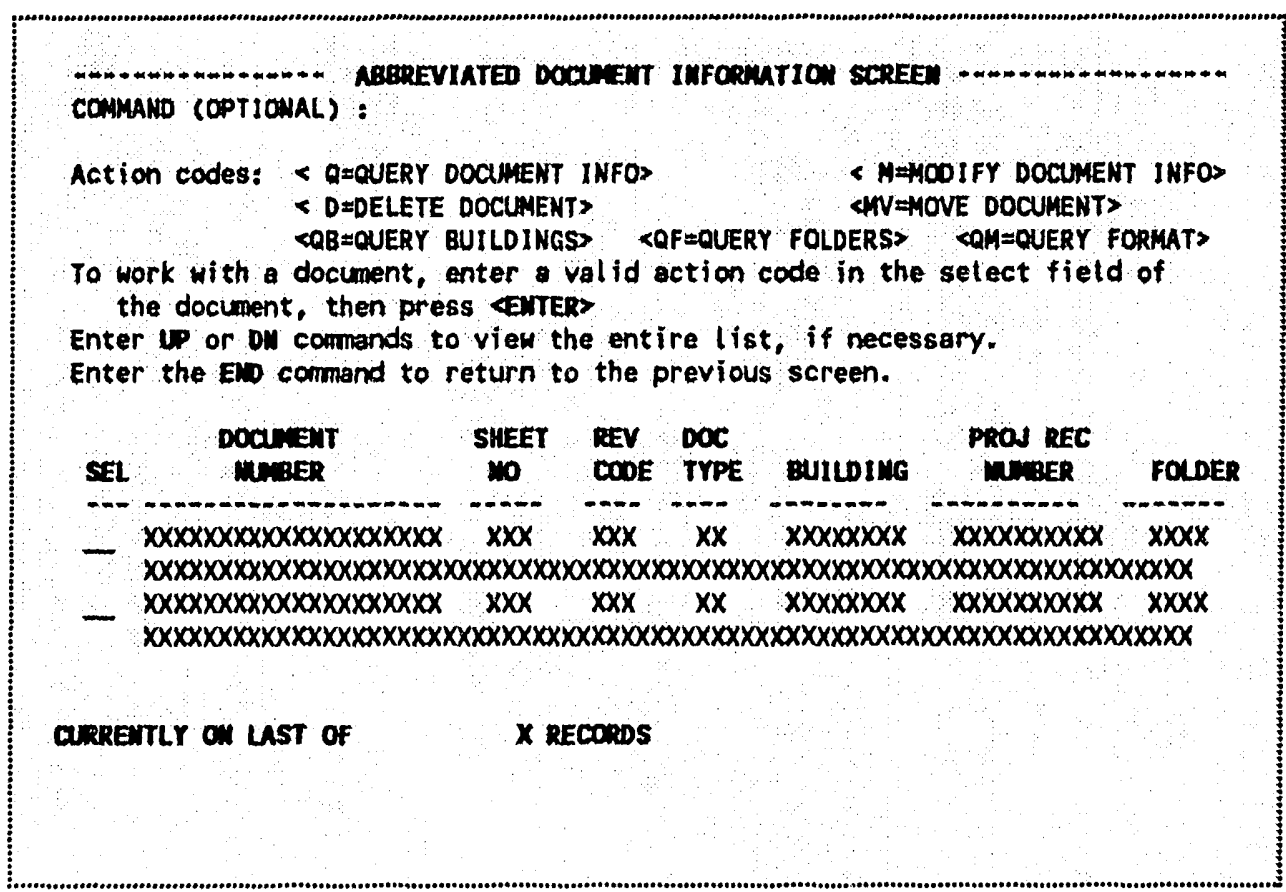

ABBREVIATED

DOCUMENT

INFORMATION

Use the $\langle\mathrm{TAB}\rangle$ or $\langle\uparrow\rangle$ and $\langle\downarrow\rangle$ keys to move the cursor to the document you wish to select for processing. If there is more than one screen of documents in the list, type DN or UP in the COMMAND line and press <ENTER > to display the next or previous screen of documents, respectively. To exit this screen without selecting a document, $\epsilon$ ter END in the COMMAND line and press <ENTER>.

Processing options are requested by placing the letter of the action you wish to perform in the SEL column beside the selected document and pressing $<$ ENTER $>$. The system then displays screens that allow you to perform the chosen action. When a function is completed, the system will return to the Abbreviated Document Information Screen for further selections. The processing options that are available are listed below and are described in detail in Sect. 3.6 of this manual.

Option

Q

QB

$\mathrm{QF}$

$\mathrm{QM}$

M

$\mathrm{D}$

MV

\section{Processing Function}

Query document (display detailed document information for the selected document)

Query building (display Document Building Listing for the selected document; add/delete building numbers)

Query folder (display Document Folder Listing for the selected document)

Query format (display Document Format Listing for the selected document)

Modify document information for the selected document

Delete copies of the document from selected folders or delete the selected document from PRIS

Move the selected document to a different folder 


\subsubsection{Modify Folder Information (M)}

The Modify Folder Information option allows you to change folder information for the selected folder. However, folder information may not be changed if the folder is deleted or pending deletion. When $M$ is entered in the Select field of a folder, PRIS displays the Modify Folder Information Screen.

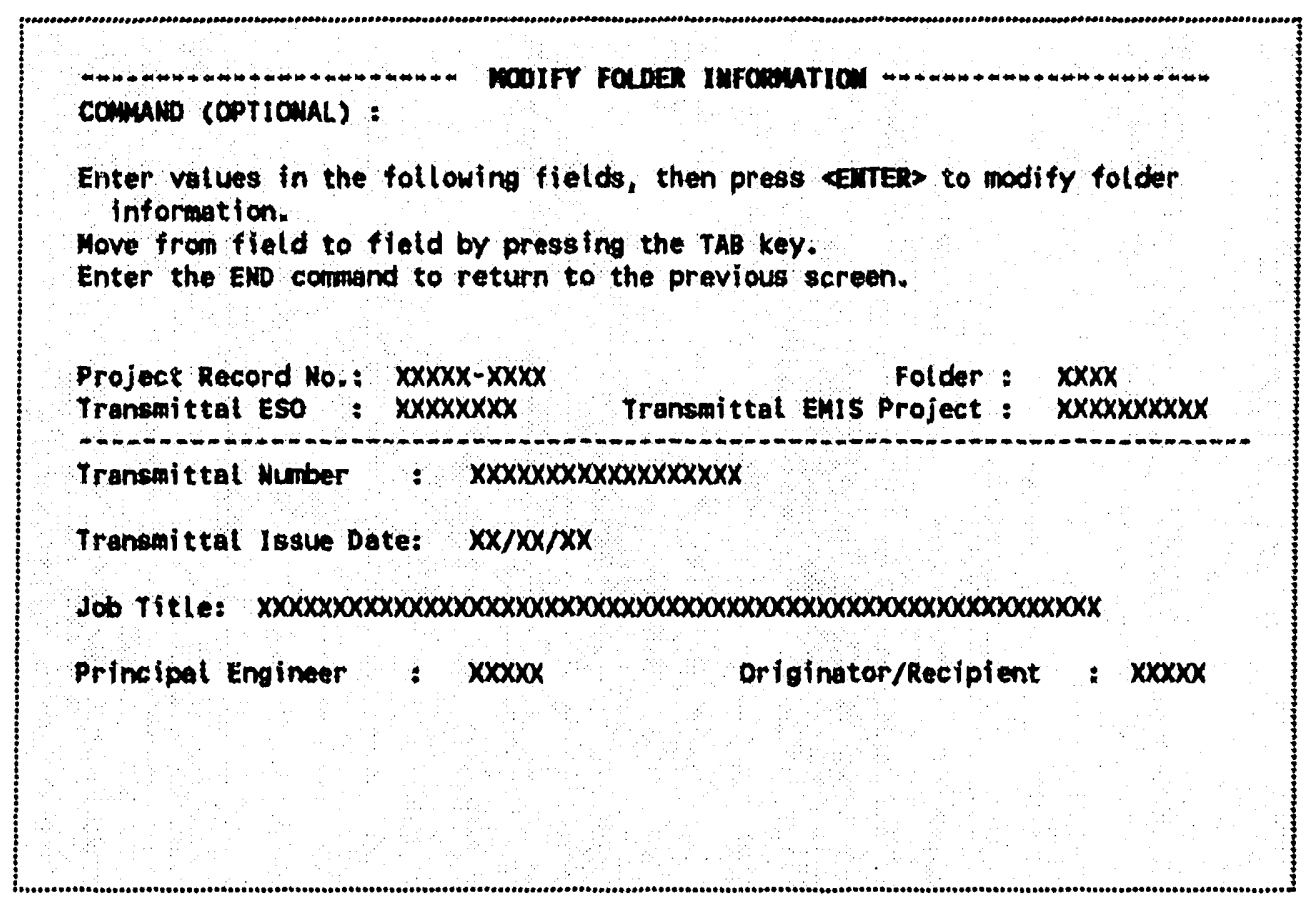

MODIFY

FOLDER

INFORMATION

This screen displays the current values for the selected folder. You can change the values for Transmittal Number, Transmittal Issue Date, Job Title, Principal Engineer, and Originator/Recipient. Project Record Number, Transmittal ESO, Transmittal EMIS Project, and Folder may not be changed. To exit this screen without modifying this folder information, type END in the COMMAND field and press <ENTER>.

Use the $\angle \mathrm{TAB}>$ key to move through the data fields to modify the displayed values. To invoke the Personnel Help Screen for the Pritsipal Engineer and/or the Originator/Recipient fields, enter a ? in the field. After entering values, press the <ENTER $>$ key.

PRIS validates the values and provides help for entered ?'s before modifying the database. If any values are invalid, the screen will be redisplayed with these fields highlighted and a message stating that the highlighted fields are incorrect. When all fields are correct, PRIS updates the folder information and redisplays the Folder Listing Screen with a message that folder information was changed. 


\subsubsection{Move Folder (MV)}

The Move Folder option allows you to refile the selected folder and its documents under a different Project Record Number and/or ESO. This option is useful in the following situations:

1. The option provides a way to correct a data entry error when a transmittal is entered under an incorrect Project Record Number and/or ESO.

2. The option provides a way to refile folders when the ERM Office removes an ESO from a project. Project Record Numbers and their associated ESO(s) are downloaded from EMIS. When an ESO is removed from a project, the database may contain folders that were added to the project under that ESO. The download process flags such folders as "pending deletion." The Move Folder option provides a way to reassign the folders to an appropriate project and/or ESO.

When you place MV in the SEL field of a folder, the system displays the Move Folder Screen.

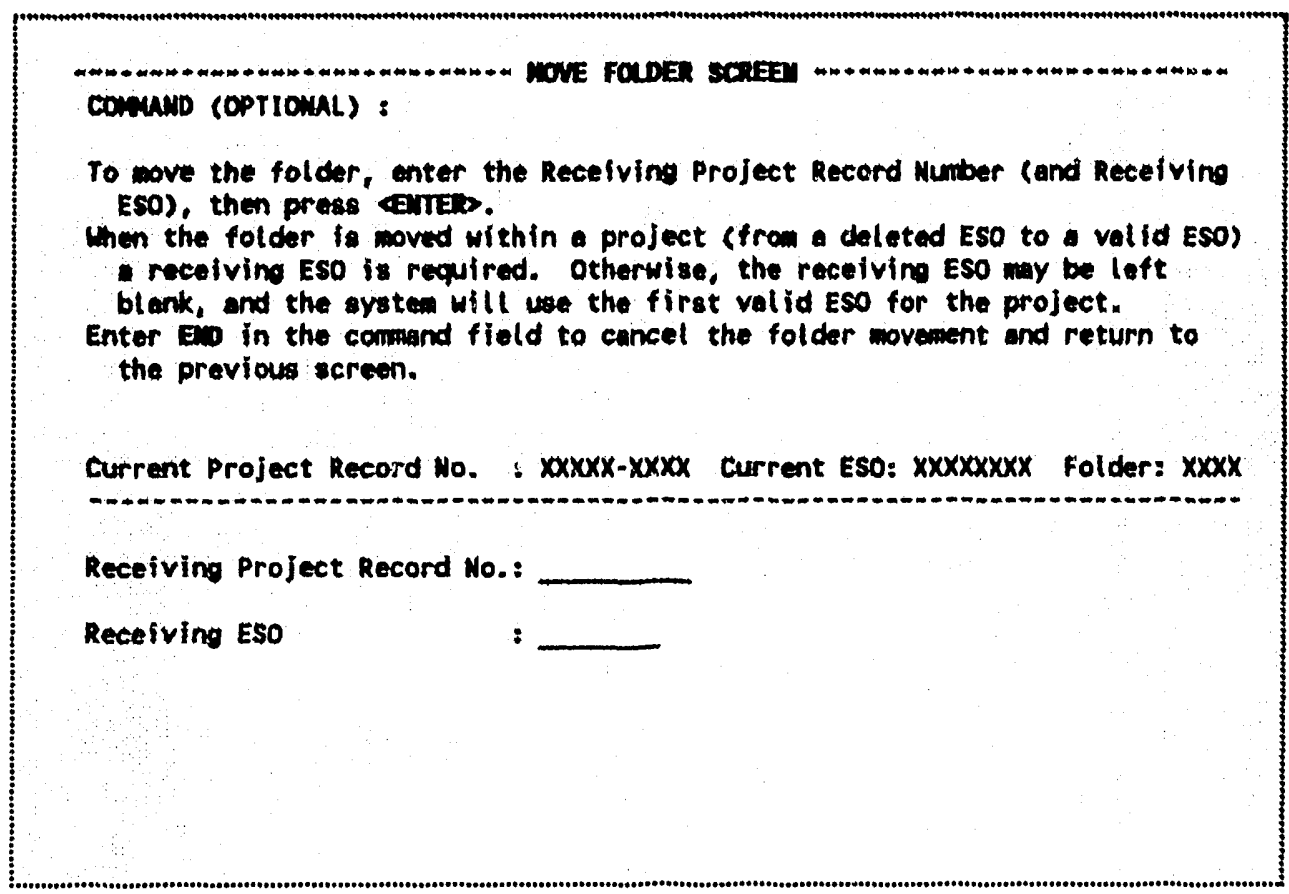

MOVE

FOLDER

This screen shows the current Project Record Number, ESO, and Folder number of the selected folder.

To move a folder between projects, you may enter only the receiving Project Record Number; PRIS confirms that the entered project exists, then assigns the folder to the first valid ESO of the project. If you enter both the receiving Project Record Number and ESO, the system confirms that the ESO is associated with the Project Record Number, then moves the folder documents to the designated ESO and project. The job title of the original folder is changed to a message similar to the following, which documents the move: 
To move a folder from one ESO to another of the current project, enter only the receiving ESO. PRIS confirms that the ESO is associated with the current Project Record Number, then assigns the folder to that ESO.

To exit this screen vithout performing a move, type END in the COMMAND line and press $<$ ENTER >; the system will redisplay the Folder Listing Screen with the message that the folder was not moved.

If the old folder was flagged for pending deletion, the nightly PRN download job will change its status to "deleted." When a project is flagged for pending deletion and the status of its last folder changes to deleted, the nightly PRN download job physically deletes the project, the project/ESO associations, and the folders of the project. No pioject information will remain in PRIS after a project is physically deleted; it will be as if the project had never existed. 


\subsection{SELECT DOCUMENT (SD)}

The Select Document option on the Primary Option Menu allows you to select and display document information in PRIS by entering selection criteria that identifies the document. PRIS searches the database for documents that match your entered criteria and displays a list of documents that are found. You may select a document from this list for further processing. When the SD option is chosen from the Primary Option Menu, the system displays the Select Document Screen.

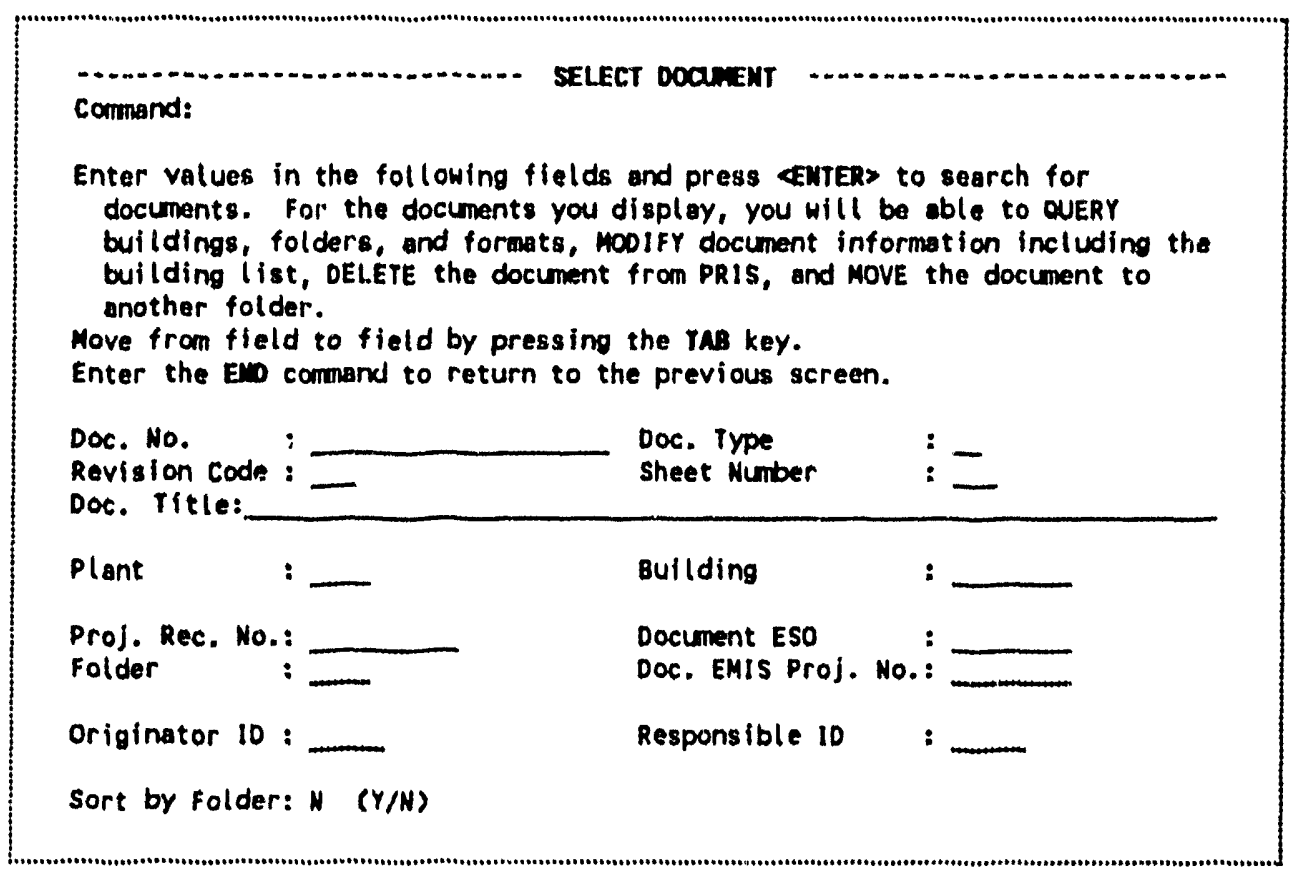

SELECT DOCUMENT

Use the $\langle\mathrm{TAB}>$ key to move the cursor through the data entry fields and enter values for one or more data elements to serve as selection criteria. To get help for the Document Type and Plant fields, enter ? (see Appendix A). If $\mathrm{K}-25, \mathrm{X}-10$, or $\mathrm{Y}-12$ is entered in the Plant field, you may enter ? in the Building field to view the list of building numbers for the entered plant. A ? may also be used in the Responsible ID and the Criginator ID fields to view the Personnel Help Screen. In the Doc. No., Doc. Title, Building,

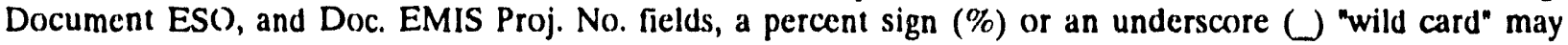
be used as part of the values entered (see Sect. 3.1.3). To cancel the search and return to the PRIS Primary Option Menu, ype END in the COMMAND field and press <ENTER>.

Press < ENTER > 10 initiate the search. PRIS will display any requested help screens and search the database for the entered criteria. If no documents are found that match the criteria, PRIS redisplays the Select Document Screen with a message stating that no documents have been selected, and you are allowed to re-enter the criteria.

If matching documents are found, PRIS displays a list of those documents on the Abbreviated Document Information Screen (shown on the next page). (If only one document matches the criteria, the Detail Document Information Screen 1 is used to display the document.) By default, the documents are ordered by document number. If you set the Sort by Folder field to $Y$ on the Select Document Screen, the documents will be sorted by Project Record Number and folder, then by document number. 


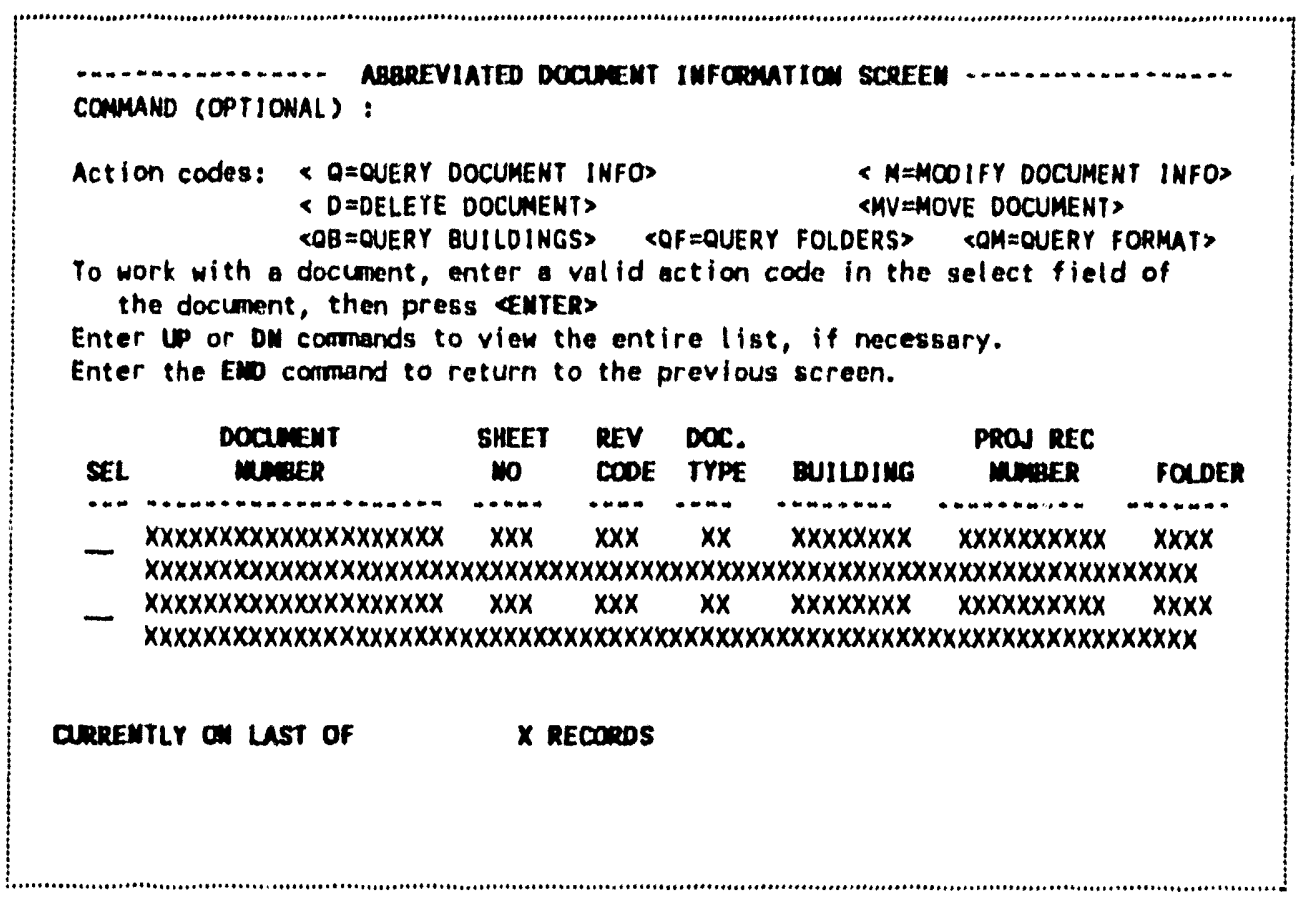

ABBREVIATTZD

DOCUMENT

INFORMATTON

Use the $\langle\mathrm{TAB}\rangle$ or $\langle 1\rangle$ and $\langle 1\rangle$ keys to move the cursor to the document you wish to select for processing. If there is more than one screen of documents in the list, type DN or UP in the COMMAND line and press <ENTER> 10 display the next or previous screen of documents, respectively.

Processing actions are requested by placing the letter of the action you wish to perform in the SEL. column beside the selected document and pressing < ENTER>. PRIS then displays screens that allow you to perform the chosen action (these are described in the following sections of this manual). When an action is completed, PRIS returns to the Abbreviated Document Information Screen for further selections. The processing options that are available are listed below:

\begin{tabular}{ll} 
Option & \multicolumn{1}{c}{ Action } \\
Q & $\begin{array}{l}\text { Query document (display detailed document information for the selected } \\
\text { document) } \\
\text { Query building (display Document Building Listing for the selected document; } \\
\text { add/delete building numbers) }\end{array}$ \\
QB & $\begin{array}{l}\text { Query folder (display Document Folder Listing for the selected document) } \\
\text { QF }\end{array}$ \\
QMery format (display Document Format Listing for the selected document) \\
M & $\begin{array}{l}\text { Modify document information for the selected document } \\
\text { Delete copies of the document from selected folders or delete the selected } \\
\text { document from PRIS }\end{array}$ \\
MV & Move the selected document to a different folder
\end{tabular}




\subsubsection{Query Document (O)}

When you Query a document, PRIS displays detailed information for the document. When a $Q$ is placed beside a document on the Abbreviated Dncument Information screen, the following Detail Document Information Screen is displayed:

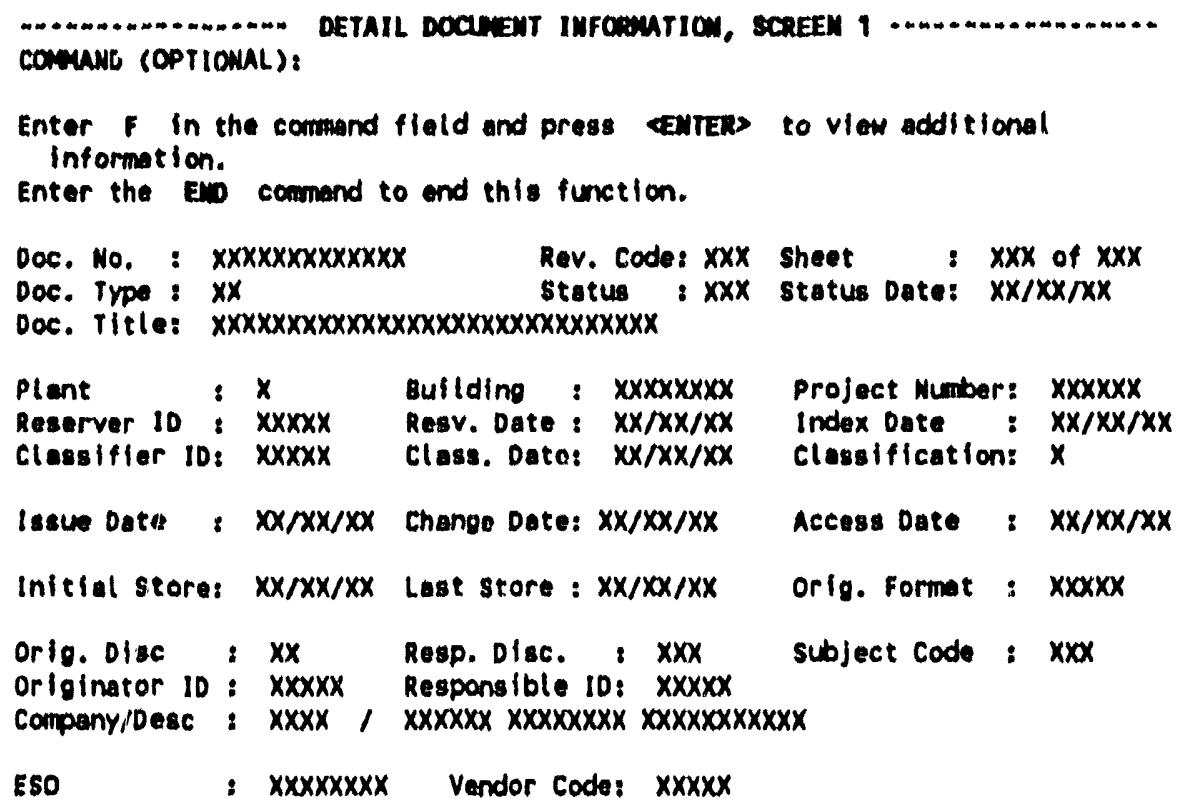

This screen displays the detailed information that exists in the EDIS Index for the selected document. If the document is a design drawing, you may enter $F$ (forward) on the COMMAND line to display a second screen with design drawing information. This screen is displayed on the following page. Enter B (back) in the COMMAND line of the second screen to return to Screen 1.

From either of these two screens, you may perform the same actions as are available from the Abbreviated Document Information Screen. However, the options are entered using the COMMAND line on these screens. Refer to the following manual pages for descriptions of these options.

Option

QB

QF

$\mathrm{QM}$

M

$\mathrm{D}$

MV

\section{Action}

Query building (display Document Building Listing for the selected document; add/delete building numbers)

Query folder (display Document Folder Listing for the selected document)

Query format (display Document Format Listing for the selected document)

Modify document information for the selected document

Delete copies of the document from selected folders or delete the selected document from PRIS

Move the selected document to a different folder 


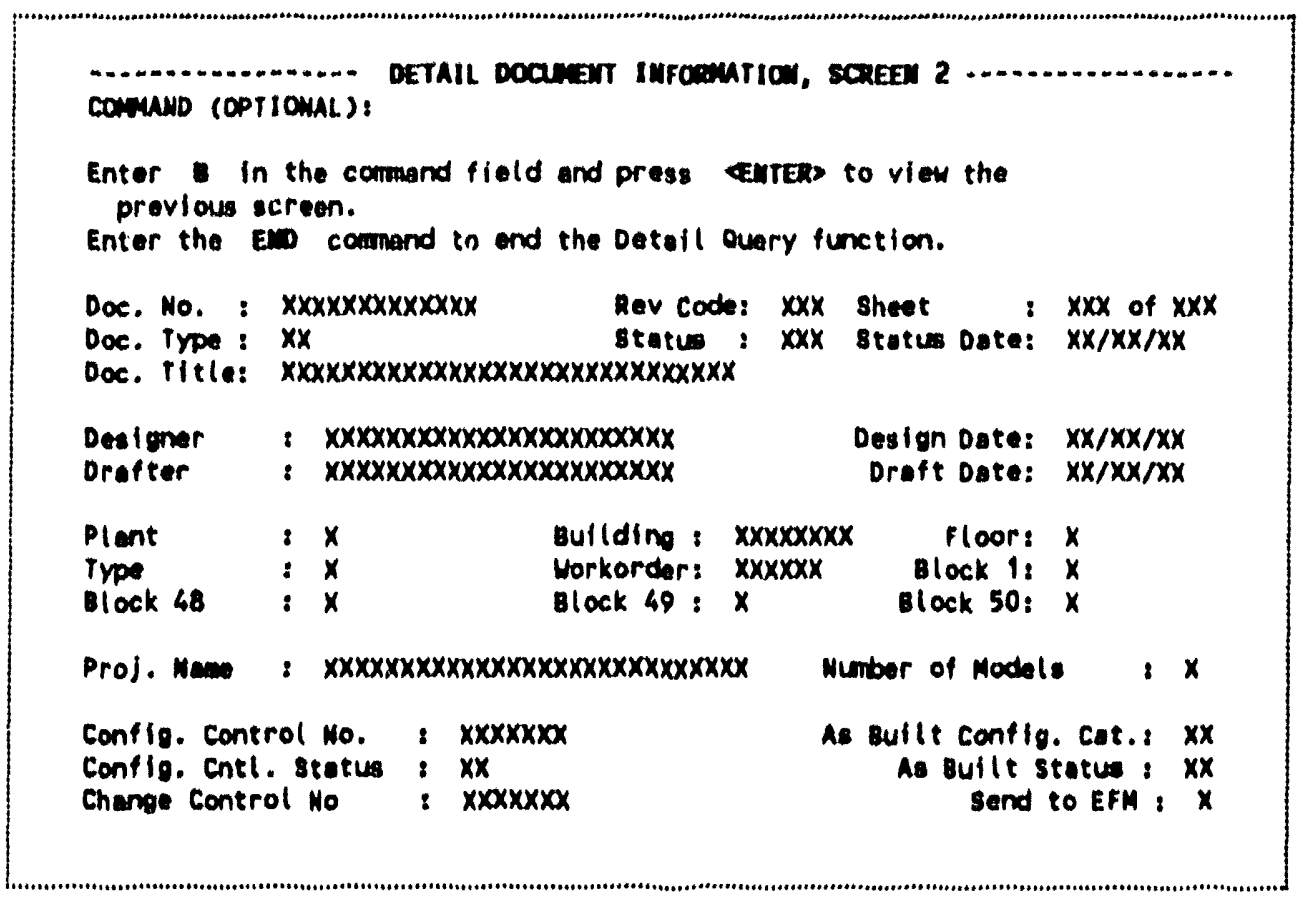

\section{DETAIL DOCUMENT \\ INFORMATION}

SCREEN 2

When you enter END on the COMMAND line of either of the two screens, the system will redisplay the Abbreviated Document Information Screen. 


\subsubsection{Query Buildines (OB)}

The Query Buildings option is available from the Abbreviated Document Information Screen and both of the Detail Document Information screens. This option allows you to display the building list for a document. You may modify the building list if the document is not a design drawing (document type other than DD) or when PRIS is the only system that has entered the document. If the document is a design drawing, you may view the building information.

When the QB option is requested from any of the three screens, the system displays the Document Building Listing Screen.

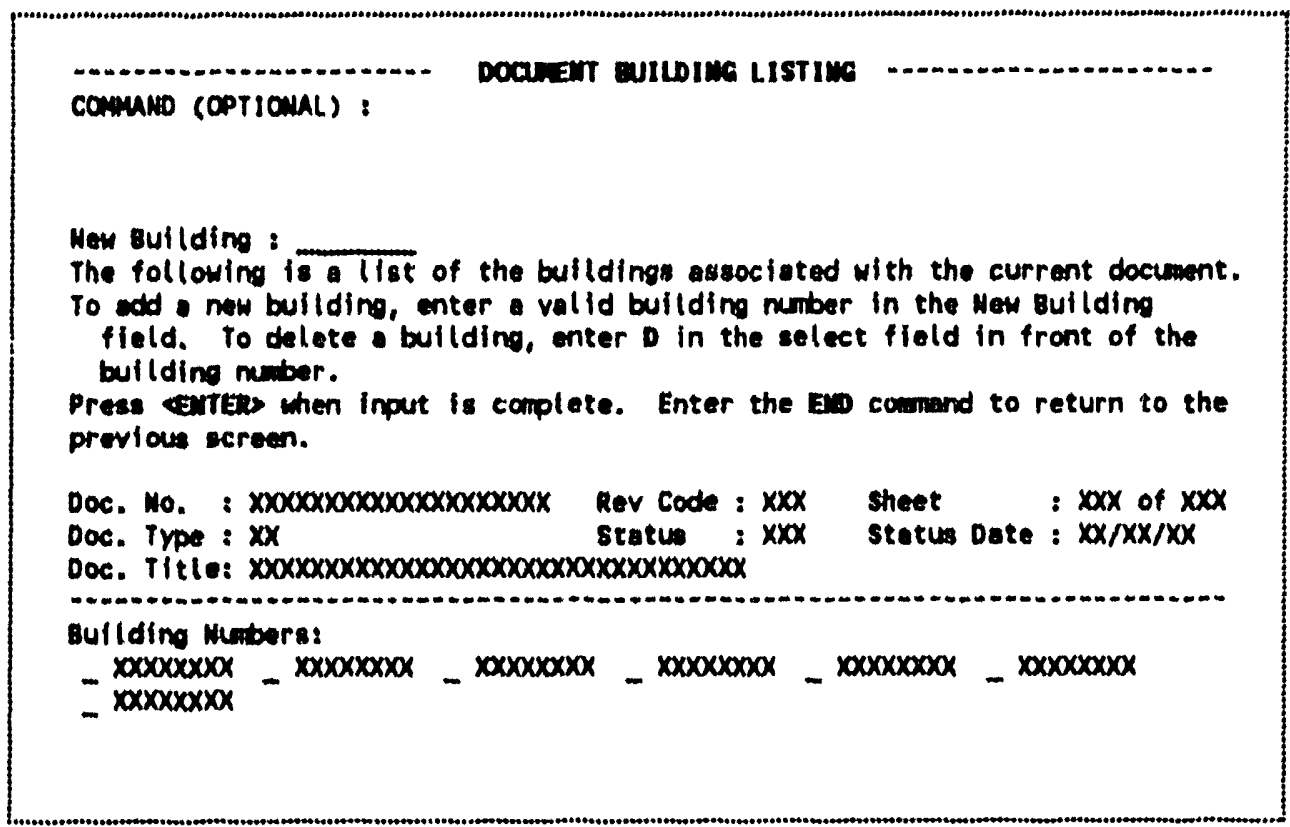

DOCUMENT

BUILDING

LISTING

This screen displays the Doc. No., Rev Code, Sheet, Doc. Type, Status, Status Date, Doc. Title, and Building Number values for the current document. You may enter additional buildings for this document by typing the building number in the New Building field and pressing <ENTER>. If you enter ? in the New Building field, the system will display a list of valid building values from which to choose (see Appendix A).

You may delete buildings by entering $D$ in the blank ahead of the building number and pressing $<$ ENTER >. The building number will be replaced with the word "DELETED." You may not delete the last building from a document.

The screen is redisplayed after each add or delete along with a message that buildings were added or deleted. To exit the screen, enter END on the COMMAND line; PRIS will redisplay the screen from which this function was requested. 


\subsubsection{Querr Folde1s (OF)}

The Query Folders option is available from the Abbreviated Document Information Screen and both of the Detail Document Information screens. When the QF option is entered on these screens, a list of folders that contain the selected document is displayed on the Document Folder List Screen.

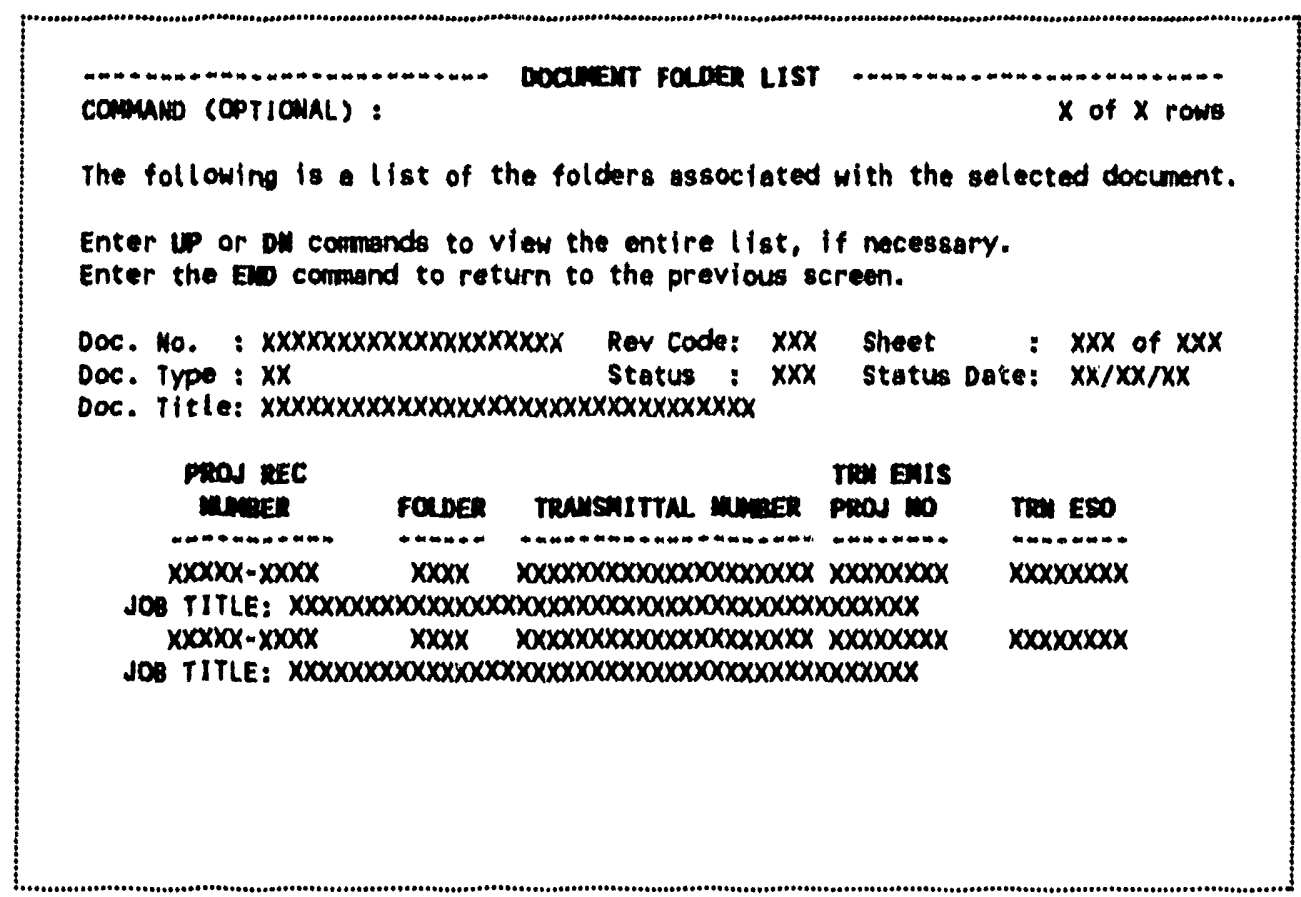

DOCUMENT

FOLDER

LIST

This screen displays identifying information for the current document. The bottom of the screen shows a list of folders where the document is stored. If there are more folders than can be displayed on one screen, enter DN or UP on the COMMAND line to view the next or previous screen. If END is entered in the COMMAND line, the system will redisplay the screen from which this function was requested. 


\subsubsection{Query Format (QM)}

The Query Formats option is provided from the Abbreviated Document Information Screen and from either of the Detail Document Information screens. When the QM code is entered from any of these screens, the system displays the Document Format Listing Screen.

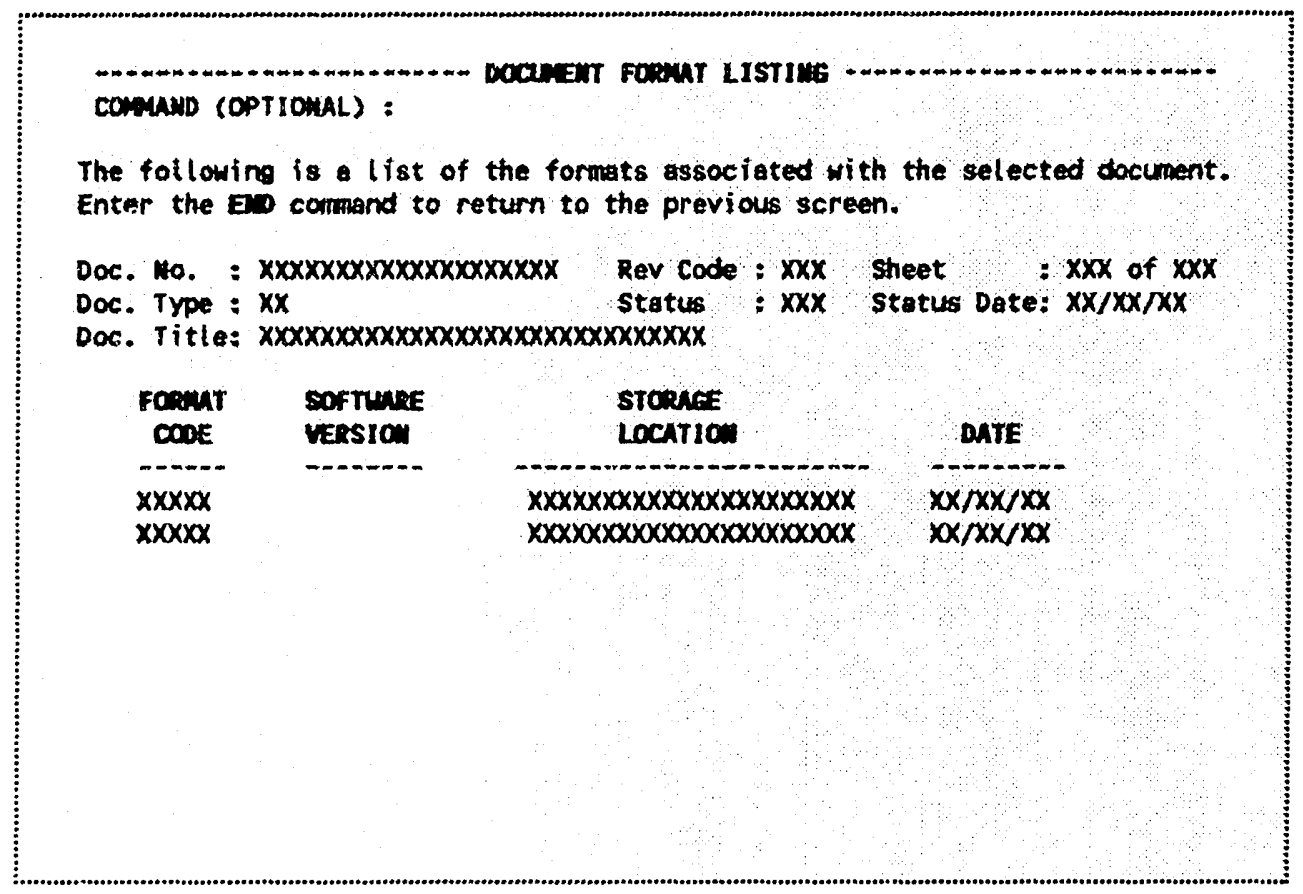

DOCUMENT

FORMAT

LISTING

The screen displays identifying information for the selected document. The bottom of the screen shows a list of formats available for this document. The Format Code, Software Version, Storage Location, and Date of each format are displayed. This information is for viewing only and cannot be modified.

Exit this screen by entering END in the COMMAND line; the system will redisplay the screen from which this query was requested. 


\title{
3.6.5 Modify Document Information (M)
}

The Modify Document Information option allows you to change document information for a PRISowned document. PRIS owns a document when the document is not a design drawing (document type other than DD) or when PRIS is the only system that has entered the document.

The Modify Document Information option is provided from the Abbreviated Document Information Screen and from either of the Detail Document Information screens. When the $M$ option is entered for a document on one of these screens, the system displays the Modify Document Information Screen. (If PRIS does not own the document, the system redisplays the screen from which the request was made with the message that PRIS cannot modify documents it does not own.)

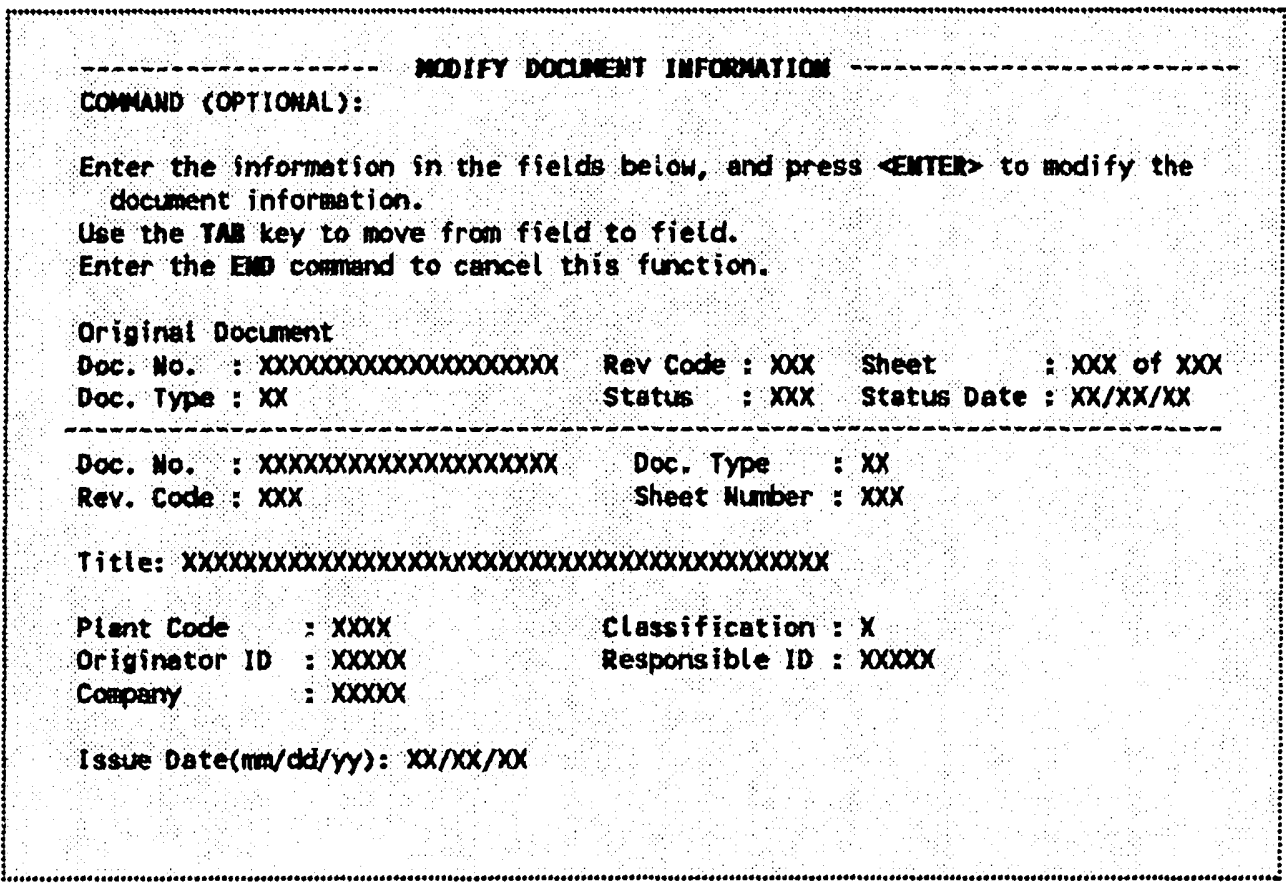

\author{
MODIFY \\ DOCUMENT \\ INFORMATION
}

The Modify Document Information Screen identifies the original document on the top of the screen and shows current values for Document Number, Document Type, Revision Code, Sheet Number, Title, Plant Code, Classification, Originator ID, Responsible ID, Company, and Issue date. Use the $\langle\mathrm{TAB}\rangle$ key to access and modify the values of any fields on the bottom half of the screen. A ? may be entered in the Doc. Type, Plant Code, and Classification fields to obtain a list of valid values for the field (see Appendix A). A ? may be entered in the Originator ID and/or the Responsible ID fields to display the Personnel Help Screen (see Appendix A).

Press <ENTER > when you complete modifications to this screen. PRIS will display any help screens requested by a ? and then update the document information. The screen from which this function was requested will be displayed with the message that document information has been changed.

If END is entered in the COMMAND line, PRIS redisplays the screen from which this function was requested with the message that docurnent information was not changed. 
For PRIS, the Document Number, Revision Code, Sheet Number, and Document Type are document key fields. Their values specify a unique document; when a key field changes, a different document is defined. If you modify a key field, PRIS attempts to match the new keys with some document that already exists in the EDIS Index. Modifications are made according to the following conditions:

1. If a key field was not changed, PRIS updates the document information. All the modified values are used.

2. If a key field was changed but no other document exists with the new keys, PRIS changes the document keys in the EDIS Index and in the building, folder, and format lists. The system updates document information using all the modified values. If the original document was a current revision, PRIS sets a new current revision flag.

3. If a key field was changed and the new keys match the keys of an existing document, PRIS redisplays the Duplicate Document Verification Screen (see page 20) with the message that the new keys match an existing document; document information from the existing document will be displayed on the screen. You may enter the END command to cancel the modifications or press <ENTER $>$ to make the changes. The changes will be made as follows, depending upon whether or not PRIS owns the document:

a. If PRIS owns the existing document, PRIS updates the existing document information with all the modified values. The system combines the building, format, and folder lists and eliminates duplicate entries. Docurient information for the former keys is deleted. If the deleted document was a current revision, PRIS sets a new current revision flag.

b. If PRIS does not own the existing document, PRIS updates the values for ESO, originator ID/discipline, responsible ID/discipline, and EMIS project number only if the field is blank in the existing record; PRIS also updates the owner field. The building, format, and folder lists are combined, and duplicate entries are eliminated. Since PRIS does not own the document, you will not be able to modify the information further. Document information for the former keys is deleted. If the deleted document was a current revision, PRIS sets a new current revision flag.

4. If the title was changed for a document whose classification is other than U, PRIS displays the Title Classification Verification Screen (see page 18). On this screen, you can verify that the title is unclassified; modify it, if necessary; or cancel the document modifications. If you confirm that the title is unclassified, PRIS modifies the document record. 


\subsubsection{Delete Document (D)}

The Delete Document option allows you to remove a document from a folder or from all folders in the PRIS database. If PRIS owns the document, Delete Document physically deletes all information from the database; if not, only information about PRIS copies of the document is deleted. This function is available from the Abbreviated Document Information Screen and from both of the Detail Document Information screens. When the D option is entered on one of these screens, a list of all folders that contain the selected document is displayed on the Delete Document Screen.

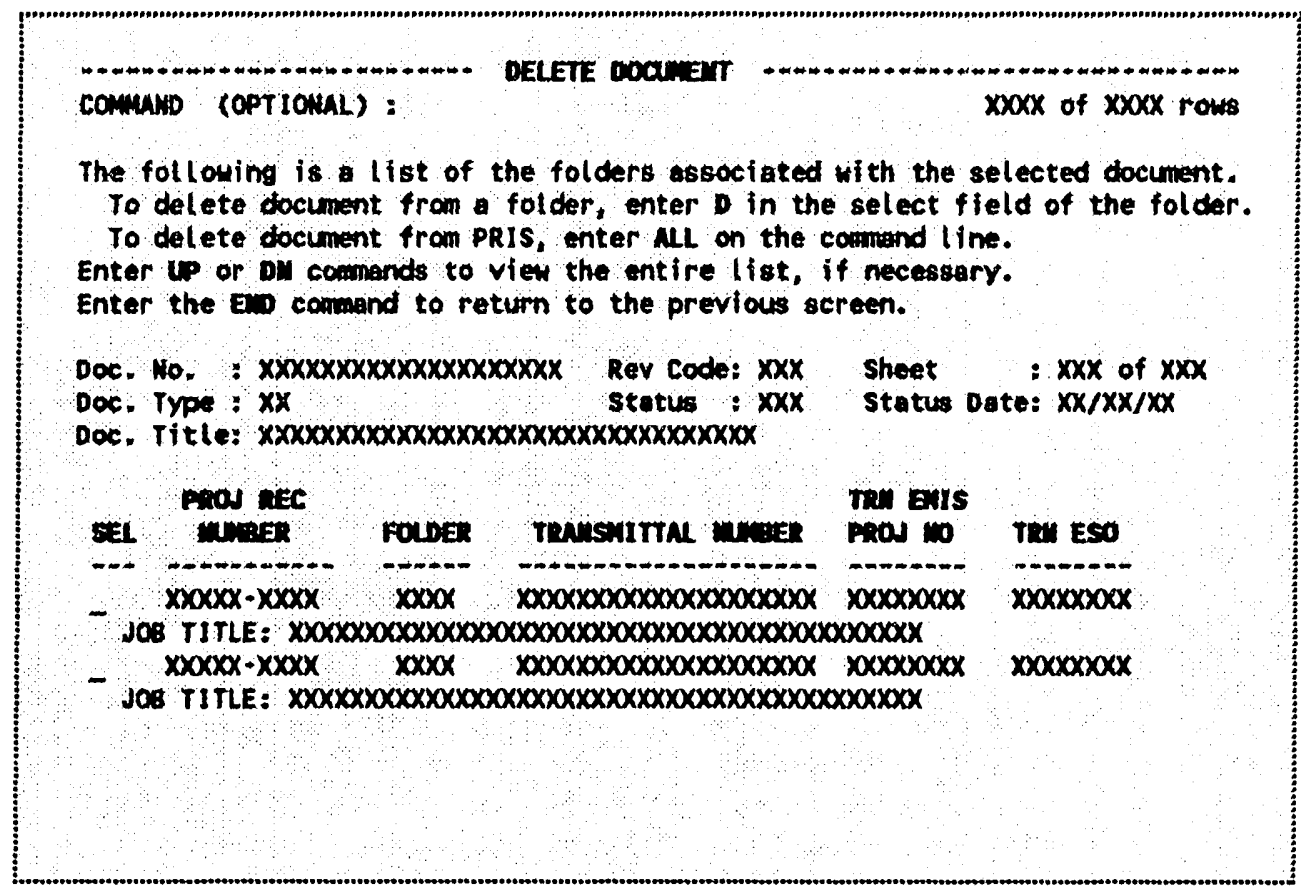

DEILETE

DOCUMENT

The middle of this screen displays the current document's information. The bottom of the screen shows a list of folders in which this document exists. If there is more than one screen of folders, enter DN and UP in the COMMAND line to view the next or previous screen. To exit this screen and cancel the Delete action, type END in the COMMAND line and press <ENTER>.

To delete a copy of the document, type D in the SEL field of the folder; then press <ENTER>. PRIS deletes the document from this folder only and removes any format that corresponds to the folder. The Delete Document Screen is redisplayed with a message that the document has been removed from the selected folder. You may continue to delete the document from other folders. If the selected folder is the only folder containing the document, you will receive the prompt "Deleting from Last Folder - Use END to Cancel, <ENTER > to Continue." Confirm or cancel the deletion by responding to the prompt.

To delete the document from all displayed folders, enter ALL in the COMMAND line and press $<$ ENTER >. The prompt "Deleting Document from PRIS - Use END to Cancel, <ENTER > to Continue" is displayed to allow you to cancel or confirm the deletion. If PRIS owns the document to be deleted, PRIS deletes all records for the document. If PRIS does not own the document, PRIS breaks its association with the document: it removes PRIS co-ownership from the EDIS Index, deletes the document from all folders, and removes any formats that correspond to the folders. After the document is deleted, PRIS displays the Abbreviated Document Information Screen with a message that the "Document has been deleted from PRIS." 


\subsubsection{Move Document (MV)}

The Move Document option allows you to refile the selected document in a different folder. You can use the Move Document option in two situations:

1. The option provides a way to correct an error when a document is entered in an incorrect folder.

2. The option provides a way to refile documents when the ERM Office dissociates an ESO from a project. Project Record Numbers and their associated ESO(s) are downloaded from the EMIS system. When the ERM office removes an ESO from a project, the database may contain documents that were added to the project under that ESO. The download process will flag the folders created under that ESO for pending deletion. The Move Document option provides a means to reassign documents in those folders to folders with an appropriate Project Record Number and/or ESO.

When MV is entered from the Abbreviated Document Information Screen or from either of the Detail Document Information screens, the system displays the Move Document Screen.

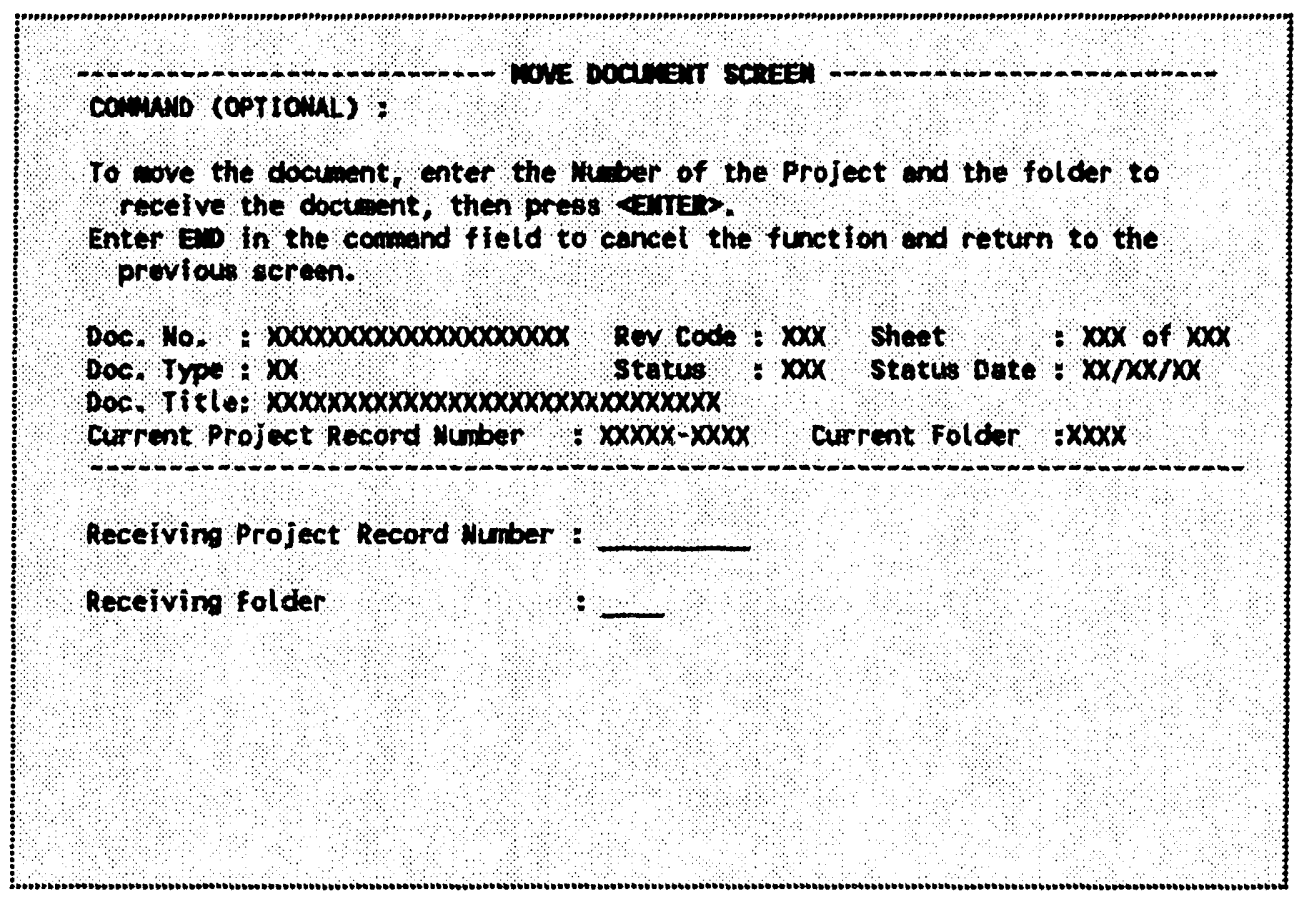

MOVE

DOCUMENT

The top of this screen displays information to identify the document to be moved. PRIS also displays the Project Record Number and folder where the document currently is filed. You must enter an new Project Record Number and folder to which the document is to be moved. To exit the screen without performing the Move function, type END in the COMMAND line and press <ENTER>. The system will redisplay the previous screen with the message that the document was not moved.

To move a document, type the receiving Project Record Number and folder for the document and press <ENTER>. If the intended receiving folder does not exist or is flagged for pending deletion, the Move Document Screen will be redisplayed with an error message. Otherwise, PRIS removes the document 
from the original folder and adds it to the receiving folder. The system then redisplays the screen from which this function was requested with a message that the document has been moved.

If the moved document was the last document in a folder that is flagged for pending deletion, the nightly PRN download job will change its status to "deleted." When a project is flagged for pending deletion and its last folder changes to deleted, the nightly PRN download job will physically delete the project, the project/ESO associations, and the folders of the project. No project information will remain in PRIS after a project is physically deleted; it will be as if the project had never existed. 


\subsection{SELECT REPORTS (SR)}

The Select Report option from the Primary Option Menu allows you to print hard-copy reports for project and document information. When SR is selected, the system displays the Select Report Screen.

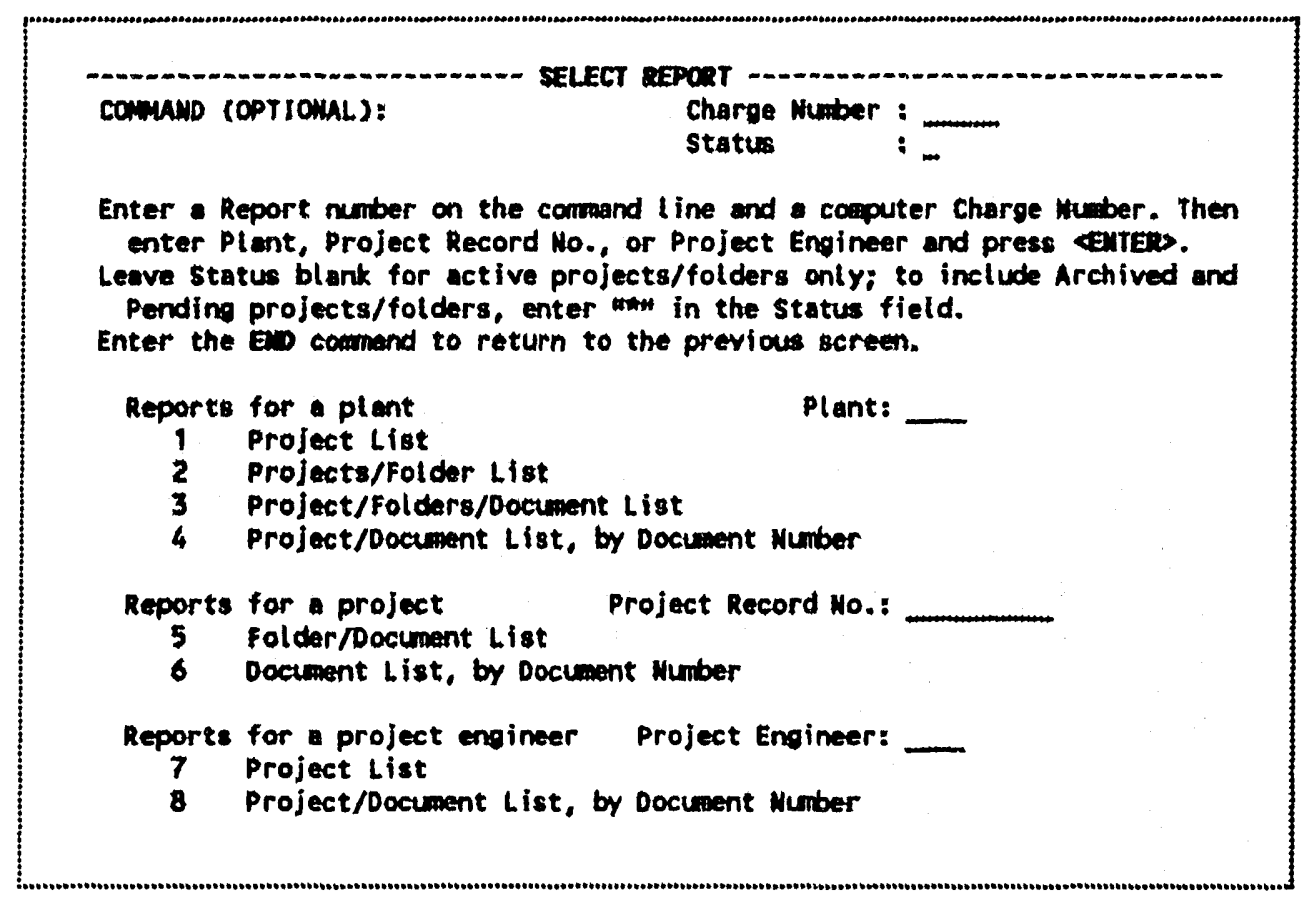

SEILCT

REPORT

Eight reports are listed on this screen. Enter the number of the desired report (1-8) in the COMMAND line. Then, use the $\angle \mathrm{TAB}>$ key to move through the data entry fields. Enter a computer charge number and either the plant, Project Record Number, or project engineer for which information is to be reported. Values for these fields are required and are validated by the system before the report can be generated. The formats for these reports are shown in Appendix B.

By default, only active folders and projects are listed in a report. To list all folders and projects, enter an asterisk (*) in the Status field.

When the requested information is complete, press <ENTER>. The report will be printed and delivered to you by plant mail. The system will redisplay the PRIS Primary Option Menu.

To exit this screen without generating a report, enter END on the COMMAND line and press $<$ ENTER >; PRIS will redisplay the Primary Option Menu. 
APPENDIX A: HELP AND ERROR SCREENS 
SELECT BUILDING NUMBER SCREEN

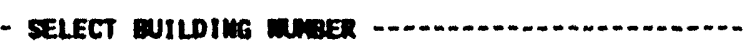

COMMAND (OPTIONAL):

Select value by placing an $X$ in the select field and pressing Emren

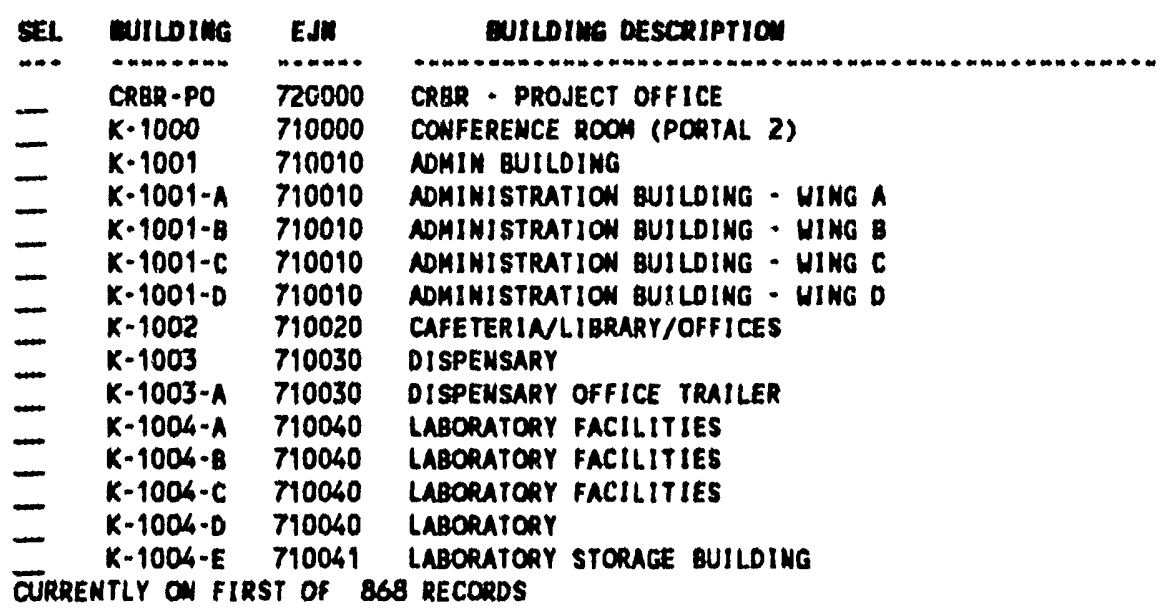




\section{CLASSIFICATION CODE LIST SCREEN}

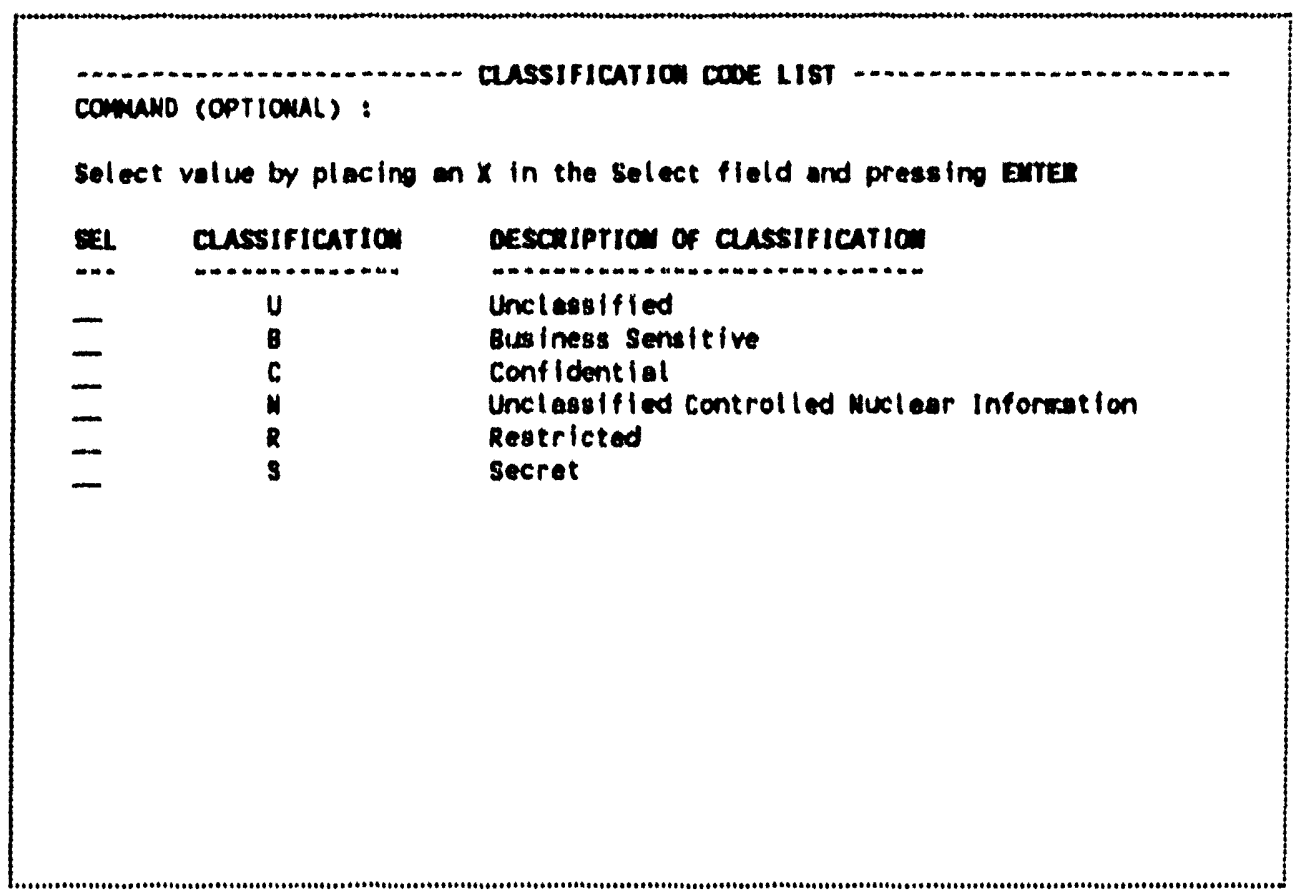




\section{SELECT COMPANY CODE SCREEN}

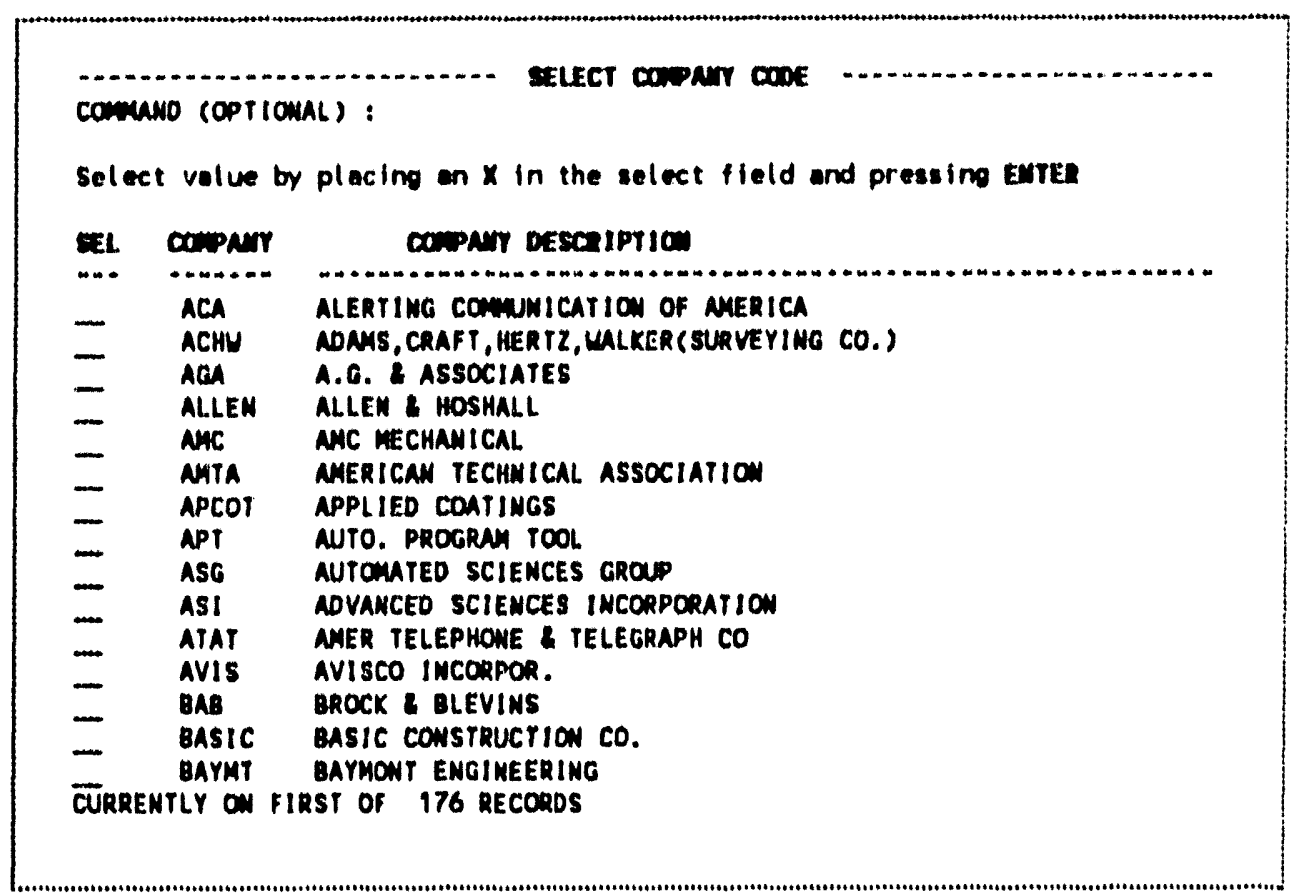




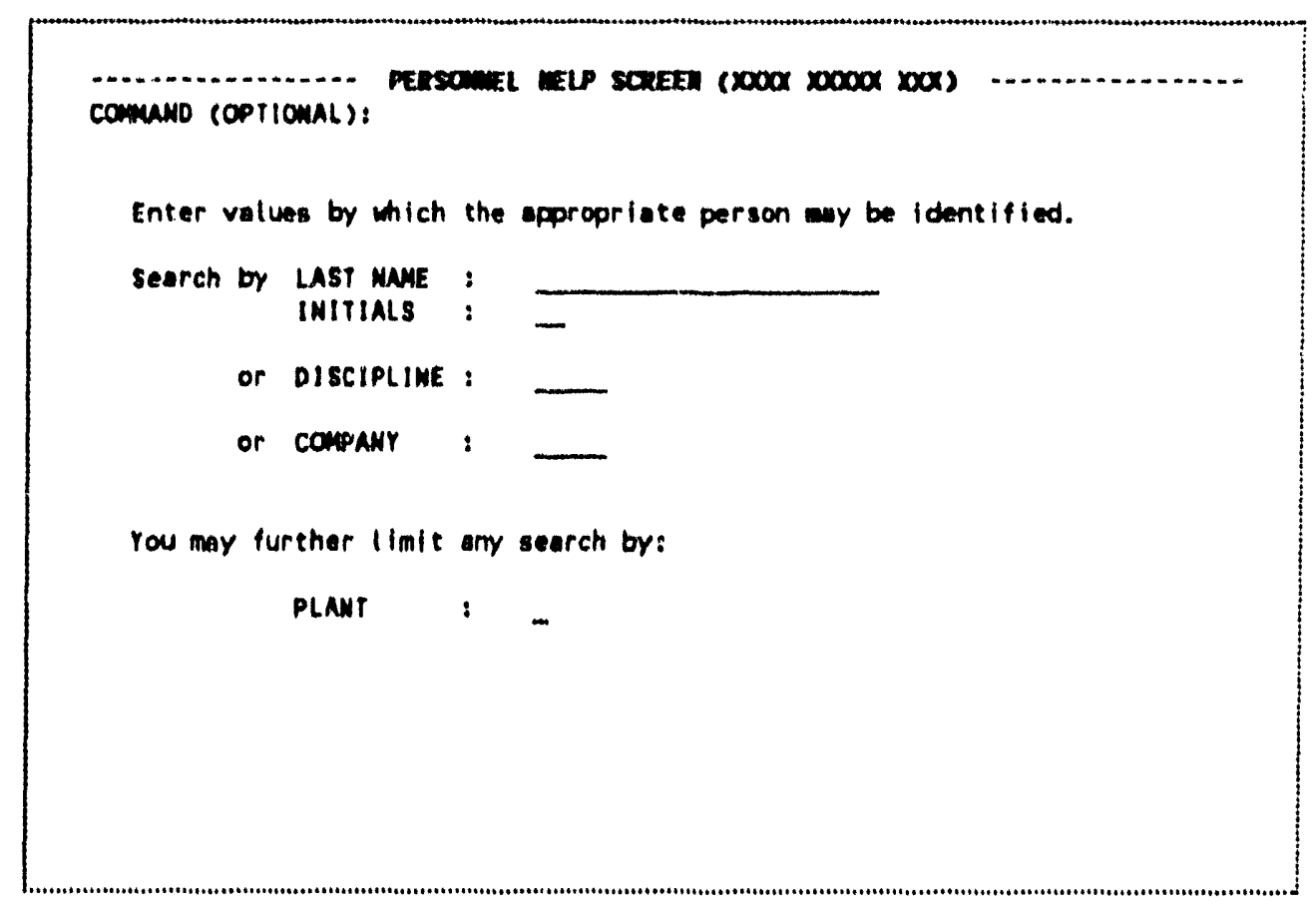

\section{SELECT EMIS ID SCREEN}

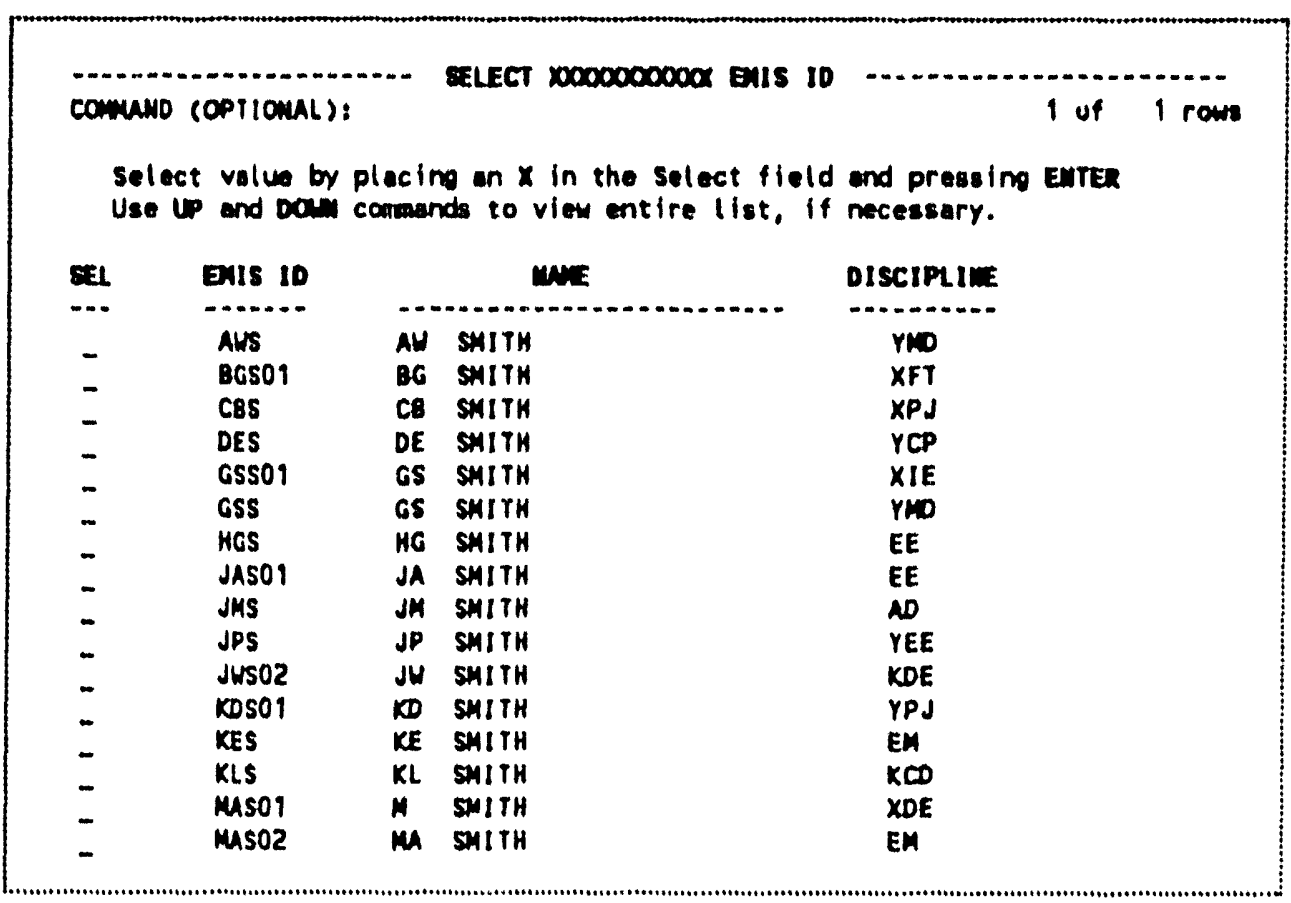


SELECT DOCUMENT TYPE SCREEN

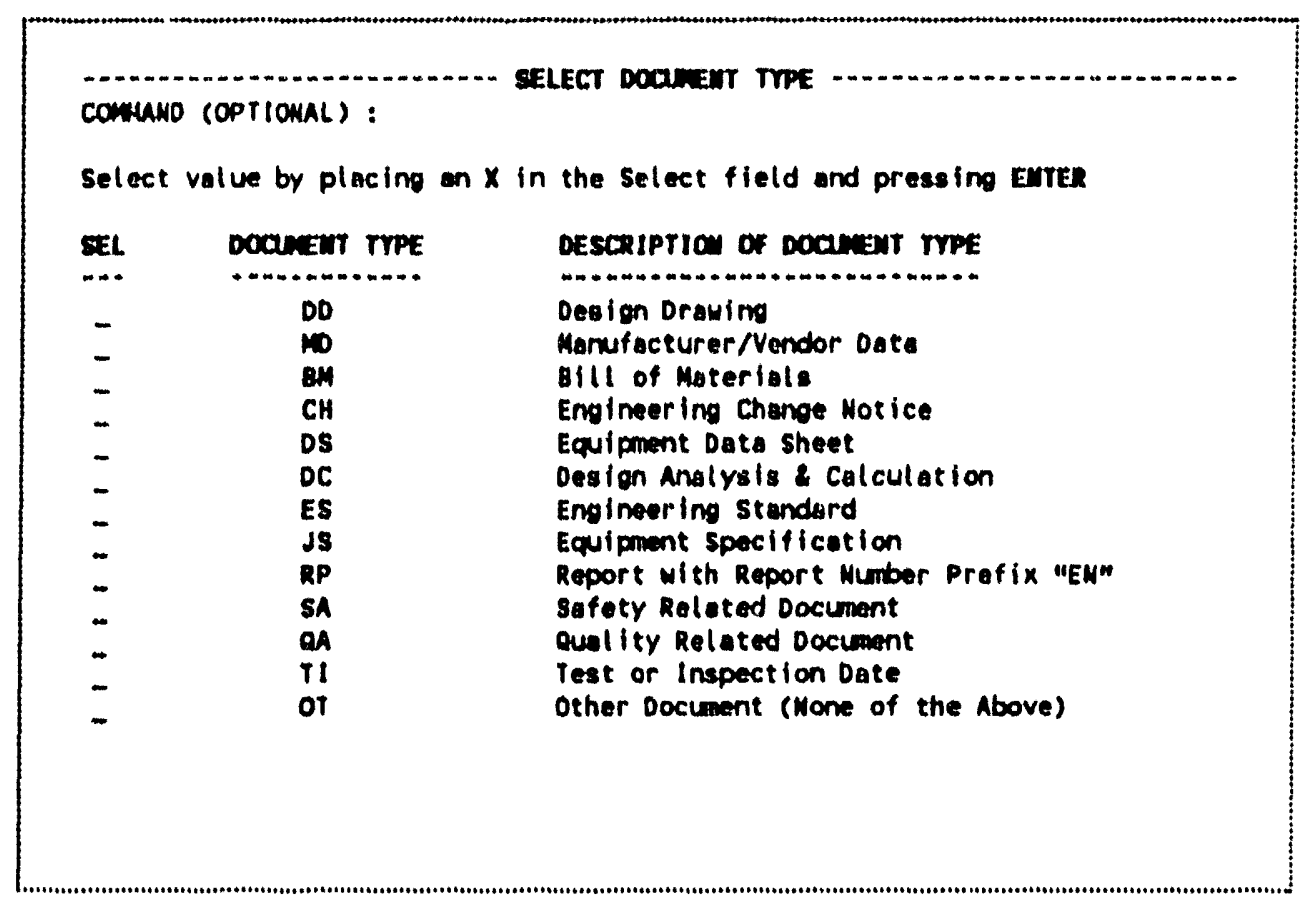




\section{PLANT LIST SCREEN}

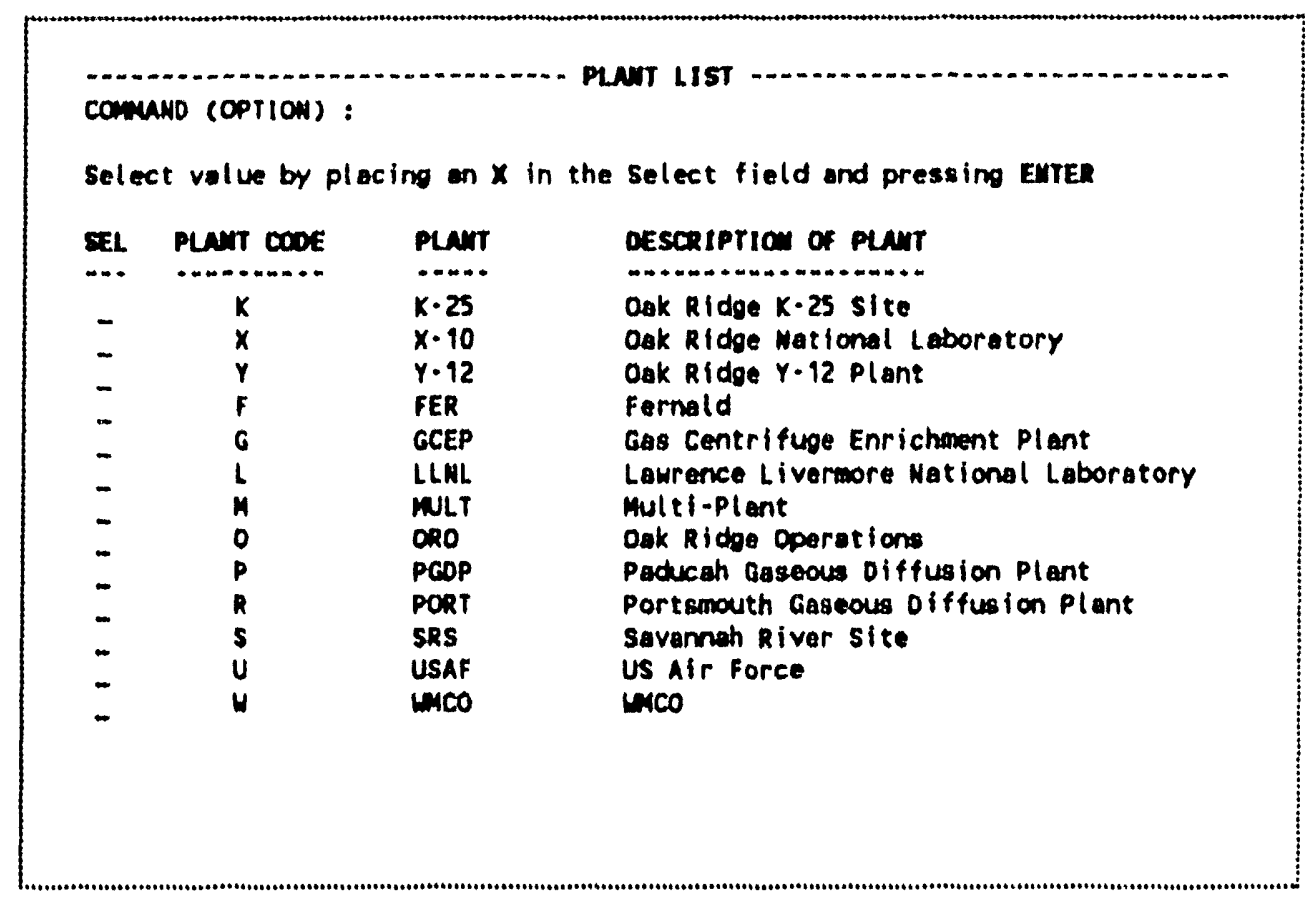




\section{DATABASE ERROR}

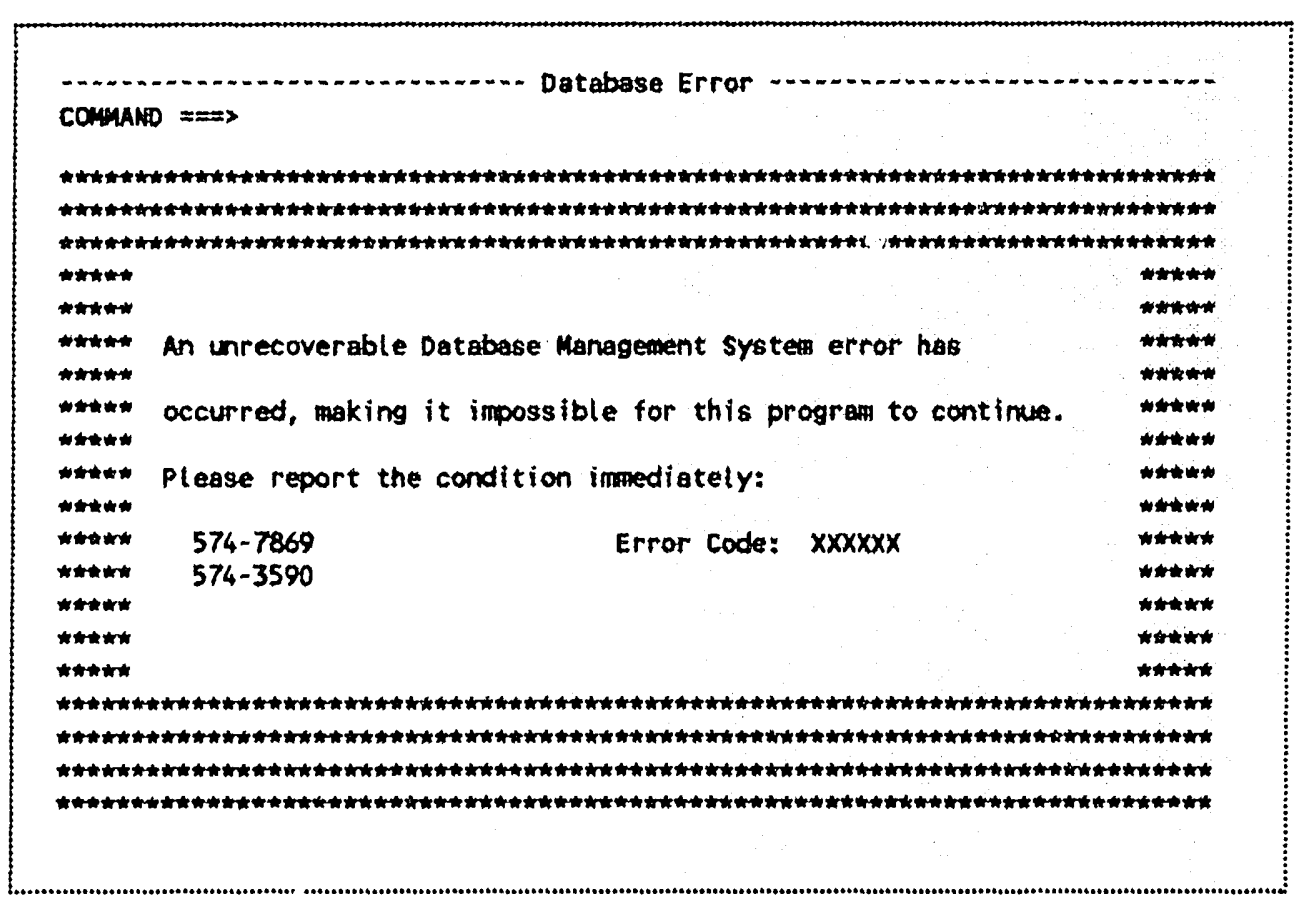


APPENDIX B: PRIS REPORT FORMATS 
Fig. B-1. PRIS Report 1 - PRIS Project List for a Given Plant.

XXXX PRIS PROJECT LISTING

\section{PROJECT \\ RECORD}

PROJECT

PROJECT

ENGINEER ACROWYM

Project titLe

\begin{tabular}{|c|c|c|}
\hline$x x x x x-x x x x$ & $x X X X X$ & $x x x x x x x x x x$ \\
\hline$x x x x x-x x x x$ & $x \times X X X X$ & $X X X X X X X X X X X$ \\
\hline$x \mathbf{x} x \mathbf{x}-\mathbf{x} \mathbf{x x x}$ & $x \times x \times x$ & $x x x x x x x x x x$ \\
\hline$x \times x x x-x x x x$ & $x \times x \times x$ & $x \times x \times x \times x \times x x$ \\
\hline$x x x x x-x x x x x$ & $x \times x \times x$ & $x \times x x x x x x x x$ \\
\hline$x x x x x-x x x x$ & $\operatorname{XXXXX}$ & $x \times x x x x x x \times x X$ \\
\hline$x x x x x-x x x x$ & $x \times x x x$ & $x x x \times x x x x x x$ \\
\hline$x x x x x-x x x x$ & $x x x x x$ & $x x x x \times x \times x x x x$ \\
\hline$X X X X X-X X X X$ & $x x x x x$ & $x x x x x x x x x x$ \\
\hline$x x x x x-x x x x$ & $x x x x x$ & $x \times x x x x x x \times x$ \\
\hline$x x x x x-x x x x x$ & $x x x x x$ & $x \times x x x x x x x x$ \\
\hline
\end{tabular}

$x$

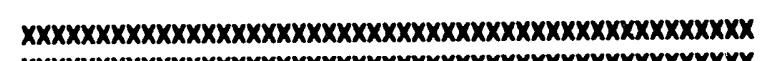

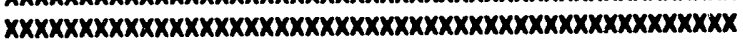

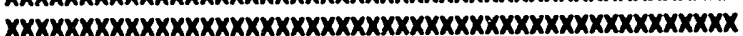

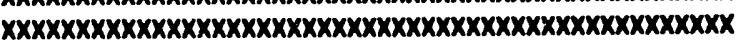

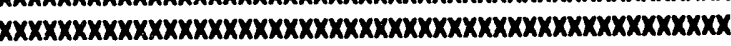

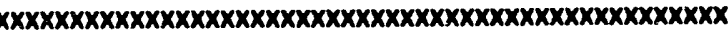

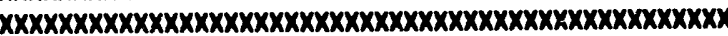

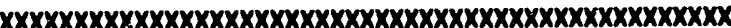

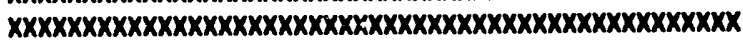

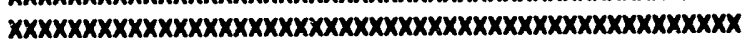

$X X X X X-X X X X \quad X X X X X$

DATE : $X X / X X / X X$

PAGE : $x$

\begin{tabular}{|c|c|c|}
\hline $\begin{array}{l}\text { RETENTION } \\
\text { PERIOD }\end{array}$ & $\begin{array}{l}\text { CREATION } \\
\text { DATE }\end{array}$ & $\begin{array}{l}\text { PROJECT } \\
\text { STATUS }\end{array}$ \\
\hline$x x x$ & $x x x x-x x-x x$ & $x \times x \times X X X X X$ \\
\hline $\mathbf{x x x}$ & $x x x x-x x-x x$ & $x x x x x x x x x$ \\
\hline $\mathbf{x x x}$ & $x x x x-x x-x x$ & $x x x x x x x x x$ \\
\hline$x x x$ & $x x x x-x x-x x$ & $x \times x \times x \times x \times x$ \\
\hline$x x x$ & $x x x x-x x-x x$ & $x \times x \times x \times x \times x$ \\
\hline $\mathbf{x x x}$ & $x x x x-x x-x x$ & $x \times x x x x x x$ \\
\hline$x x x$ & $x x x x-x x-x x$ & $x \times x \times x \times x x$ \\
\hline$x x x$ & $x x x x-x x-x x$ & $x \times x x x x \times x x$ \\
\hline $\mathbf{x x x}$ & $x x x x-x x-x x$ & 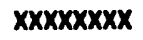 \\
\hline$x x x$ & $x x x x-x x-x x$ & $x \times x \times x \times x x$ \\
\hline$x X X$ & $x x x x-x x-x x$ & $x \times x \times x x x \times x$ \\
\hline
\end{tabular}


Fig. B-2. PRIS Report 2 - Project/Folder List for a Given Plant.

$X-X X$ PROJECT/FOLDER LISTING

DATE : $X X / X X X / X X$

PAGE : $x$

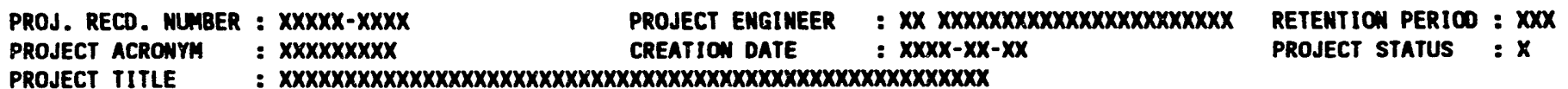

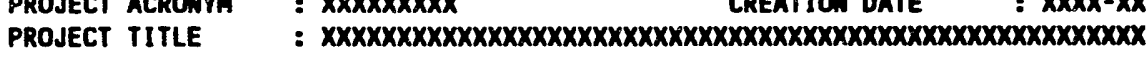

\begin{tabular}{|c|c|c|c|c|c|c|}
\hline FOLDER & TRANSHITTAL & JOB TITLE & $\begin{array}{l}\text { PRINCIPAL } \\
\text { ENGINEER }\end{array}$ & $\begin{array}{l}\text { ORIGIMATOR/ } \\
\text { RECIPIENT }\end{array}$ & $\begin{array}{l}\text { EMIS } \\
\text { PROJECT } \\
\text { MUABER }\end{array}$ & ESO \\
\hline -..... & - n & , & $\cdots$ & -......... & -....... & (n) \\
\hline $\mathbf{x x x x}$ & $x x x x x x x x x x$ & $X X X X X X X X X X X X X X X X X X X X X X X X X X X X X X X X X X X$ & $\mathbf{X X X X X X}$ & $\mathbf{X X X X X X}$ & $x x x x x x$ & $x \times x \times x \times x \times x$ \\
\hline $\mathbf{x X X X}$ & $x \times x \times x x x x x x$ & $x \times x \times x \times x \times x \times x \times x \times x \times x \times x \times x \times x \times x \times x \times x \times x \times x \times$ & $x \times x \times x$ & $x \times x \times x$ & $x \times X X X X X$ & $x \times x \times x \times x \times x$ \\
\hline 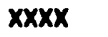 & $x x x x x x x x x x$ & 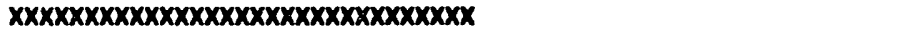 & $\mathbf{x x x \times x}$ & $x \times x \times x x$ & $\mathbf{x x x \times x \times x}$ & $\mathbf{x x x \times x \times x \times x}$ \\
\hline $\mathbf{x x x x}$ & $x x x x x x x x x x$ & $x \times x \times x \times x \times x \times x \times x \times x \times x \times x \times x \times x \times x \times x \times x \times x \times x \times x x$ & $\mathbf{X X X X X X}$ & $\mathbf{X X X X X X}$ & $\mathbf{X X X X X X X}$ & $x \times x \times x \times x \times x$ \\
\hline $\mathbf{X X X X}$ & $x x x x x x x x x x$ & 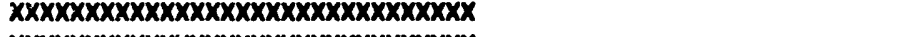 & $\mathbf{X X X X X X}$ & $\mathbf{X X X X X X}$ & $\mathbf{x x x x x x}$ & $x \times x \times x \times x x$ \\
\hline $\mathbf{X X X X}$ & $x x x x x x x x x x$ & 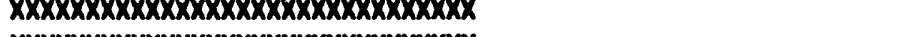 & $\operatorname{xxxxx}$ & $x x x x x$ & $x x x x x x$ & $\operatorname{xxxx\times x\times x}$ \\
\hline $\mathbf{x x x x}$ & $x x x \times x X X X X X$ & 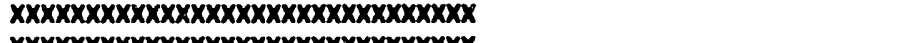 & $\mathbf{x X X X X}$ & $\mathbf{x X X X X}$ & $x \times X X X X$ & $x x x x x x x x$ \\
\hline $\mathbf{x x x x}$ & $x x x x x x x x x x$ & 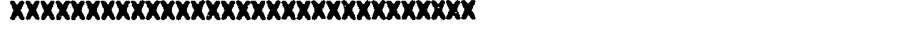 & $x \times x \times x$ & $x \times x \times x$ & $x x x x x x x$ & $x \times x \times x \times x \times x$ \\
\hline
\end{tabular}


Fig. B-3. PRIS Report 3 - Project/Folder/Document List for a Given Plant.

X-XX PROJECT/FOLDER/DOCUMENT LIST

DATE : $X X / X X / X X$

PAGE : $\quad x$

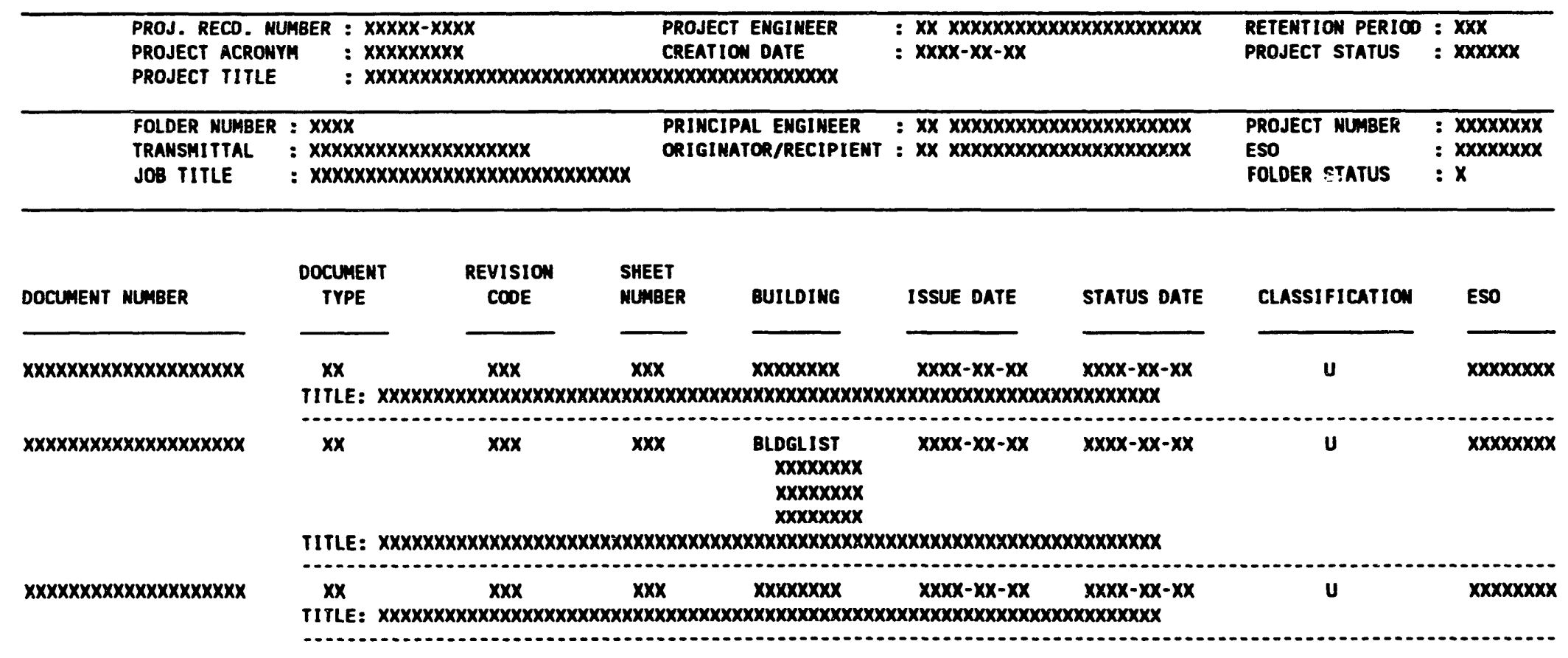


Fig. B-4. PRIS Report 4 - Project/Document List For a Given Plant.

(by Document Number)

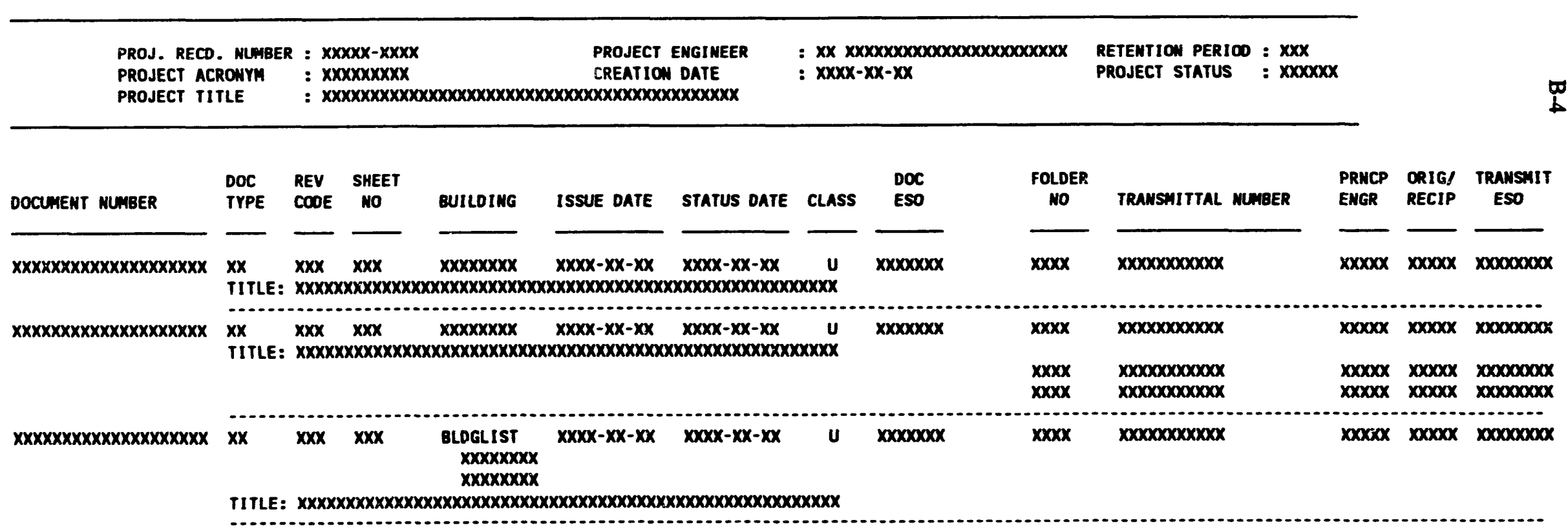


Fig. B-5. PRIS Report 5 - Folder/Document List for a Given Project.

FOLDER/DOCUNENT LIST FOR PROJECT $X X X X X X-X X X X$

DATE : $\times x / x \times / x \times$

PAGE : $X$

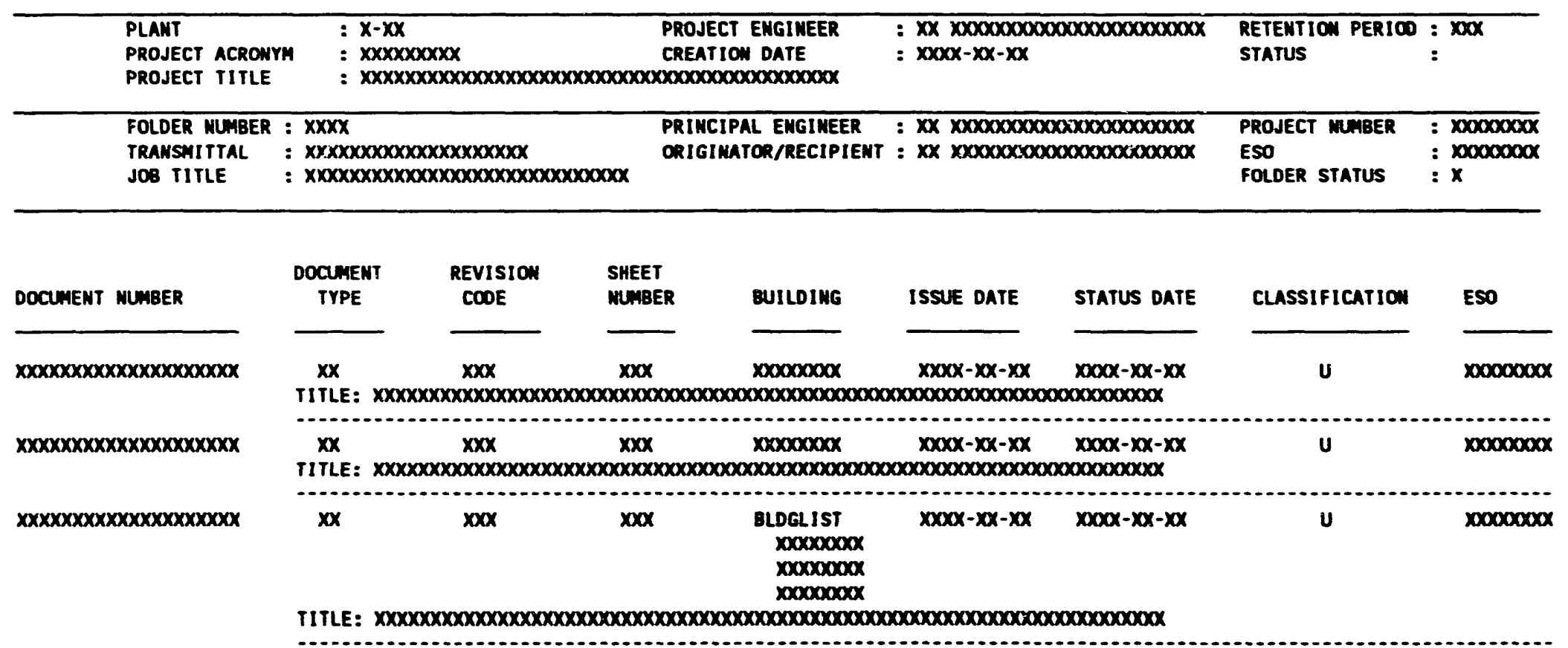


Fig. B-6. PRIS Report 6 - Document List For a Given Project.

(by Document Number)

DOCUMENT LIST FOR PROJECT XXXXXX-XXXXX

DATE : $\times x / \times \times / / X X$

PAGE : $x$

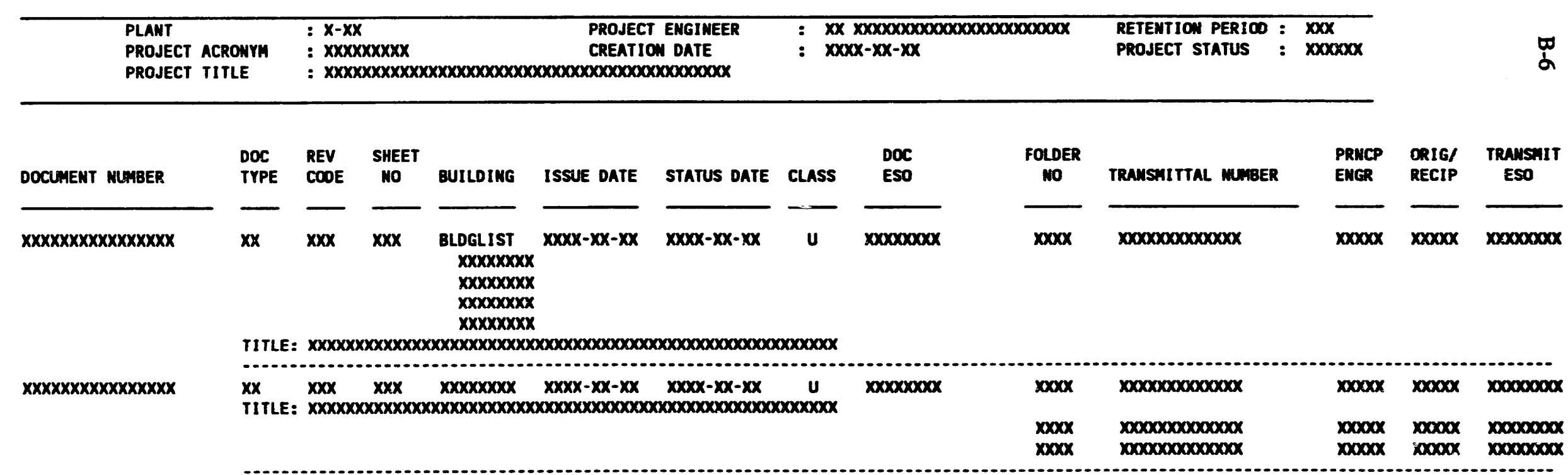


Fig. B-7. PRIS Report 7 - Project List for a Given Project Engineer.

PRIS PROJECT LISTING

PROJECT ENGINEER : $X X \times X \times 0 \times 00000 \times \times 0 \times 000000 \times \times \times X$

PLANT : $x-x x$
DATE : $\times x / x \times / \times x$

PAEE : $x$

\section{RETENTIO \\ PERICO}

$\mathbf{x o x}$

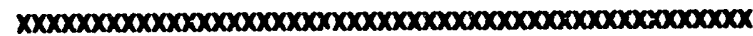

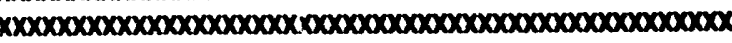

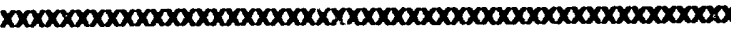

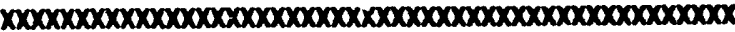

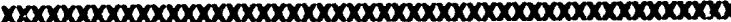
r $x \times x \times x \times x \times x$ $0000000 x$

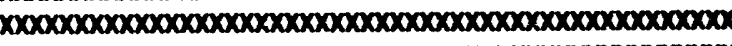

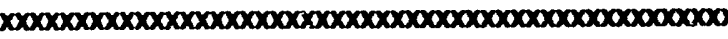

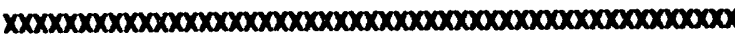

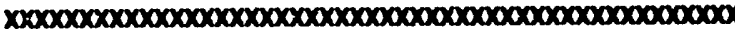

\begin{tabular}{|c|c|c|c|}
\hline $\begin{array}{l}\text { RETENTIOH } \\
\text { PERICO }\end{array}$ & $\begin{array}{l}\text { CREATION } \\
\text { DATE }\end{array}$ & CREATOR & $\begin{array}{l}\text { PROJECT } \\
\text { STATUS }\end{array}$ \\
\hline$x 00 x$ & $x x x x-x x x-x x$ & $x 0000 x$ & $x 000000 \times x$ \\
\hline$x x x$ & $x x x x-x x-x x$ & $x 0000 x$ & $x 0000000$ \\
\hline$x x x$ & $x x x x-x x-x x$ & $x 000 x$ & $x 0000000 x$ \\
\hline$x x$ & $x x x x-x x-x x$ & $x 000 x$ & $x 0000000 x$ \\
\hline$x x x$ & $x \times c \alpha x-x \alpha x-x \alpha$ & $x 0000 x$ & $x 000000 x$ \\
\hline$x 00 x$ & $x 000 x-x x-x x$ & $x 000 x$ & $x 000000 x$ \\
\hline$x \mathbf{x}$ & $x>0 x x-x x-x x$ & $x 00 x x$ & $x 0000000 x$ \\
\hline$x \mathbf{x x}$ & $x 00 x-x x-x x$ & $x \cos x$ & $x 0000000 x$ \\
\hline$x 0 x$ & $x 00 x-x x-x x$ & $x x x x x$ & $x 0000000 x$ \\
\hline $\mathbf{x x x}$ & $x x x x-x x-x x$ & $x 0000 x$ & $x 0000 \times 00 x$ \\
\hline$x \times x$ & $x \times x \times x-x \times-x x$ & $x 0000 x$ & $x 0000000 x$ \\
\hline
\end{tabular}

$x x x x x-x x x x$

$x x x x x-x x x x$

$x x x x x-x x x x$
$x \times x x x-x x x x$

$x x x x x x-x x x x$

$\mathbf{X X X \times X \times X X}$

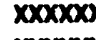

$\underset{x \times x \times x \times x}{x}$

$x x x x x x-x x x x x$ 
Fig. B-8. PRIS Report 8 - Project/Document List for a Given Project Engineer (by Document Number)

PROJECT/OOCUNEWT LIST FOR PROJECT EWGIWEER XX $1000000000000000000000 \times$

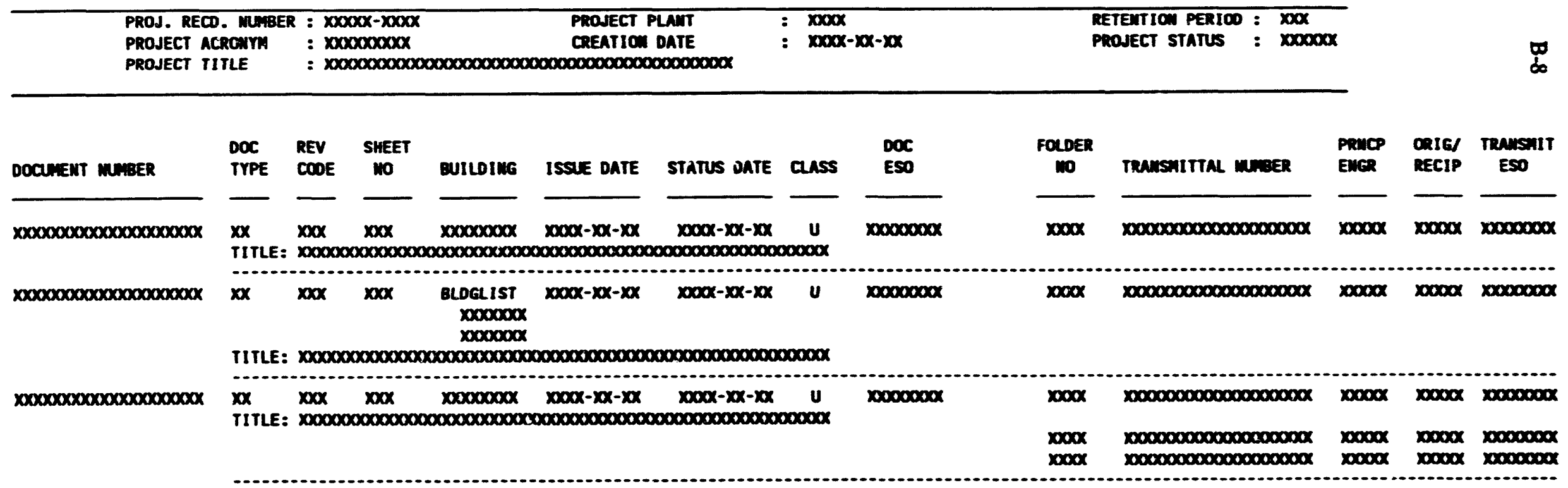


APPENDIX C: PRIS DATA DICTIONARY 
DATA DICTIOMARY

PROJECT RECORDS IMFORMATION STSTEM

Data Elements

$10 / 01 / 93$

Page 1

\begin{tabular}{|c|c|c|c|c|c|c|c|c|c|c|}
\hline $\begin{array}{l}\text { Iten } \\
\text { No. }\end{array}$ & $\begin{array}{r}\text { Data } \\
\text { Item } \\
\text { Manenclat } \\
\end{array}$ & & & $\begin{array}{l}\text { Data Requirement } \\
\text { Deseription }\end{array}$ & $\begin{array}{c}\text { Source } \\
\text { of } \\
\text { Data }\end{array}$ & $\begin{array}{l}\text { Value } \\
\text { or } \\
\text { Range }\end{array}$ & Type & $\begin{array}{l}\text { Field } \\
\text { size }\end{array}$ & Align & $\begin{array}{c}\text { Retrieval } \\
\mathrm{KeY}\end{array}$ \\
\hline 1 & DOCAMENT_MARER & - & Docino & A nuber that uniquely identifies all documents referenced in the PRIS index. & $\begin{array}{l}\text { Dociment or } \\
\text { Title slock }\end{array}$ & $\cdots$ & AM & 20 & LEFT & 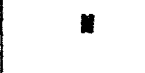 \\
\hline 2 & COMP_DRAWING_NO & - & COAPORUG & $\begin{array}{l}\text { Compressed version of the DOCUNEMT_MMBER. All blanks and special characters } \\
\text { are el iminated and left justified. }\end{array}$ & SYSTEM & $\cdots$ & AN & 20 & LEFT & $\mathbf{r}$ \\
\hline 3 & DOCUNEMT_TYPE & - & DOCTYPE & $\begin{array}{l}\text { A code that Identifies the category of documents to which the document } \\
\text { belongs. Menull input should be a val id code from the Document Type table. }\end{array}$ & $\begin{array}{l}\text { Document } \\
\text { Initiator }\end{array}$ & $\begin{array}{l}\text { PRis } \\
\text { list }\end{array}$ & AN & 2 & LEFT & $\mathbf{Y}$ \\
\hline 4 & REVISION_COOE & - & REVCODE & $\begin{array}{l}\text { A code that indicates the level of the document revision. codes for } \\
\text { revisions made by Martin Marietta are charscters begiming at man: for } \\
\text { archit tect/engineers, they are nubers beginning at } \\
\text { initial The field is } \\
\text { revision nuber in sequence. }\end{array}$ & $\begin{array}{l}\text { Document or } \\
\text { Title Block }\end{array}$ & Coode & AM & 3 & RIGIT & $\mathbf{r}$ \\
\hline 5 & REVISION_DATE & - & REVDATE & 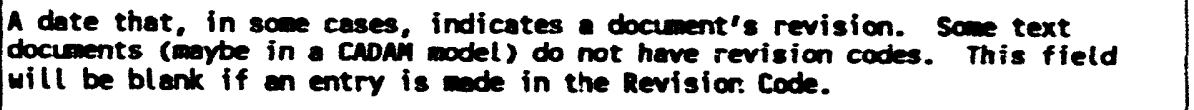 & $\begin{array}{l}\text { Document } \\
\text { Initiator }\end{array}$ & Date & DATE & 10 & LEFT & $r$ \\
\hline 6 & REVISION_DATE & - & REVT8 & 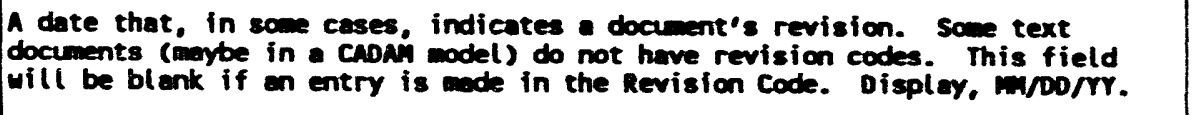 & $\begin{array}{l}\text { Document } \\
\text { Initiator }\end{array}$ & Date & DATE & 8 & LEFT & $r$ \\
\hline 7 & SHEET_MUBER & - & SHEETWO & $\begin{array}{l}\text { The muber of the sheet of a multiple sheet document. Sheet nuber defaul ts } \\
\text { to } 001 \text { for single sheet documents and for documents that are not design } \\
\text { drawings. }\end{array}$ & $\begin{array}{l}\text { Dociment or } \\
\text { Title Block }\end{array}$ & -- & ax & 3 & Rreit & $\mathbf{r}$ \\
\hline 8 & STATUS_COOE & - & STATCOOE & $\begin{array}{l}\text { A code indicating the stope of development of the document. } \\
\text { REL = Released } \\
\text { oas }=\text { Obsolete }\end{array}$ & STSTEM & REL, C8S & An & 6 & an & $n$ \\
\hline 9 & PLANT & - & PLANT & A code indicating the plent to which the drawing pertains. & $\begin{array}{l}\text { Document or } \\
\text { Title Block }\end{array}$ & $\begin{array}{l}\text { PRIS } \\
\text { List }\end{array}$ & An & 4 & LEFT & n \\
\hline 10 & CLASSIFICATION & - & Class & $\begin{array}{l}\text { A code indicating the classification level of the document. Manual input } \\
\text { should be a valid code from the classification table. }\end{array}$ & $\begin{array}{l}\text { Document } \\
\text { Initiator }\end{array}$ & $\begin{array}{l}\text { PRIS } \\
\text { List }\end{array}$ & ail & 4 & LEFT & $\omega$ \\
\hline 11 & BLK48_DISCIPLINE & - & B480ISC & $\begin{array}{l}\text { A code that identifies the Engineering discipl ine to which the document } \\
\text { belongs (applies to design drewings only). }\end{array}$ & Title Block & $\begin{array}{l}\text { Code } \\
\text { List }\end{array}$ & ail & 3 & RIGUT & * \\
\hline 12 & BLK49._MATURE_UORK & - & B49NON & $\begin{array}{l}\text { A code that identifies the mature of the work contained in the document } \\
\text { (appl ies to design drewings only). }\end{array}$ & Title Block & $\begin{array}{l}\text { Code } \\
\text { List }\end{array}$ & AM & i & & * \\
\hline 13 & BLK50_WORK_SUBSET & - & BSOSUB & $\begin{array}{l}\text { A code that signifies a subset of the type of work being performed (applies to } \\
\text { design drawings only). }\end{array}$ & Title Block & $\begin{array}{l}\text { Code } \\
\text { List }\end{array}$ & $a n$ & 1 & & $n$ \\
\hline
\end{tabular}


DATA DICTIONARY

PROJECT RECORDS IMFORMATIOU SYSTEM

Data Elements

10/01/93

Poge 2

\begin{tabular}{|c|c|c|c|c|c|c|c|c|c|c|}
\hline $\begin{array}{l}\text { Item } \\
\text { No. }\end{array}$ & $\begin{array}{l}\text { Data } \\
\text { Item } \\
\text { Momenclatu }\end{array}$ & & & $\begin{array}{l}\text { Data Requirement } \\
\text { Description }\end{array}$ & $\begin{array}{c}\text { Source } \\
\text { of } \\
\text { Data }\end{array}$ & $\begin{array}{l}\text { Value } \\
\text { or } \\
\text { Range }\end{array}$ & Type & $\begin{array}{l}\text { Field } \\
\text { size }\end{array}$ & Align & $\begin{array}{c}\text { Retrieval } \\
\text { Key }\end{array}$ \\
\hline 14 & EsO & & ESO & $\begin{array}{l}\text { The Engineering Service Order (ESO) to wich specific work done on the } \\
\text { document is charged. }\end{array}$ & $\begin{array}{l}\text { Document } \\
\text { Initiator }\end{array}$ & $\begin{array}{l}\text { EnIs } \\
\text { List }\end{array}$ & AN & 18 & LEFT & ! \\
\hline 15 & DOCUMENT_TITLE & - & DOCTITLE & A title that describes the document. & $\begin{array}{l}\text { Document } \\
\text { Initiator }\end{array}$ & $\cdots$ & AM & 72 & LEFT & м \\
\hline 16 & PROJECT_MAME & $\cdot$ & PROJMAME & The title of the Engineering Project with wich the docunent is associated. & Title Block & & an & 28 & LEFT & $\mathbf{Y}$ \\
\hline 17 & CONFIG_CONTROL_STA & - & CCSTATUS & $\begin{array}{l}\text { A code indicating whether or not a drawing is under configuration control. } \\
c c=\text { Under Conf iguration Control MC }=\text { Hot Under Configuration control }\end{array}$ & Title Block & $c c, w c$ & An & 2 & LEFT & * \\
\hline 18 & AB_OR_CONFIG_CAT & $\cdot$ & ABCONCAT & $\begin{array}{l}\text { A code indicating the reason that a drawing is under configuration control or } \\
\text { is As-Built. } \\
\begin{array}{ll}A R=A s-B u i l t \\
A B=A \text { required } & \text { IN }=\text { Information } \\
A B & \end{array}\end{array}$ & Title slock & IN, AB, & AM & 2 & LEFT & $\omega$ \\
\hline 19 & AS_BUILT_STATUS & - & ABSTATUS & $\begin{array}{ll}\text { A code indicating the As-Built status of a drawing. } \\
\text { SS = Safety System } & \text { Or = other } \\
\text { RC = Regulatory Control } & \text { SG = Safequards/Security } \\
C I=\text { Cost Impact } & \text { MA = Mot Appl Icable }\end{array}$ & Title Block & $\begin{array}{l}\text { SS, OT, } \\
\text { RC, SG, } \\
\text { Cl, }\end{array}$ & an & 2 & LEFT & $\boldsymbol{x}$ \\
\hline 20 & VEMDOR_COOE & - & VENDCOOE & $\begin{array}{l}\text { A code describing the vendor of a document of type mo (manufacturing or } \\
\text { vendor data). A list of valid vendor codes is mointained by } 150 \text {. }\end{array}$ & $\begin{array}{l}\text { Document } \\
\text { Initiator }\end{array}$ & $\begin{array}{l}\text { ISD } \\
\text { List }\end{array}$ & AN & 5 & LEFT & $n$ \\
\hline 21 & VENDOR_SUBJECT & - & VENOSUBJ & $\begin{array}{l}\text { A code describing the subject of a document of type wo (manfacturing or } \\
\text { vendor data). A list of valid subject codes is maintained by ISD. }\end{array}$ & $\begin{array}{l}\text { Document } \\
\text { Initiator }\end{array}$ & $\begin{array}{l}\text { Iso } \\
\text { List }\end{array}$ & AN & 9 & LEFT & $n$ \\
\hline 22 & ORIGIMATOR_DISC & - & ORICDISC & $\begin{array}{l}\text { The EMIS discipline code associated with the EMIS ID of the originator of } \\
\text { the document. }\end{array}$ & $\begin{array}{l}\text { Document } \\
\text { Initiator }\end{array}$ & $\begin{array}{l}\text { Emis } \\
\text { List }\end{array}$ & AN & 5 & LEFT & \% \\
\hline 23 & RESPONSIBLE_DISC & - & RESPOISC & $\begin{array}{l}\text { The EMIS discipl ine code associated with the EMIS tO of the person who is } \\
\text { reponsible for the document. }\end{array}$ & $\begin{array}{l}\text { Document } \\
\text { Initiotor }\end{array}$ & $\begin{array}{l}\text { Emis } \\
\text { List }\end{array}$ & $A N$ & 5 & LEFT & $n$ \\
\hline 24 & PROJECT_MUABER & - & PROJNO & The EMIS project number with wich the document is associated. & EMIS & EnIs & AN & 8 & LEFT & $n$ \\
\hline 25 & ORIGIMATOR_CO_COOE & - & ORCOCODE & $\begin{array}{l}\text { The EMIS compeny code identifing the compeny of the originator of the } \\
\text { dociment. }\end{array}$ & $\begin{array}{l}\text { Document } \\
\text { Initiator }\end{array}$ & Code & AM & 5 & LEFT & $n$ \\
\hline 26 & ORIGIMATOR_IO & - & ORIGID & The EMIS ID of the person originat ing the document. & $\begin{array}{l}\text { Doctument } \\
\text { Initiator }\end{array}$ & $\begin{array}{l}\text { EMIs } \\
\text { List }\end{array}$ & an & 5 & LEFT & n \\
\hline 27 & RESPONSIBLE_ID & - & RESPID & The EMIS ID of the person (normally the Eng. RED) responsible for the document & $\begin{array}{l}\text { Document } \\
\text { initiator }\end{array}$ & $\begin{array}{l}\text { EnIs } \\
\text { List }\end{array}$ & AN & 5 & LEFT & " \\
\hline
\end{tabular}


DATA DICTIONARY

PROJECT RECORDS INFORMATION SYSTEM

Dats Elements

10/01/93

Page 3

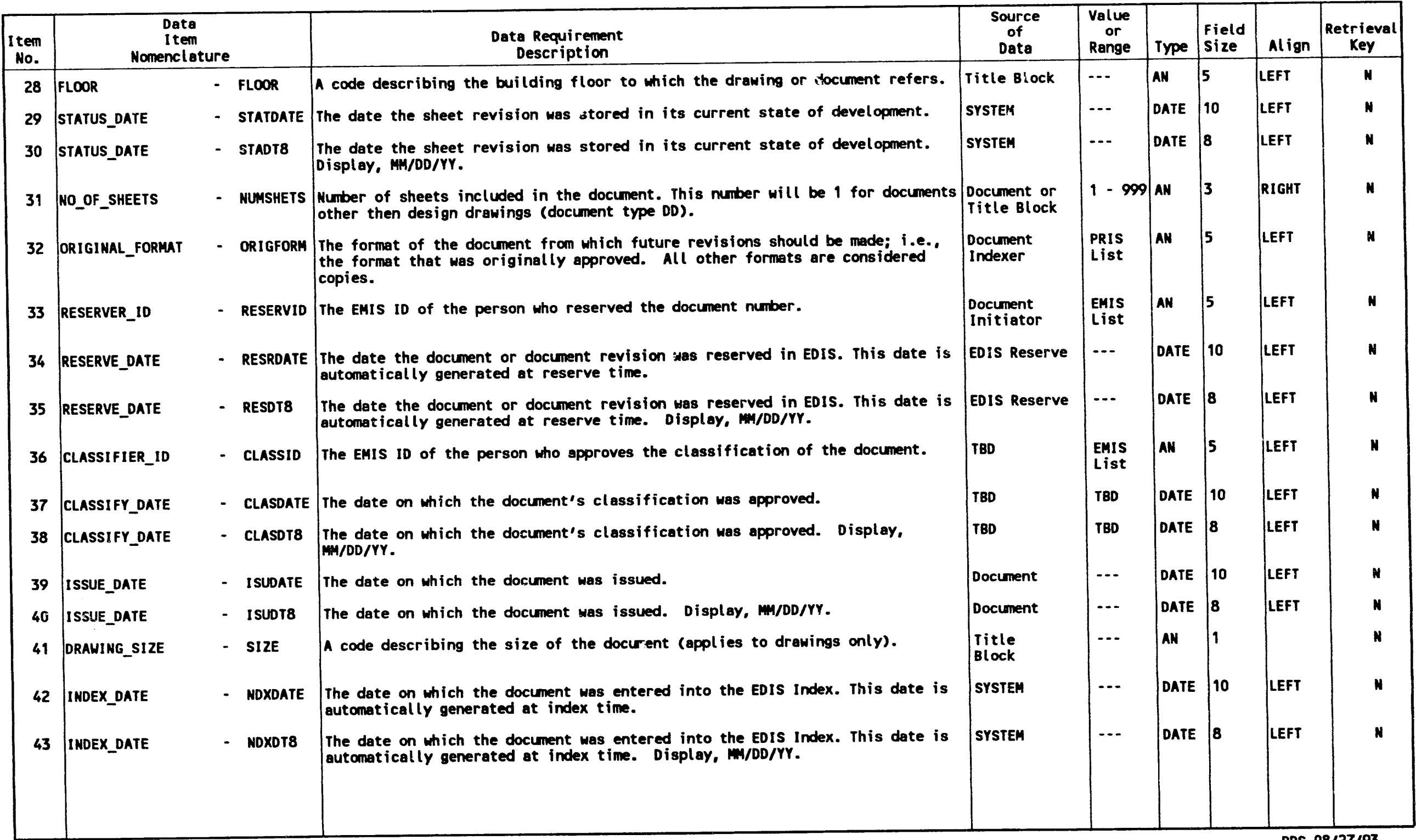


DATA DICTIONARY

PROJECT RECORDS INFORMATION SYSTEM

Data Elements

10/01/93

Page 4

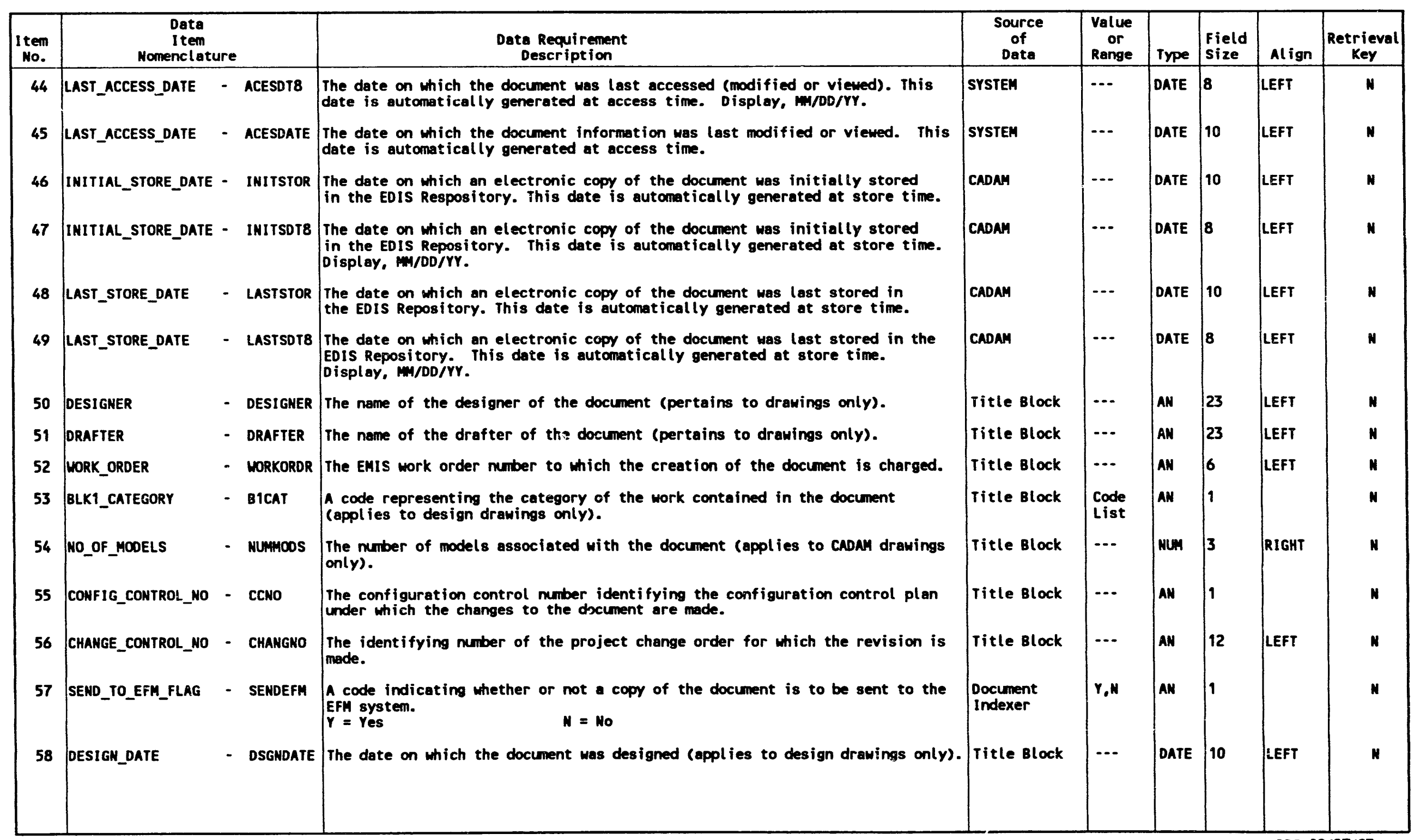


DATA DICTIONARY

PROJECT RECORDS INFORMATION SYSTEM

Data Elements

10/01/93

Page 5

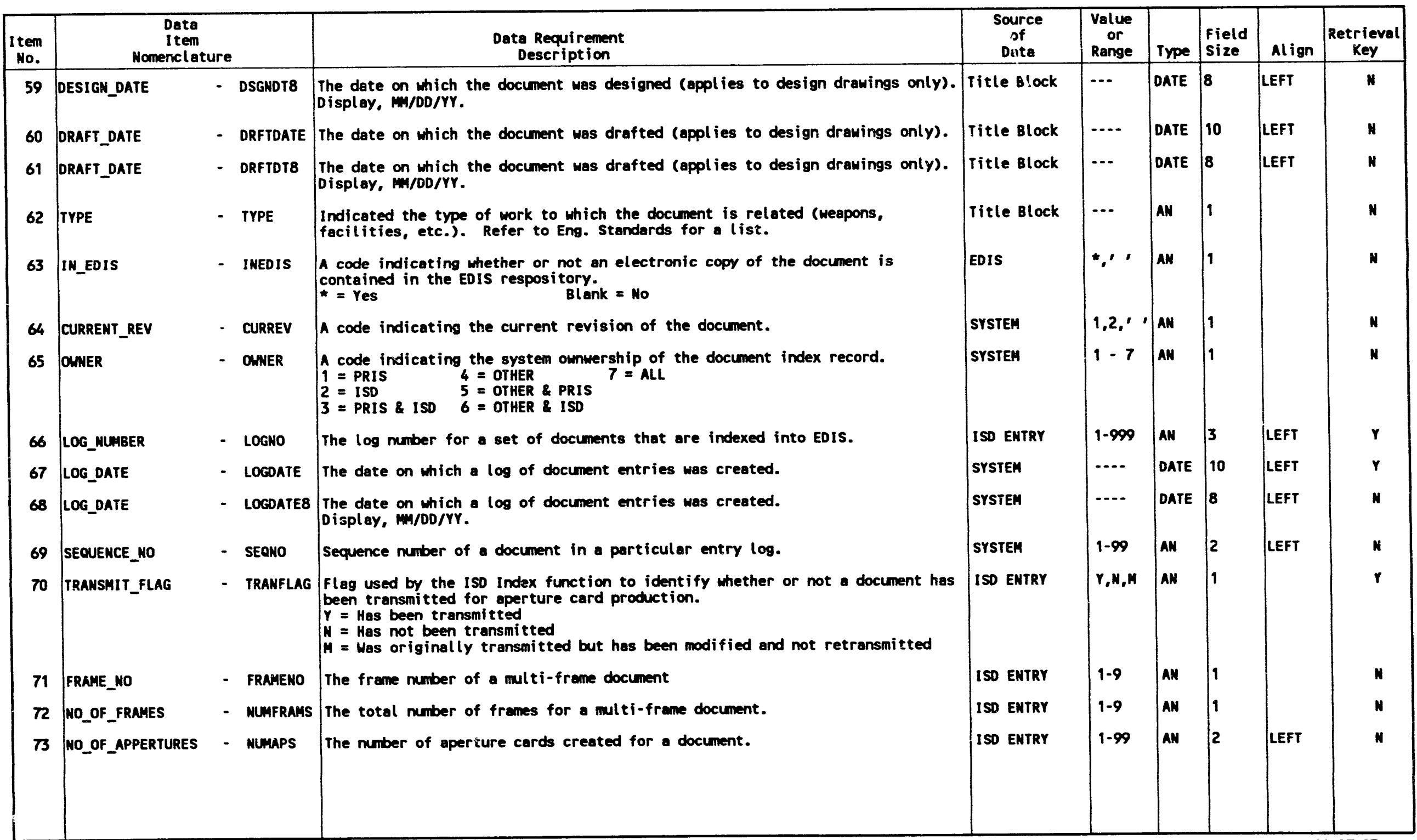


DATA DICTIONARY

PROJECT RECORDS IMFORMATION SYSTEM Data Elements

10/01/93

Page 6

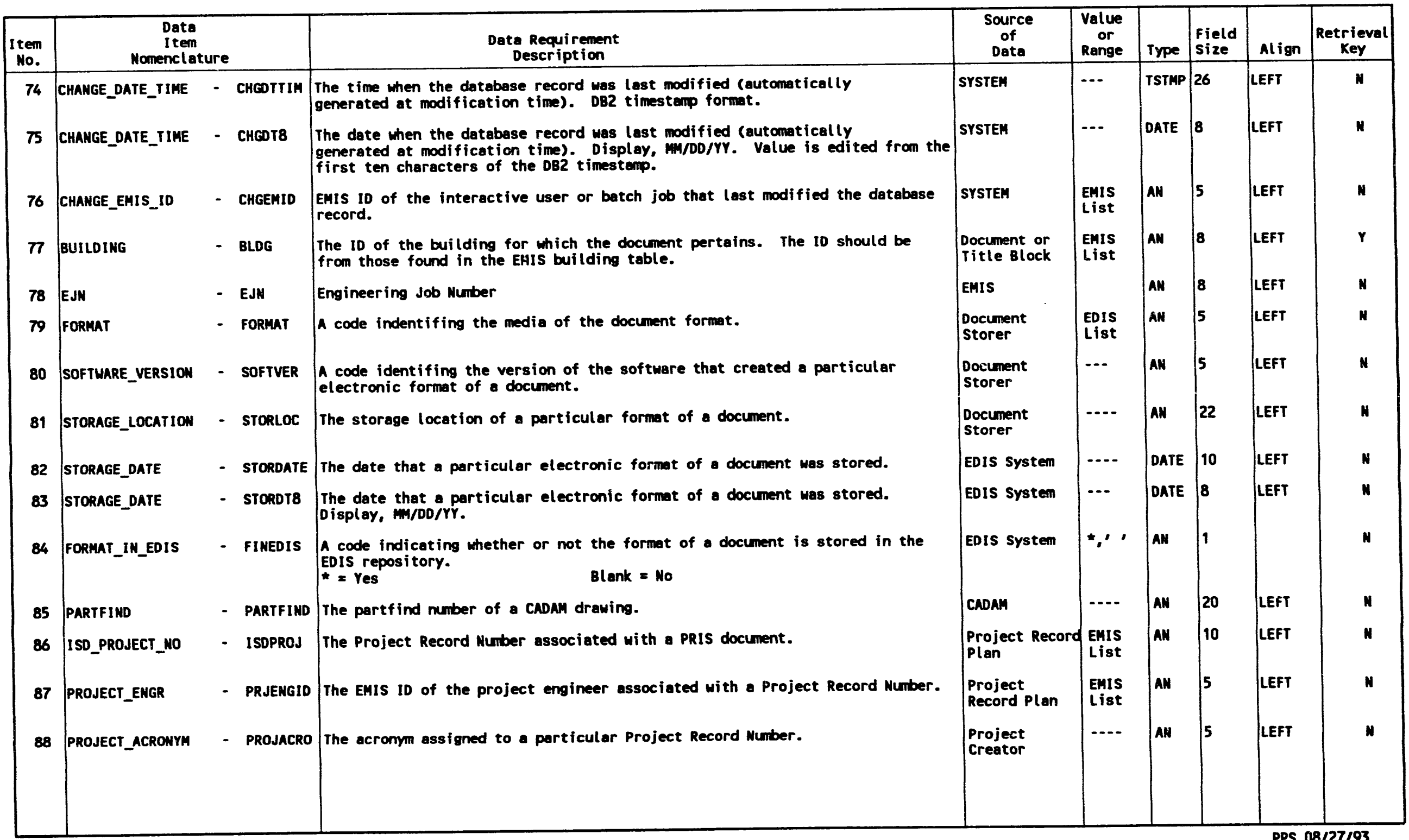


DATA DICTIOMARY

PROJECT RECORDS IMFORMATION SYSTEM

Data Elements

$10 / 01 / 93$

Page 7

\begin{tabular}{|c|c|c|c|c|c|c|c|c|c|}
\hline $\begin{array}{l}\text { Item } \\
\text { No. }\end{array}$ & $\begin{array}{l}\text { Data } \\
\text { Item } \\
\text { Nomenclatur }\end{array}$ & & $\begin{array}{l}\text { Data Requirement } \\
\text { Description }\end{array}$ & $\begin{array}{c}\text { Source } \\
\text { of } \\
\text { Data }\end{array}$ & $\begin{array}{l}\text { Value } \\
\text { or } \\
\text { Range }\end{array}$ & Type & $\begin{array}{l}\text { Field } \\
\text { Sizo }\end{array}$ & Align & $\begin{array}{c}\text { Retrieval } \\
\text { Key }\end{array}$ \\
\hline 89 & PROJECT_TITLE & - PROJTITL & The title of a Project Record Number. & $\begin{array}{l}\text { Project } \\
\text { Record Plan }\end{array}$ & $\cdots$ & AN & 65 & LEFT & $\mathbf{H}$ \\
\hline 90 & PROJECT_RETENTION & - PROJRET & $\begin{array}{l}\text { The retention period required for project documents. } \\
L=\text { Life of plant } \\
P=\text { Permanent }\end{array}$ & $\begin{array}{l}\text { Project } \\
\text { Record Plan }\end{array}$ & $\begin{array}{l}\text { L,P, } \\
\text { number }\end{array}$ & AN & 3 & & $\mathbf{N}$ \\
\hline 91 & DEFAULT_STOR_LOC & - PROJSLOC & A code indicating the default storage location for project documents. & $\begin{array}{l}\text { Project } \\
\text { Creator }\end{array}$ & $X, K, Y$ & AN & 1 & & N \\
\hline 92 & DEFAULT_BACK_LOC & - PROJBLOC & A code indicating the backup storage location of project documents. & $\begin{array}{l}\text { Project } \\
\text { Creator }\end{array}$ & $X, K, Y$ & AN & 1 & & N \\
\hline 93 & PROJECT_CREAT_DATE - & - PROJDATE & $\begin{array}{l}\text { The date when a Project Record Number is downloaded from EMIS to PRIS } \\
\text { (automatically generated at download time). }\end{array}$ & System & $\cdots$ & DATE & 10 & LEFT & N \\
\hline 94 & PROJECT_CREAT_OATE - & PROJDT8 & $\begin{array}{l}\text { The date when a Project Record Number is downloaded from ERIS to PRIS } \\
\text { (automatically generated at download time). Display, MH/OD/YY }\end{array}$ & system & -- & DATE & 8 & LEFT & N \\
\hline 95 & PROJECT_CREATOR & - PCREATID & The EMIS ID of the project creator. & $\begin{array}{l}\text { Project } \\
\text { Creator }\end{array}$ & $\begin{array}{l}\text { EMIS } \\
\text { List }\end{array}$ & AN & 5 & LEFT & M \\
\hline 96 & PROJECT_STATUS & - PSTATUS & $\begin{array}{l}\text { A code indicating the status of a Project Record Number. } \\
A=\text { Archived } \quad P=\text { Pending Deletion } \quad B \text { lank }=\text { Active }\end{array}$ & PRIS System & $A, P, \cdot 1$ & AN & 1 & & N \\
\hline 97 & FOLDER & - FOLDER & The system generated sequential number of the PRIS folder. & PRIS System & $1-9999$ & AN & 4 & LEFT & $N$ \\
\hline 98 & TRANSHITTAL_NO & TRANSNO & $\begin{array}{l}\text { The number identifing the transmittal that accompanies the documents sent to } \\
\text { the project record (PRIS) files. }\end{array}$ & Transmittal & $\cdots$ & AN & 20 & LEFT & M \\
\hline 9 & TRANS_ISSUE_DATE & - TISOATE & The date on wich the transmittal was issued. & Transmittal & Date & AN & 10 & LEFT & N \\
\hline 100 & TRANS_ISSUE_DATE & - TISDT8 & The date on which the transmittal was issued. Display, m/DD/YY. & Transmittal & Date & AN & 8 & |LEFT & $N$ \\
\hline 101 & PROJECT_JOB_TITLE & - PJOBTITL & $\begin{array}{l}\text { The job title on the transmittal that accompanies the project record documents } \\
\text { sent to iso for storage. }\end{array}$ & Transmittal & $\cdots$ & AM & 65 & LEFT & N \\
\hline 102 & PRINCIPAL_ENGR & - PRNENGID & $\begin{array}{l}\text { The EMIS 10 of the principal engineer identified on the transmittal sent } \\
\text { to project records. }\end{array}$ & Transmittal & $\begin{array}{l}\text { EMIS } \\
\text { List }\end{array}$ & AM & 5 & LEFT & N \\
\hline 103 & ORIG_RECIP & - ORGRECID & $\begin{array}{l}\text { The EMIS ID of the originator or the recipient identified on the transmittal } \\
\text { sent to project records. }\end{array}$ & Transmittal & $\begin{array}{l}\text { EMIS } \\
\text { List }\end{array}$ & AN & 5 & LEFT & $\mathbf{N}$ \\
\hline
\end{tabular}

PPS 08/27/93 
DATA DICTIONARY

PROJECT RECORDS INFORMATION SYSTEM

Data Elements

10/01/93

Page 8

\begin{tabular}{|c|c|c|c|c|c|c|c|c|c|c|}
\hline $\begin{array}{l}\text { Item } \\
\text { No. }\end{array}$ & $\begin{array}{l}\text { Data } \\
\text { Item } \\
\text { Nomenclatu }\end{array}$ & & & $\begin{array}{l}\text { Data Requirement } \\
\text { Description }\end{array}$ & $\begin{array}{c}\text { Source } \\
\text { of } \\
\text { Data }\end{array}$ & $\begin{array}{l}\text { Value } \\
\text { or } \\
\text { Range }\end{array}$ & Type & $\begin{array}{l}\text { Field } \\
\text { size }\end{array}$ & Align & $\begin{array}{c}\text { Retrievol } \\
\text { Key }\end{array}$ \\
\hline 104 & BOX_NUMBER & & Box & $\begin{array}{l}\text { The number of the box that contains this PRIS folder (applies to archived } \\
\text { folders only). }\end{array}$ & PRIS & $-\cdots$ & AH & 6 & LEFT & N \\
\hline 105 & AISLE_NUMBER & - & AISLE & $\begin{array}{l}\text { The aisle number where the box is stored that contains this PRIS folder } \\
\text { (applies to archived folders only). }\end{array}$ & PRIS & $\cdots$ & AN & 6 & LEFT & $N$ \\
\hline 106 & SHELF_NUMBER & - & SHELF & $\begin{array}{l}\text { The shelf number where the box is stored that contains this PRIs folder } \\
\text { (applies to archived folders only). }\end{array}$ & PRIS & $\cdots$ & Ait & 6 & LEFT & N \\
\hline 107 & FOLDER_STATUS & - & FLDRSTAT & $\begin{array}{l}\text { A code indication the status of a PRIS project folder. } \\
\begin{array}{ll}\hat{A}=\text { Archived } & \text { Deleted } \\
\mathbf{P}=\text { Pending Deletion } & \text { Blank }=\text { Active }\end{array}\end{array}$ & PRIS & $A, D, P$, & AN & 1 & & N \\
\hline 108 & PROJECT_ESO_STATUS & - & PESOSTAT & $\begin{array}{l}\text { A code indication the status of a project/ESO association } \\
P=\text { Pending Deletion }\end{array}$ & PRIS & P.' & AN & 1 & & N \\
\hline 109 & USER_EMIS_ID & - & UEMISID & User's EMIS 10. & EMIS & $\begin{array}{l}\text { EMIS } \\
\text { list }\end{array}$ & AN & 5 & LEFT & N \\
\hline 110 & LASTMAME & $\cdot$ & LASTMAME & EMIS user's surnane. & EMIS & & AN & 23 & LEFT & N \\
\hline 111 & INITIALS & - & INITIALS & EMIS user's first and middle initials. & EMis & & AN & 2 & LEFT & N \\
\hline 112 & UPLANT & - & UPLANT & Code indicating the user's plant as contained in EMIS. & EMIS & & AN & 1 & & N \\
\hline 113 & UPLANT_LOC & - & UPLANTL & EMIS code indicating the User's physical plant location. & EMIS & & AN & 1 & & N \\
\hline 114 & UBLDG & - & UBLDG & EMIS user's building. & EMIS & & AM & 8 & LEFT & N \\
\hline 115 & ROON & $\cdot$ & & EMIS user's Room Number. & EMIS & & AN & 4 & LEFT & M \\
\hline 116 & BADGE & - & & ENIS user's bodge number. & EMIS & & AN & 6 & LEFT & M \\
\hline 117 & EDIS_ACCESS & - & & $\begin{array}{l}\text { EDIS Access flag. Indicates whether or not EMis user is allowed to access } \\
\text { EDIS. } \\
Y=\text { Yes }\end{array}$ & EMIS & Y,N & AN & 1 & & N \\
\hline 118 & K25_ACCESS & - & KACCES & 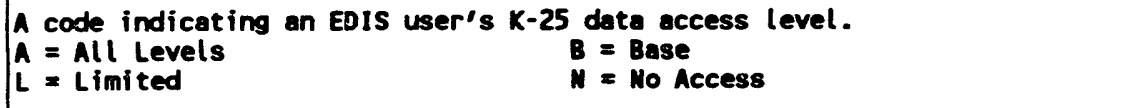 & EMIS & $A, B, L, M$ & AN & 1 & & N \\
\hline 119 & X10_ACCESS & - & XACCES & A code indicating on EDIS user's $x-10$ data access level. & EMIS & $A, B, L, N$ & AN & 1 & & N \\
\hline
\end{tabular}


DATA DICTIONARY

PROJECT RECORDS IMFORMATION SYSTEM Data Elements

10/01/93

Page 9

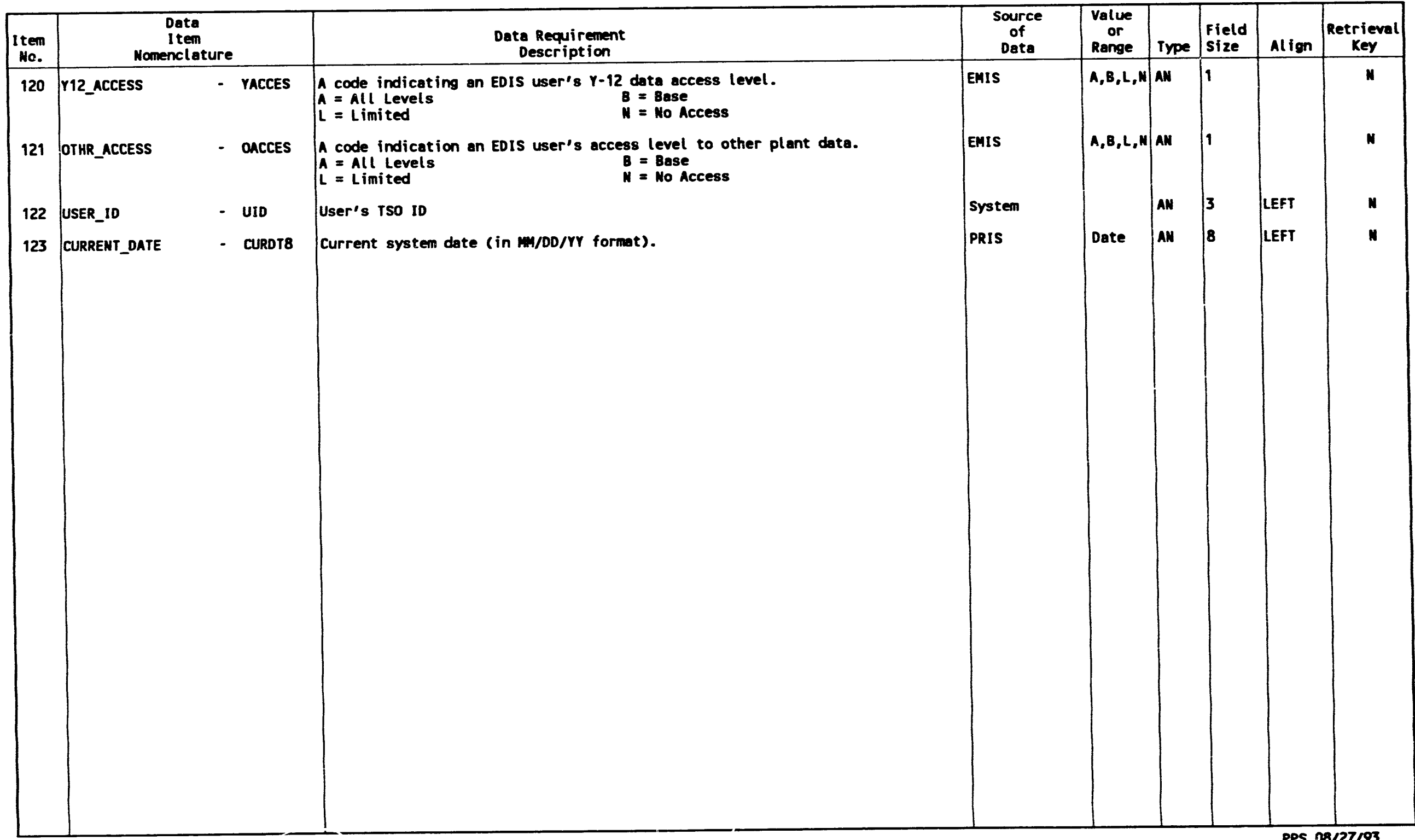


KJCSD/TM-93

Revision 2

Dist. Category UC-905

\section{DISTRIBUTION}
1. H. J. Boles
2. M. D. Brandon
3. B. E. Cline
4. N. P. Conklin
5. S. T. Costello
6. C. W. Gudmundson
7. M. S. Guthrie
8. D. A. Holloway
9. R. A. Lawson
10. A. M. Lokey
11. J. L. Loveday
12. P. A. Moore
13. R. P. Prince
14. R. K Schwarz
15. G. W. Scott
16. K. Y. Shaw
17-21. P. S. Smith
22. D. K. Stair
23. D. L. Stair
24. Applied Technology Library
25. K-25 Site Records Department - RC
26-37. Office of Scientific and Technical Information 

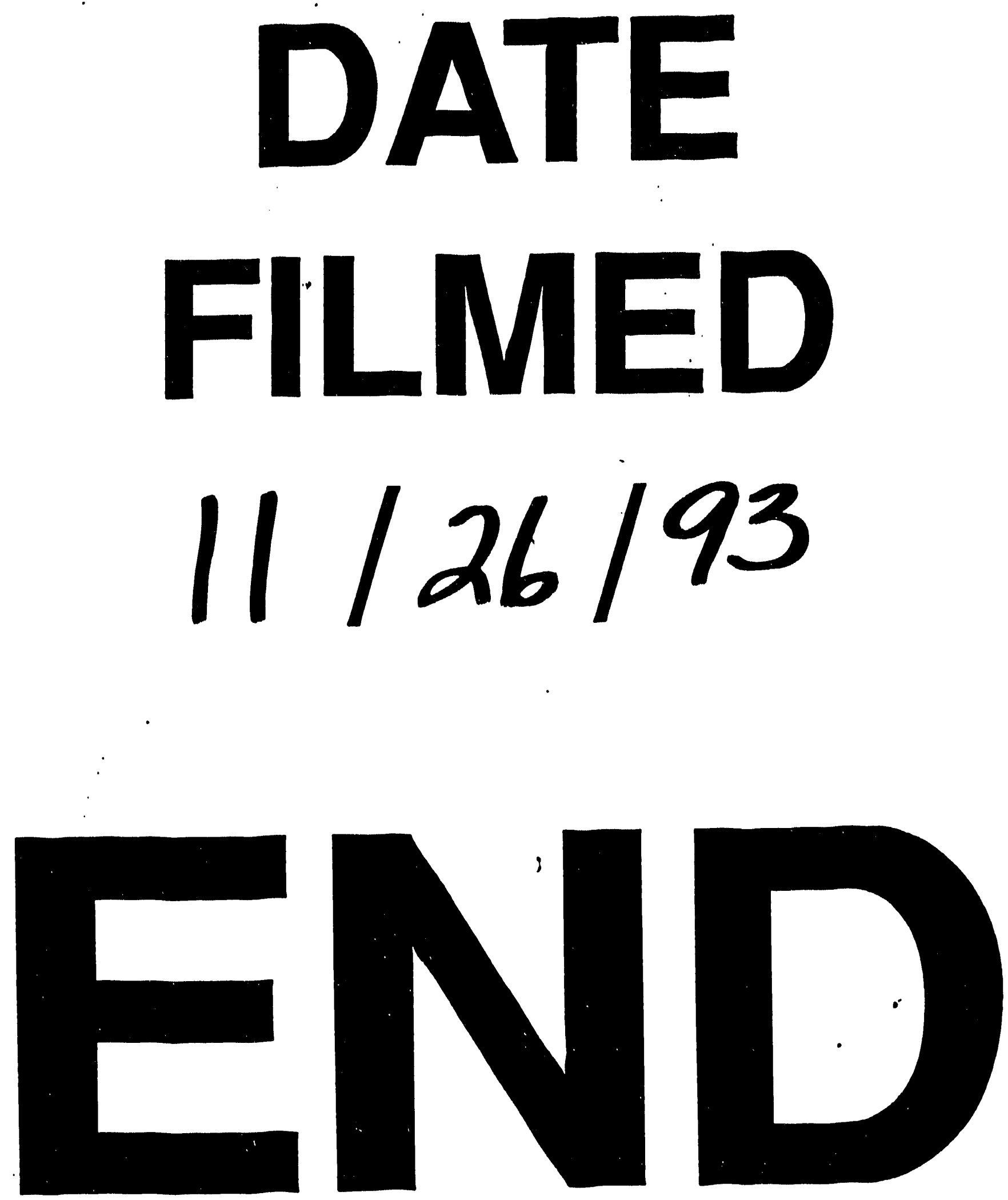
- 